\title{
A PRACTICE-BASED INTERVENTION TO PREPARE PRESERVICE TEACHERS FOR INLCUSION USING UNIVERSAL DESIGN FOR LEARNING
}

\author{
A Dissertation \\ presented to
}

the Faculty of the Graduate School

at the University of Missouri-Columbia

\author{
In Partial Fulfillment \\ of the Requirements for the Degree \\ Doctor of Philosophy
}

by

Mary Decker

Dr. Delinda Van Garderen, Advisor

JULY 2019 
The undersigned, appointed by the dean of the Graduate School, have examined the dissertation entitled

\section{A PRACTICE-BASED INTERVENTION TO PREPARE PRESERVICE TEACHERS FOR INLCUSION USING UNIVERSAL DESIGN FOR LEARNING}

presented by Mary Decker, a candidate for the degree of doctor of philosophy, and hereby certify that, in their opinion it is worth of acceptance.

Professor Delinda Van Garderen

Professor Carol Gilles

Professor Erica Lembke

Professor Rebecca McCathren

Professor Cathy Newman-Thomas 
To my favorites-

Jared, Mea, Jaden, Jensen \& Maesyn

We did hard things! 


\section{ACKNOWLEDGEMENTS}

This work would not have been possible without the support from those whom I have had the pleasure of working with and learning from. Through this program I have met some truly exceptional thinkers and people. I am forever grateful for this experience.

My three advisors each played an important role in my journey and gave me exactly what I needed to grow and the exact right time. Dr. Amy Barth recruited me and told me that a Ph.D. was a possibility. She saw potential and I appreciate it. Dr. Cathy Newman-Thomas, allowed me to talk through problems, make mistakes and fix them. Her patience flexibility and grace gave me the space to truly find my passion. Dr. van Garderen has given me the final push to finish. This may have been the toughest leg of the journey, but Dr. vG has encouraged, gave some tough love and made sure that quitting was not an option. Each of these women have been an example, to them, thank you.

Each member of my committee has provided me with their time and feedback which has been invaluable. They have selflessly given me the attention that I needed to do quality research. Thank you.6033 
To my friends and fellow doctoral students, I am so thankful for the endless supply of Dr. Pepper, a safe place to vent, and conversations that have changed who I am as a person. You all are going to change the world!

This work would not have been possible without the support of the instructors who allowed me to come into their classes and try something new. I am thankful to the students in each of the sections who were willing participants in this study and made this work successful but also enjoyable. Thank you.

Finally, thank you to my family. I would like to thank my grandparents, parents, and siblings who may not have understood what I was doing, but always asked and politely nodded as I rambled on. To my children, who rolled with the beautiful chaos that is graduate school, you deserve all the praise! You are my inspirations! To my husband, Jared, I could not have done this without the pep talks, consultations, and kicks in the butt to move forward. 


\section{TABLE OF CONTENTS}

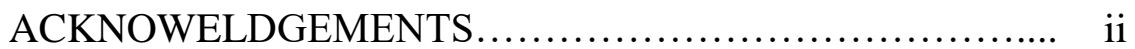

LIST OF FIGURES..................................... vi

LIST OF TABLES....................................... vii

ABSTRACT ........................................... viii

CHAPTER 1

Introduction....................................... 1

Preparing Pre-Service Teachers to be

Inclusive........................................ 5

Best Practices for Preparing Pre-Service

Teacher.......................................... 8

CHAPTER 2

Rationale and Purpose of Current Study............. 11

Review of Literature.............................. 14

Fundamental Knowledge Bases for Teaching 14

(Technological, Pedagogical, Content

[TPACK])

TPACK and Pre-Service Teacher Preparation........ 22

Role of Self-Efficacy in Preparing Teachers........... 24

Conceptual Framework for Preparing Pre-Service

Teachers............................................. 31

Universal Design for Learning...................... 32

Summary and Rationale for Study.................. 43

Research Questions............................... 46

\section{CHAPTER 3}

Methods............................................ 47

Research Design.................................. 47

Sampling and Participants......................... 48

Setting of Study................................ 50

Measures and Scoring............................ 51

Intervention Design and Development.............. 54

Procedures........................................ 60

Threats to Reliability and Fidelity.................. 66

Data Analysis.................................... 67

CHAPTER 4

Results...................................... 78 
Descriptive Statistics............................. 78

Research Question 1............................. 83

Research Question 2............................ 94

CHAPTER 5

Discussion......................................... 103

Summary........................................ 103

Limitations.................................... 106

Implications for Further Research................ 107

Implications for Practice........................... 109

Conclusion..................................... 109

REFERENCES........................................ 112

APPENDICES

A IRB Approval.................................. 131

B TPACK infused UDL Survey..................... 132

C Twenty-First Century Teacher's Self-Efficacy Scale.............................................. 135

D Scenario-based Assessment......................... 136

E Rubric for SBA............................... 138

F PowerPoint Slides for Lecture-based Instruction......................................... 139

G Instruction Stations for Practice-based Group......................................... 147

VITA.................................................. 153 


\section{LIST OF FIGURES}

Figure 1. TPACK Framework............................ 17

Figure 2. Conceptual framework of TPACK and self-efficacy.............................. 32

Figure 3. UDL framework .............................. 36

Figure 4. UDL as an overlay............................. 43

Figure 5. Triangulation design........................... 48

Figure 6. UDL addressed learning stations.................. 58

Figure 7. Intervention schedule.......................... 63

Figure 8. Sample reflection............................... 64

Figure 9. Procedural fidelity............................. 66

Figure 10. Boxplot TPACK ............................... 84

Figure 11. Violin plot TPACK............................ 84

Figure 12. Boxplot T-TSE.............................. 89

Figure 13 Violin plot T-TSE............................ 89

Figure 14. Boxplot SBA............................... 92

Figure 15. Violin plot SBA............................. 92

Figure 16. Scatterplot SBA compared to TPACK-UDL...... 97

Figure 17. Scatterplot SBA compared to TPACK-UDL Subject removed............................. 98 


\section{LIST OF TABLES}

Table 1. Content Covered in Conditions..................... 55

Table 2. Examples of Coded Responses.................... 74

Table 3. Descriptive Statistics.............................. 81

Table 4. Counts of UDL terminology in SBA responses....... 100

Table 5. Counts of Quantity and Quality Responses.......... 101 


\begin{abstract}
General education pre-service teachers are expected to teach diverse learners, including those with disabilities, in the general education settings. Yet many are not adequately prepared to teach all students. Universal Design for Learning (UDL) is a framework to increase inclusive practices, however, it is unknown how to best teach this to pre-service teachers. The purpose of this study is to examine the impact of using a practice-based approach to teach UDL as compared to a lecture-based approach to teach UDL to better prepare general education pre-service teachers. Constructs of interest include pre-service teachers' fundamental knowledge including UDL, self-efficacy and UDL application. A mixed methods triangulation design was employed. While pre-service teachers from both groups had significant gains in their foundational knowledge, reported self-efficacy, reported UDL knowledge and ability to apply UDL ideas, participants in the practice-based group did have some advantages, specifically in the area of UDL application.
\end{abstract}




\section{CHAPTER 1}

\section{Introduction}

Recent data from the U.S Department of Education indicates that in $2017,62.1 \%$ of students with disabilities are spending $80 \%$ or more of their school time in the general education classroom. This is an increase from previous years where, for example, in 1989 , only $31.7 \%$ of students with disabilities spent the majority of their time in the general education classroom. (U.S. Department of Education National Center for Education Statistics, 2008; U.S. Department of Education, 2017). Student being in the physical classroom is common, however the extent to which they are meaningfully included in instruction is still unknown. (Jorgensen, 2018). Under the law (e.g.: Individuals with Disabilities Education Act, 2004, No Child Left Behind, 2001; Every Student Succeeds Act, 2015), students with disabilities should not only be physically included in the general education classroom but also have access to the supports, adaptations, and accommodations necessary to ensure academic and social success. They should also be given access to the same curriculum and high standards with accountability. These laws have increased pressure on general education teachers to meaningfully include students with disabilities in the classroom beyond "watered-down content area inclusion" (Vaughn, Bos, \& Schumm, 2007, p. 428). 
Unfortunately, many general education teachers report feeling unprepared or underprepared to teach in today's diverse setting even though policies that mandate meaningful inclusion have been established for years (Ayantoye \& Luckner, 2016; Leuszler, 2015; Tirado, 2016). In a metasynthesis of 28 surveys about general educators' perceptions of inclusion sent to mostly elementary general education teachers, Scruggs and Mastropieri (1996) discovered that two-thirds of general educators supported the idea of inclusion and half believed that inclusion is indeed beneficial for students with disabilities. However, less than one-third of the 10,560 general educator respondents thought they had adequate resources, training, time, or ability to implement inclusive practices successfully. Even 20 years after this landmark study, these favorable attitudes toward inclusion and lack of perceived preparedness and selfefficacy to implement inclusive practices still remain (Cornoldi, Capodieci, Colomer Diago, Miranda \& Shephard, 2018) Cornoldi (2018) surveyed 557 teachers and found that while they were in favor of supporting student differences in the general education classroom, they reported feeling unprepared or less positive towards the inclusion of students who had behavioral or emotional differences. Also, it was found that these teachers lacked an understanding of their role in accommodating students in meaningful ways in their classrooms. Alarmingly, the teachers 
also appeared to lack a feeling of responsibility for providing interventions to students with disabilities.

Tomilinson and Tighe (2006) synthesize and extend that research to suggest that teachers who teach students who have been identified on either end of the spectrum, whether as gifted or as struggling, do not appropriately accommodate the differences and rarely provide experiences catered to the specific needs of those children. Often, teachers require gifted students to spend much of their day on tasks they have mastered while those struggling are not given the time or individualization to grasp the lacking concepts. This is mostly due to the fact that general education teachers lack understanding and are not fully prepared to differentiate for students who deviate from the average student (Landrum \& McDuffie, 2010; Sousa \& Tomlinson, 2011d).

Preparing teachers to enter the field equipped and prepared to teach all should be the focus of teacher preparation programs, yet findings from studies suggest that pre-service general education teachers lack the fundamental knowledge and skills to teach in diverse inclusive classrooms (Vaughn, Bos, \& Schumm, 2009). Vaughn, Bos and Schumm (2009) suggest that while pre-service teachers report they are willing to include students with differences in the classroom, they are unable to effectively pre-plan adaptations to curriculum and tests or revise objectives based on 
students' performance following the completion of educational activities. For example, Washburn, Joshi, and Cantrell (2011) found that 91 general education pre-service teachers had misconceptions about the nature and impact of specific reading disabilities in school. They also lacked knowledge of evidence-based instruction that would be appropriate for these students. Similarly, Norman, Caseau and Stefanich (1998) found that general education pre-service science teachers not only lacked a foundational understanding about the disabilities but also knowledge of pedagogical practices that would support students with disabilities in their classroom.

Given the findings of the research regarding both in-service and pre-service teachers' ability to work with students with disabilities, there is a need to identify ways to better prepare pre-service teachers to meet the needs of all students in the general education classroom. While gaps in knowledge, skills and self-efficacy are understandable in pre-service teacher programs as students are there to learn these important constructs, ensuring that pre-service teachers are not only prepared but prepared to be inclusive is imperative to teaching the diverse populations that will be required. 


\section{Preparing Pre-service Teachers to be Inclusive}

Sharma and colleagues $(2006,2008)$ suggest that pre-service teacher education is one of the most influential variables in building knowledge and skills that facilitate effective inclusion. However, there is little research on how best to prepare general education pre-service teachers. Clearly, from the research described above, general education pre-service teachers need more content about working with students with disabilities in their classrooms. A recent initiative to address this need that is gaining some attention involves enhancing existing programs (van Larrhoven, et al. 2007). There are two main ways enhancements are implemented in existing programs: (a) revising existing courses or adding new courses that focus on disability, and (b) inclusive pedagogy in addition to the current courses required of general education teachers (Cook, 2002; Lombardi \& Hunkam 2001; Strawderman \& Lindsey, 1995). Generally, these approaches to enhance teacher preparation programs and better prepare pre-service teachers to teach in inclusive environments have varied significantly in both scope and content (van Larrhoven, 2007).

Existing research on the impact of enhancements is limited because of lack of definition as to what constitutes an enhancement. Though research is sparse, one longitudinal study of 53 pre-service teachers by van Laarhoven (2007) examined the effects of course 
enhancements course revision-in a preparatory program. Pres-service teachers were placed in one of three conditions: courses with revised content, standard courses, and standard courses with additional coursework to receive a minor in special education. As the students progressed through the program, they were taught about topics related to special education in their content courses. At the end of each year, participants were asked to complete a survey about the courses they took which asked about the content covered and their ability to apply the content. The results indicated that the students who experienced the revised courses were more knowledgeable than the students who completed the traditional courses.

A much more complex enhancement approach was taken by Frey, Andres, McKeeman, and Lane (2012), in which a secondary general education teaching program was revised and enhanced by including new courses as well as revising every course to model inclusive practices and include content related to inclusive practices. This single group design focused on outcomes of participants based on artifacts related to each course as well as self-reports. Application measures in which students were required to incorporate inclusive ideas (e.g. lesson plans, student teaching observations) also showed an increase in inclusive practices. The results of this program-level enhancement were similar to the van 
Laarhoven's work in that pre-service teachers reported feeling more confident in their ability to teach in inclusive environments.

Emerging research suggests that enhancing programs appears to work (e.g., Frey et al., 2012), but, of concern, is the lack of details in most of these studies specifying what practices were taught, what theories or content was covered, and how the pre-service teachers were taught. For example, in the study by Frey (2012) there were changes made such as including UDL as covered content and design pedagogy for courses yet, and there was no indication of the extent to how these changes were implemented or what additional content was taught. -Fisher, Frey and Thousand (2003) suggest several critical enhancements which have the potential to positively impact pre-service teachers' ability to meaningfully include students with disabilities that should be focused on. These include curricular and instructional accommodations and modifications that lead to effective strategies based on student need, education on assistive technology, positive behavior support methods, and teaching pre-service teacher to collaborate with special educators. While each of these practices are researched-based (e.g. Edyburn, 2000; Lee, Wehmeyer, \& Soukup; 2010; Reinke, Herman, \& Stormont; 2013; Ripley, 1997), there is little understanding of how these specific enhancements actually impact pre-service teacher preparation and ability to teach students with 
disabilities. Brownell (2005) supports this claim by calling for more research in the areas of teacher preparations. Where she states,

We need to know how preparation programs make a difference.

Currently, teacher educators create programs that include knowledge of validated practices and that meet some or many of the criteria for high-quality teacher education identified in the literature on general teacher education programs. Although the link between evidence-based practice and student achievement exists, no research exists to show that including this knowledge in teacher preparation programs or including specific teacher education program components make a difference in outcomes for teachers or their students with disabilities. (p. 241)

\section{Best Practices for Preparing Pre-Service Teachers}

There is an abundance of empirical evidence for teaching K-12 special education students effectively. Unfortunately, that empirical foundation is missing when it comes to how to prepare teachers to effectively work with those same students. One highly recommended way to prepare future teachers in general is by using active-learning pedagogy (Braslavsky, \& AACTE, 2002; Benedict, et al., 2016; Brownell, 2005).

Active-learning pedagogies represent a model of teaching that involves minimal teacher lecture or direct transmission of factual 
knowledge. Instead, learners are actively involved in their learning, knowledge acquisition and application of knowledge through problemsolving and practice. A subset of active pedagogies is practice-based learning. Researchers have indicated that effective teaching practices cannot be developed from reading about or studying about them instead, learners must be engaged in high-quality practice-based opportunities where the knowledge is applied (Phelps, 2009; Loewenberg Ball \& Forzani, 2009). Performance-based fields such as medicine and the military develop their candidate's expertise in the fields through opportunities to repeatedly practice and apply their knowledge and skills in authentic contexts (Albanese \& Mitchell, 1993; Barrows \& Tamblyn, 1980; Boud \&Feletti, 1997;). This methodology requires individuals to apply their knowledge to situations and is more effective in producing the automaticity and expertise than passive learning pedagogies (Savery, 2015). Benedict (2016) states, "It is the commitment towards deliberate opportunities to practice rather than experience that separates experts from their peers" (p.2).

Typically, practice-based learning includes activities in which students are given a problem and granted the space to collaborate, discuss, try solutions, and make mistakes. In these situations, candidates integrate content and pedagogy by applying what they learned to practical problems 
(Steinemann, 2003). These could include microteaching experiences where pre-service teachers plan and implement a lesson in from of their peers (Garland, Vasquez \& Pearl, 2012). Another example would include lesson studies in which pre-service teachers collaboratively analyze practices and problem solve solutions for classroom situations (Benedict, et al., 2018). For pre-service teachers, these activities are opportunities to work in a relatively safe classroom without the pressure of teaching under actual teaching conditions. Novice pre-service teachers can experiment with incorporating different methods in their practice and receive specific and detailed feedback on their performance (Antoniou \& Kyriakides, 2013). This is particularly critical for pre-service teachers who lack confidence in teaching in diverse situations as they are able to build the skills that will lead to confidence.

Though only a small number of studies have examined active pedagogies including practice-based learning activities in preparing preservice teachers, they have produced some evidence suggesting that use of active pedagogies prepares teachers to more effectively teach all students (e.g.: Anderson \& Lingnugaris/Kraft, 2006; Niemi \& Nevgi, 2014; Nieme, Nevgi \& Aksit, 2016;; Zeichner, 2012). However, focus on the use of practice-based learning in the field of special education to prepare preservice teachers, is just beginning to be addressed (e.g., Brownell, Chard, 
Benedict, \& Linguaris, 2018; Lignugaruis/Kraft \& Harris, 2014).

Consequently, much more research is needed that focuses on the use of practice-based learning as a way to increase pre-service teacher's capacity to meaningfully include and teach students with disabilities.

\section{Rationale and Purpose of Current Study}

When teachers are knowledgeable about disabilities and feel prepared to teach students with disabilities, they make more meaningful adjustments in the classroom that create more positive environments for all students (Alsheikh \& Elhoweris, 2006; Rojewski \& Pollard, 1993; Sharma, Forlin, Loreman \& Earle, 2006;). Additionally, when teachers have a greater sense of perceived preparedness, they are more likely to have a greater sense of self-efficacy. In contrast, when teachers feel they are unprepared to teach students with a learning, emotional, or social difficulty or disability, they report diminished student learning outcomes, increased stress, and lower levels of job satisfaction, and there is evidence of higher rates of teacher turnover (Brunsting, Sreckovic \& Lane, 2014; Enochs, Scharmann, \& Riggs, 1995; Klassen \& Chiu, 2010; Oliver \& Reschly, 2010). Unfortunately, the findings from numerous studies (e.g., Able, Sreckovic, \& Schultz, 2015; Allday, Neilson-Gatti \& Hudson, 2013; Harvey, Yssel, \& Bauserman, 2010; Specht, McGhie-Richmond, \& Loreman, 2016) ) suggest many teachers are not adequately prepared nor 
have the confidence to teach students with disabilities, thus demonstrating the need for better teacher education and preparation.

Currently, research on what and how to teach pre-service teachers resulting in the more meaningful inclusion all students in the classrooms is sparse. While it is clear that general education pre-service teachers need to learn more about disabilities as well as practices that help the success of all students (Ayantoye \& Luckner, 2016; Leuszler, 2015; Tirado, 2016; Vaughn, Bos \& Schumm \&, 2009), little research is available validating what should be taught in teacher education programs (e.g., Brownell, 2005; Brownell et al., 2016). It is highly recommended that a practicebased learning approach is used as a way to provide pre-service teachers the time and space to apply new knowledge and deepen their understanding about complex issues within the safety of a course without the added pressure of students (Benedict et al., 2016). Or as Brownell (2005) suggests, to help them move beyond "their initial, sometimes simplistic, views of teaching and learning" (p.244). However, despite the push for practice-based learning, there is limited research on how effective this is as an approach for preparing pre-service teachers (Lignugaris/Kraft et al. 2014).

Therefore, the purpose of this study is to examine the impact of using a practice-based approach as compared to a lecture-based approach 
to use inclusive practices, namely Universal Design for Learning (UDL) to better prepare general education pre-service teachers to teach students with disabilities in an inclusive setting. 


\section{CHAPTER 2}

\section{Review of the Literature}

Strong teacher preparation is an effective way to have a lasting positive change in classroom and student outcomes (Bransford, DarlingHarmond \& Lepage, 2005). However, more research is needed on how best to prepare pre-service teachers, particularly to prepare them to use inclusive practices in their classroom. The remainder of this chapter will outline what are critical ideas about pre-service teacher education. First, the fundamental knowledge bases important to being a successful teacher (technological knowledge, pedagogical knowledge, and content knowledge) will be outlined. Second, the relationship between belief impact the application of the knowledge that teachers have. Third, information about Universal Design for Learning (UDL) and how it serves as an inclusive practice that should be included in pre-service teacher preparation will be presented. Finally, a case will be made as to how the three important factors, foundation knowledge (TPACK) self-efficacy and UDL contribute to preparing pre-service teachers for teaching all students. Fundamental Knowledge Bases for Teaching (Technological, Pedagogical, and Content Knowledge [TPACK])

Various models of what teachers need to know to teach exist (e.g., Darling-Hammond, 2008; Gess-Newsome, 1999; Heller, Daehler, \& 
Wong, 2012). The Technological, Pedagogical, and Content Knowledge Framework (TPACK) represents the fundamental knowledge related to technology, pedagogy, and content that are "whole knowledge and insights that underline teachers' actions and practices" (Verloop, Van Driel, \& Meijer, 2001, p. 445). While TPACK is a framework for understanding necessary teacher knowledge, it is not a checklist nor does it offer suggestions on how to prepare teachers (Niess, 2012).I t is a framework to help determine what skills are vital for success and be used by teacher educators to determine where to focus pre-service teacher preparation (see Figure 1). The TPACK framework builds on Shulman's (1987, 1986) work regarding Pedagogical Content Knowledge (PCK). Generally, this framework focuses on what teachers teach (content), how teachers teach (pedagogy), and, most importantly, how information is taught most effectively (pedagogy and content). TPACK adds to this framework by incorporating teachers' understanding of technologies and examining how that interacts with PCK to produce the most effective teaching.

The TPACK framework has been conceptualized and developed over time and through a series of studies, with the most complete description found in Mishra and Koehler (2006) and Koehler and Mishra (2008). Further, it has been used in various studies related to validating 
teacher knowledge bases (e.g., Archambuilt \& Barnett, 2010; Graham, 2011; Harris \& Hoefer, 2011; Schmidt, Baran \& Thompson, 2009, Tondurn et al., 2017). The TPACK framework is comprised of seven components (Mishra \& Koehler, 2006; Thompson \& Mishra, 2007; see Figure 1). Three of the components are foundational: Technology Knowledge (TK), Pedagogical Knowledge (PK), and Content Knowledge (CK). While these foundational knowledge bases can stand alone, the most impactful teaching is achieved when the knowledge bases interact and are meaningfully combined. These interactions include: Technological Pedagogical Knowledge (TPK), Technological Content Knowledge (TCK), Pedagogical Content Knowledge (PCK), and Technological Pedagogical Content Knowledge (TPACK) (Mishra \& Koehler, 2006). In the next section each foundational knowledge base will be described as well as the interactions among the bases. 


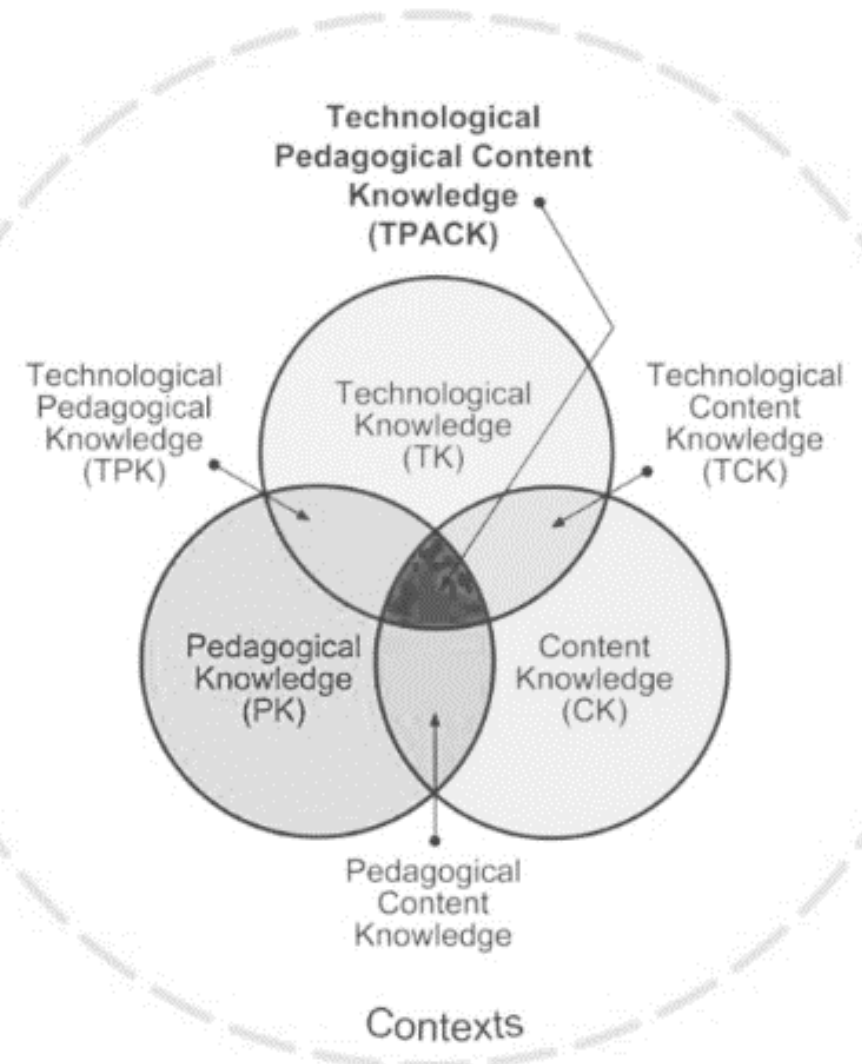

TPACK, (2012) Retrieved from URL: http://tpack.org

Figure 1. TPACK Framework

Technological Knowledge (TK). Technological knowledge is the knowledge of educational, instructive, and assistive technology. Because technology is evolving and changing, the definition of technological knowledge is broad enough as to not limit it to a specific tool (e.g., teachers may understand how text-to-speech functions, yet they are not tied to a specific program, application or screen reader). Generally, TK is the understanding of technological tools that can increase productivity and 
transform learning environments. It includes recognizing that technology can assist or impede the achievement of a goal and necessitates continually adapting to the changes of new technology and tools (Koelher \& Mishra, 2009).

Content Knowledge (CK). Shulman (1986) determined that content knowledge includes knowledge of concepts, theories, ideas, organizational frameworks, and established practices that are used synonymously within a discipline when developing knowledge. While CK differs greatly between fields (e.g., elementary fourth grade teachers and high school Spanish teachers will have vastly different CK), all teachers should have a deep understanding of the disciplines in which they teach (Koelher \& Mishra, 2009; Shulman, 1986).

Pedagogical Knowledge (PK). This knowledge base is an understanding of how students learn, general behavior management skills, lesson planning, assessment, and, most importantly, the characteristics of students and how those impact learning (Gess-Newsome, 1999). While other models separate knowledge about students out, TPACK includes understanding of the students as a piece of PK. A teacher with deep pedagogical knowledge understands how to create and adjust classroom environments based on student need so that they are successful (Mishra \& Koelher, 2006). 
Pedagogical Content Knowledge (PCK). Schulman (1986)

describes PCK as the interaction of a teacher's cognitive understanding of content and the ability to translate that knowledge to the student.

Specifically, according to Shulman, this translation happens as the teacher interprets the subject matter, then finds ways to represent it based on student needs or background knowledge. This knowledge base is important because PCK is the specialized knowledge that teachers have that sets them apart as professionals (Wilson, Schulman \& Richert, 1987).

Technological Content Knowledge (TCK). The interaction between technology and content also impact teachers and the way they teach. TCK is the understanding of how technology and content support as well as constrain one another (Mishra \& Koehler, 2009). For example, technology has changed the way that subject matter is represented in the classroom. Teachers are now able to use microscopes, satellite images and video conferencing to illustrate subject matter in unprecedented ways. Teachers must understand the possibilities that the technology affords the content.

Technological Pedagogical Knowledge (TPK). Technological pedagogical knowledge is an understanding of how teaching and learning can change when particular technologies are used. Teachers with TPK understand the affordances of a technological tool as well as how it would 
contribute to learning in the classroom. This knowledge would include an understanding of what tools are pedagogically and developmentally appropriate. Teachers must not use technology simply for the sake of using technology, but rather understand what the technology affords the situation (Mishra \& Koehler, 2009). For example, a teacher may want to use a calculator in their math lesson. They would need to understand that the calculator affords students greater accuracy and allows them to spend less time calculating simple equations, thus allowing them to dive deeper into conceptual knowledge. In addition, they would need to understand the concepts that the students should be engaging in, while understanding that an expensive, high-end calculator may not be inappropriate, as it might distract from the focus of the lesson.

Technological Pedagogical Content Knowledge (TPACK). The intersection of all the knowledge bases is at the center of the TPACK model. Mishra and Koehler (2006) state, separating the three components (content, pedagogy, and technology) is an analytic act and one that is difficult to tease out in practice...In actuality, these components exist in a state of dynamic equilibrium...Viewing any of these components in isolation from the others represents a real disservice to good teaching. (p. 1029) 
When all of the pieces of TPACK are combined, the most effective classroom decisions are made (Mishra \& Koehler, 2006).

A good teacher must not only understand each knowledge base, they must understand how each work together when making educational decisions in the classroom. To demonstrate, a teacher may introduce his students to the anatomy of plant and animal cells, including images of cells captured by microscopes. After, the teacher may have the students collaborate with one another about the differences between plant and animal cells and create a Venn diagram illustrating their findings on a collaborative Google Document. The teacher in this scenario has a deep content knowledge (CK) as he understands the biology of the cell. He also understands the importance of students collaborating, which illustrates pedagogical knowledge (PK). The teacher, knowing that collaborating in science is an effective way for students to learn about concepts, illustrates the PCK in use. This teacher also relies on the technological tools microscopic images, (TCK) that are vital to understanding and uses the technology Google Document, (TPK) for students to collaborate about the content (TPACK). By fully integrating all the knowledge bases, teachers are able to use the tools, pedagogy, and content that are most effective for teaching their students. To be an effective pre-service teacher program, pre-service teachers must be prepared across TPACK knowledge bases so 
that they can effectively teach the content, in appropriate ways, using the necessary tools to help all student be effective.

\section{TPACK and Pre-Service Teacher Preparation}

Teacher preparation classes are considered a key catalyst in helping new teachers acquire knowledge and skills. Little research has been completed to determine how instruction impacts growth in TPACK (whether a part of the framework or the framework as a whole). Of the available research, only two studies were found that both centered around pre-service teacher education that had measured outcomes related to teacher effectiveness related to TPACK knowledge. While other studies examined change in TPACK before and after a course or intervention, the purpose of these were to validate the framework (e.g: Shin et al., 2009; Hathaway \& Norton, 2018; Lui, 2011). These studies were the only studies in which applying practices was examined with the purpose of changing TPACK (Angeli, 2005; Ozgun-Koca et al, 2010).

Angeli (2005) examined pre-service teacher education regarding science content in a science education class using two groups. The first group of 116 pre-service teachers was given a technological tool that allowed them to model scientific principles. The other group of 111 was given the same tool along with discussions based around the tool that addressed affordances of the technology and effective use of the tool. 
Both groups made gains in overall TPACK knowledge implemented technology in an applied science setting in an appropriate way as determined by greater integration and connected practices. However, those students who had additional training on and discussions around decision making had more significant gain in using the technology to support teaching strategies. The authors concluded that teacher educators need to explicitly teach how the unique features of a tool can be used to transform a specific content domain for specific learners and that students need to be explicitly taught about the interactions among technology, content, pedagogy, and learners.

In a descriptive study, Ozgun-Koca et al., (2010) examined TPACK development by 22 pre-service teachers in a mathematics methods course. The authors pre-tested and post-tested students' TPACK perceptions along with their ability to create effective lesson plans following classes related to all areas of TPACK. The authors found that a gap in one knowledge base made it difficult for pre-service teachers to effective. For example, if the student had little knowledge about math, they had a difficult time incorporating a technology tool that could be an effective way to teach the concept. The students with higher ratings on the TPACK assessments created much more well-developed lesson plans (as assessed by the researcher). Finally, with the increase in TPACK scores, 
Ozgun-Koca et al., indicated that these pre-service teachers made a shift from thinking of themselves as "learners of math" to "teachers of math" (p. 18).

These two studies suggest that when pre-service teacher's TPACK bases are purposefully targeted via instruction, they can have significant shifts in all areas of foundational knowledge. Not only did the pre-service teachers have shifts in foundational knowledge, but they were also able to apply this knowledge to effective teaching practices. One limitation of the TPACK model is that is does not take into consideration internal factors, such as self-efficacy, that may impact a pre-service teacher's ability to internalize and apply ideas.

\section{Role of Self-Efficacy in Preparing Teachers}

According to Hoy, Hoy and Davis (2009), self-efficacy beliefs can "trump" other beliefs in navigating classroom situations, most predicts classroom action most accurately and serves as filter through which knowledge is acted upon when making critical classroom decisions during instruction.

Self-efficacy theory. As a general construct, self-efficacy is defined as a perception about one's abilities within a context (Bandura, 1997). Further, Bandura (1997) describes self-efficacy as "beliefs in one's capabilities to organize and execute the courses of action required to 
produce given attainments" (p. 3). Self-efficacy theory suggests that the beliefs regarding one's ability to bring about a desired outcome influences both thoughts and actions (Schunk, 1991). The expectation is that people with stronger self-efficacy beliefs will be more likely to engage in an action. Conversely, lower self-efficacy can hinder a person's likelihood to engage in an action.

Teacher perceptions about their efficacy is an internal factor that is both difficult to shift and to measure accurately (Bandura, 2006). However, these perceptions have been found to be closely tied with classroom decision-making and practices (Tschannem-Moran et. al., 1998). In a meta-analysis of 43 studies relating to teacher self-efficacy and teaching effectiveness, a statistically significant relationship was found between a teacher's reported self-efficacy and reported use of effective teaching practice (Klassen \& Tse, 2014). In particular, higher levels of self-efficacy spent less time on non-academic tasks, implemented hands on methods of teaching, and used more student-centered approaches (Klassesn \& Tse, 2014). Wolfolk and Hoy (1990) state that while researchers have found very few relationships that correlate teacher behavior with student outcomes consistently, self-efficacy is an "exception to the rule" (p. 81). That is, higher levels of self-efficacy is one of the only consistent predictors of teacher behavior that results in positive 
student outcomes. Further, there is an overwhelming consensus in the literature that when teachers have confidence and positive perceptions of their abilities to teach, teachers are more active in their interactions with students (Gibson \& Dembo, 1984); are more committed to teach students with differing abilities (Coladarci, 1992); are more progressive in their instructional experimentation (Allinder, 1994); are more organized, plan for greater differences, and are more fair in their practices (Allinder, 1994); exhibit a greater willingness to keep students with diverse learning needs in the general classroom (Meijer \& Foster, 1988; Podell \& Soodak, 1993); produce better student academic outcomes overall (e.g., Moore \& Esselman, 1994); and have students with more positive attitudes (e.g., Woolfolk, Rosoff, \& Hoy, 1990). Teacher beliefs influence thought patterns, emotions, and actions toward students. Therefore, it is essential for all teachers to believe that they have the ability to teach all students, or, in other words, exhibit strong self-efficacy. Because student outcomes are more positive when teachers have a strong sense of efficacy, it is important to find ways to develop pre-service teachers' beliefs about their abilities to teach so that develop higher levels of self-efficacy $=$ they enter their professional roles.

Pre-service teacher self-efficacy and beliefs. Similar to research on currently practicing teachers as noted previously, there have been 
studies that examine pre-service teachers' self-efficacy as it relates to classroom practices (Albion, 1999; Bull, 2009; Sharma, Forlin \& Loreman, 2008; Sze, 2009). Multiple studies have indicated that selfefficacy in pre-service teachers directly affects the practices they employ as well as the behavior they exhibit (Abbitt \& Klett,2007; De Jong, Mainhard, Van Tartwijk, Veldman, Verloop, \& Wubbels, 2014; Jamil, Downer.\& Pianta, 2012). Jamil et al., (2012) examined exit surveys of 509 pre-service teachers upon completion of their education programs and found that participants who reported high efficacy were more likely to employ student-centered approaches, were more confident in their teaching abilities, and were more likely to have placements postgraduation. In a separate study that demonstrated positive correlations between self-efficacy and behavior, De Jong et al., (2014) showed that pre-service teachers with higher efficacy were friendlier, behaved fairer to the students in practicums, and developed more positive relationships with students. Finally, Abbitt and Klett, (2007) report that when pre-service teachers had more self-efficacy they were more willing to try new practices and integrate new tools into their planning. These positive correlations of self-efficacy and teaching practices have also been studied in relation to teaching students with differences. 
Research has shown that there is a direct correlation between preservice teacher attitude and success (or lack thereof) in teaching exceptional students (Sharma, Folin \& Loreman, 2008; Lancaster \& Bain, 2010; Woodcock, Hemmings \& Kay; 2012). Coursework focused on inclusive education within teacher education programs for general educators has been shown to positively influence pre-service teachers' attitudes, confidence, and competency to work within inclusive classrooms (Bannister-Tyrell, Mavropoulou, Jones, Bailey, O’Donnell-Ostrini, 2018; Mergler, Carrington, Kimber \& Bland, 2016; Tangen \& Beutel, 2016). In a mixed-methods study (Mergler et al, 2016) of 491 pre-service teachers, participants reported that they felt more confident and that they believed inclusion to be more important after they had taken a course focused on inclusive pedagogy. In addition, they were more likely to include many types of diversity into their instructional planning including ability, sexuality, and ethnicity. Likewise, Tangen and Beutel (2016) found that participants who were taught inclusive pedagogies felt more prepared to teach student of varying abilities, were able to list more practices to support inclusion, and rated inclusion to be more important than participants had believed prior to receiving the courses. In a large survey study of 993 students across levels of pre-service preparation, BannisterTyrrell (2018) also found that the more training participants received, the 
more inclusive their thinking was. Additionally, as training increased, students were more likely to report that they had higher efficacy to teach many different types of learners. Finally, Sharma, Forlin, and Loreman (2008) indicate that when pre-service teachers are given more knowledge about disabilities, how disabilities impact students, and practices that help teachers teach students, they are more likely to be inclusive and positive toward students with disabilities as well as confident in their ability to teach students with differences. Clearly, self-efficacy is one of the strongest predictors of pre-service teacher behaviors, including behaviors relating to inclusivity and confidence to teach students with differences and is vital to post-graduation success.

Connecting TPACK and self-efficacy. While self-efficacy beliefs are a part of the picture, they are not the complete picture. Schunk (1991) states "high-efficacy will not produce competent performances when required skills are lacking” (p. 3). Thus, pre-service teachers need to have a strong foundational TPACK as well as higher self-efficacy and beliefs.

To date, there are 3 studies that have examined the relationship of self-efficacy and to the TPACK knowledge bases. Two studies found that in-service teachers' TPACK knowledge strongly correlates with positive beliefs about their ability to teach students effectively (Koh, \& Chai, 2014; 
Lin, Tsai, Chai, Lee, 2013). In addition, there is research to indicate that in-service teachers with higher TPACK knowledge are more able to meaningfully incorporate technology into the classroom (Lee \& Tsai, 2010).

To date, there is one study that examined the impact of instruction on pre-service teachers' TPACK knowledge bases and self-efficacy for technology integration (Abbitt, 2011). In this study, 45 pre-service teachers were taught a methods course infused with technology use. These students were taught about important educational technology as well as how decisions about technology impacted student learning. Results indicated that following that specific course, there was a statistically significant increase in both TPACK knowledge and self-efficacy for using technology. While this study focused on pre-service teachers' bases technology knowledge base, there were positive shifts across the TPACK knowledge bases as a whole.

To date, no study has investigated the impact of instruction on changes in pre-service teacher knowledge and self-efficacy for including diverse learners in the classroom. This is most likely due to the fact that the TPACK model is often seen as a technology integration framework (Mishra \& Koelher, 2006). But, just as technology is essential to teaching in the $21^{\text {st }}$ century, so is the ability to teach diverse populations .And, 
unfortunately, many pre-service teachers continue to lack the skills and efficacy to teach students with differences, including those students with disabilities (Emmer \& Stough, 2001; Schumm \& Vaughn, 2009; Tomlinson \& Tighe, 2006).

\section{Conceptual Framework for Preparing Pre-service Teachers}

Technological, pedagogical, and content knowledge are fundamental knowledge bases that result in teachers knowing practices, student behaviors, and the required content. However, knowing things does not always result in teachers doing them. Self-efficacy filters the practices because the pre-service teacher decides if the practice is something they could actually implement. If a teacher is lacking the efficacy to do a practice, they may choose not to engage in the practice even if they know the practice is effective. Figure 2 demonstrates the framework that is guiding this study for preparing pre-service teachers to teach diverse learners. Illustrated is both TPACK and self-efficacy to teach diverse learners in relation to classroom practices. This relationship is bidirectional relationship in that both TPACK and self-efficacy may determine the classroom practices that are chosen, while successful classroom practices may lead to higher TPACK or higher self-efficacy beliefs. 


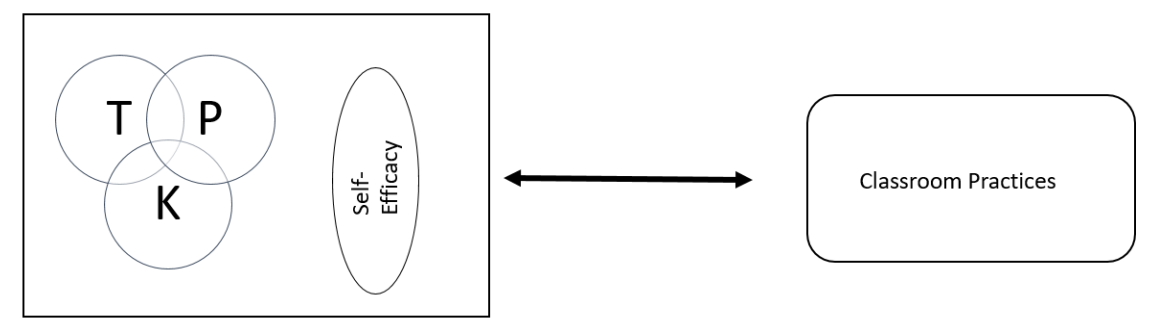

Figure 2. Conceptual framework of TPACK and self-efficacy

\section{Universal Design for Learning}

Fundamentally, pre-service teacher preparation is focused on preparing individuals to have the knowledge and self-efficacy to be effective teachers. Given the diverse nature of the classrooms that most pre-service teachers will likely work in, it is important that they are adequately prepared to work in these settings - they can use inclusive pedagogy and a strong self-efficacy to work with diverse learners. An inclusive pedagogy is one that integrates all the knowledge bases of TPACK Some researchers look at each component of TPACK individually, which is known as a transformative approach (GessNewsome, 2002), meaning that each knowledge base can be affected independently. Others see this framework as an integrative model. As each piece is interrelated in a way that makes it difficult to piece out each knowledge base (Graham, 2011). For the purposes of this study the researcher takes an integrative look at the TPACK model understanding 
that a growing one knowledge base is not independent from making gains in other bases. TPACK is looked at holistically to observe changes in preservice teacher knowledge (Mishra \& Koehler, 2009). This places a demand on pre-service preparation programs to instructional approaches that have the potential to address all the knowledge bases and self-efficacy for teaching in inclusive classrooms. One such approach that may be effective in doing this is Universal Design for Learning.

UDL has emerged as the most prolific model of universal design in education, appearing liberally in federal policy and mandates including the National Instructional Materials Accessibility Standards (2006), the Higher Education Opportunity Act (2008), the Common Core State Standards Initiative (2010), the National Educational Technology Plan (2010), and the Every Student Succeeds Act (2015). Per the Center for Applied Special Technology (CAST, 2019), UDL may be broadly defined as "a framework to improve and optimize teaching and learning for all people based on scientific insights into how humans learn" (para. 1). A parallel definition is presented at CAST's udlcenter.org (2014), which notes that UDL is "a set of principles for curriculum development that give all individuals equal opportunities to learn" (p. 1). According to the CAST website, "UDL provides a blueprint for creating instructional goals, methods, materials, and assessments that work for everyone — not a single, 
one-size-fits-all solution but rather flexible approaches that can be customized and adjusted for individual needs" (p. 1).

Grounded in research about learner differences, the capacities of new media, and the most effective teaching practices and assessments, UDL provides a framework for creating more robust learning opportunities for everyone. By using a UDL approach in the classroom, teachers proactively design their educational environments and instruction to meet the needs of a diverse group of learners rather than retroactively adjusting for individual students with special needs (Jimenez et al., 2007). The UDL framework is built on three specific principles for learning: engagement, representation, and action and expression. CAST defines engagement as the why of learning (Meyer, Rose \& Gordon, 2016). This includes how learners are motivated and challenged as well as how they sustain or persist in the task. Representation is the what of learning. It includes the way information is presented (visually, auditorily, etc.) so that students can identify patterns and receive information (Meyer, Rose \& Gordon, 2016). Action and expression is the how of learning and includes how students show what they have learned (Meyer, Rose \& Gordon, 2016). These three principles are structured toward three overarching goals: students become purposeful and motivated, resourceful and knowledgeable, and strategic and goal-oriented. To guide students to 
these goals, nine guidelines have been developed that form the primary foundation of UDL (Rose, \& Gravel, 2009; see Figure 3). The guidelines support the principles, but the main purpose of the guidelines is to guide educators and curriculum developers in using evidence-based methods to address the wide range of individual differences encountered in any typical classroom (CAST, 2019). Checklists under each guideline give further guidance to reduce obstacles or barriers that would restrict the way a student engages in the classroom, receives information, or demonstrates their knowledge. Each of the guidelines and checkpoints is founded in researched-based practices.

As a complete framework, research to support the use of the framework in classrooms is limited; however, each principle, along with the supporting guidelines and checklist, has research that supports it. Application of UDL does not require that all guidelines or checkpoints be utilized in any given lesson, unit, or even classroom setting. A broader focus of learner variability, appropriate scaffolding, and student choice are vital to a classroom based on UDL principles (CAST, 2018). 


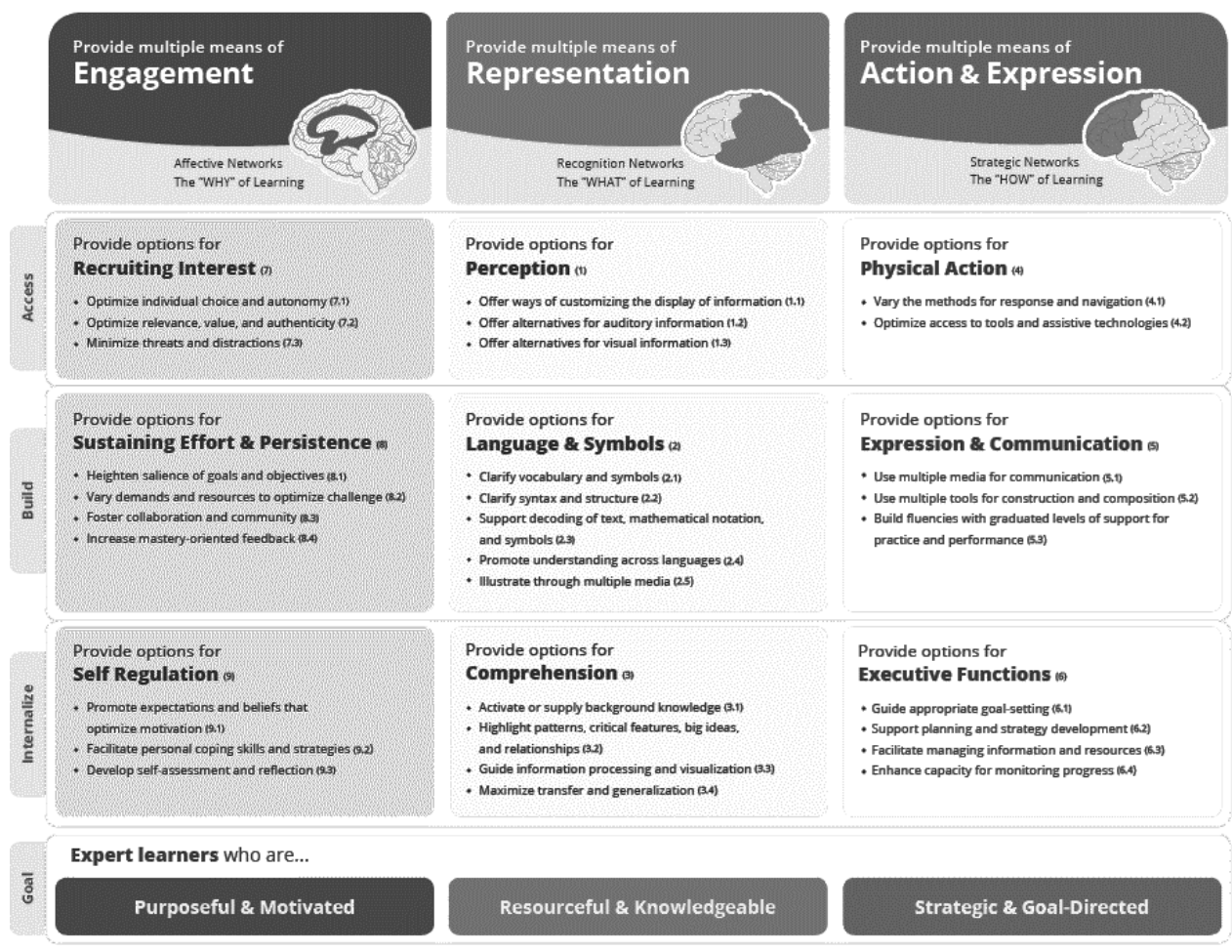

UDL Guidelines (2018), Retrieved from: http://cast.org

Figure 3. Universal Design for Learning Framework

Implementing UDL. The core UDL pillars of any lesson are

goals, methods, materials, and assessments. UDL principles can be applied to all four core pillars so teachers can systematically make decisions that increase accessibility for all students (Israel, Ribuffo, \& Smith, 2014). A UDL approach to effective learning goals consists of three key components: (a) separating the means from the end, (b) addressing variability in learning, and (c) providing UDL options in the materials, methods, and assessments. By determining clear goals, the 
foundation of accessibility is laid. Flexibility in the way content is presented and the way students interact with the content is an essential element of the UDL pillars. Materials are the media used to present information and demonstrate learning. Often materials contain embedded supports that help students access content (such as digital text that can be accessed by a screen reader). Methods are generally defined as the instructional strategies used by educators to support student learning. Methods should be evidence-based and supported by an analysis of learner variability. Methods based on UDL principles are flexible and guided by learner needs. Assessment within the UDL framework refers to the process of gathering information about a learner's progress using a variety of methods and materials. UDL assessments are particularly concerned with accurately measuring learner knowledge, skills, and engagement by maintaining construct relevance and reducing or eliminating irrelevant or distracting elements that interfere with the assessment's validity (Meyer Rose \& Gordon, 2017). The core pillars are particularly of interest for general education teachers as they focus on keeping the integrity of the standards that are required for teachers in the general education classroom while increasing the accessibility across the lessons (Meyers, Rose \& Gordon, 2017). 
UDL research. Research on the UDL framework is somewhat limited. However, studies have demonstrated several benefits of using the UDL framework (Edyburn, 2010; Hehir, 2009). First, Courey, Tappe, Siker, and LePage (2013) found that when UDL was taught to special educators, they were able to more effectively collaborate with general educators in creating inclusive lessons for all students. Second, in several studies, teachers who were taught to use UDL were more successful in designing a lesson plan accessible to all learners' needs, rather than retroactively trying to make a lesson plan accessible (Scott et al., 2017). Third, students with disabilities, including intellectual and learning disabilities, have greater access to the general education curriculum in classrooms implementing UDL (Gregg, 2009; Hall, et. al., 2015; Wehmeyer, 2006;). Fourth, improvements in engagement (Scott et al. 2015) and learning outcomes for students with and without disabilities has been found (Coyne, Pisha, Dalton, Zeph, \& Smith, 2010; Dalton, Pisha, Eagleton, Coyne, \& Deysher, 2002; Dymond et al., 2006; Kortering, McClannon, \& Braziel, 2008).

UDL in pre-service teacher education. Despite the benefits of UDL, in a national survey of colleges teaching UDL principles to preservice general education teachers, research found pre-service teachers are offered very little education about UDL (Vitelli, 2015). Of the colleges 
that responded $60.34 \%$ said they had knowledge of UDL principles, yet only $24.14 \%$ teach UDL (Vitelli, 2015). When research has been conducted on training pre-service teachers, there have been documented benefits of training them to utilize UDL.

Four studies were identified that examined the effects of teaching pre-service teachers about UDL (Courey, Tape, Silker and LePage, 2013; Frey, Andres, McKeeman, \& Lane, 2012; Spooner, Baker \& Harris, 2007). Spooner et al. (2007) used a pre/post-experimental randomized control design to examine 72 pre-service teachers' (both general education and special education) ability to create UDL lesson plans that reflected the three guiding principles of UDL (engagement, representation, and action/expression). The instructors of the study provided the treatment group a one-hour direct instruction lecture about UDL. The control group of students only received the UDL instruction after taking the post-test. Both groups were given a twenty-minute timed post-test in which the students were required to create an inclusive lesson plan for a particular student with a disability. They scored the results of the assessment using a three-point rubric in which each lesson plan was scored for how effectively participants planned implementing for the UDL principles. The students in the treatment group showed a statistically significant positive 
difference in their ability to design a UDL lesson compared to their control counterparts.

Similarly, Courey et al. (2013) examined 45 pre-service special education teachers' ability to plan a lesson based on UDL principles. The participants were tasked with designing lesson plans to be used for teaching a whole class (rather than individual students, as was the case in Spooner's work) in a general education setting. Courey and team expanded explicit UDL training to three hours. The participants were randomized into two groups. The control group was given an abbreviated lesson on how to use the lesson plan template that would be used during their pre-, post-, and maintenance post-tests. The treatment group was given a three-hour training session on UDL based on the IRIS training module, which is designed using UDL principles (videos, closed captioning, audio). In addition, the treatment group was given direct instruction on how to use the lesson template and time to create a practice lesson plan with guidance from the research instructors. The authors matched Spooner's research by using a pre-test and immediate post-test measure, but they added a maintenance post-test at the end of the semester. The findings suggest that those participants in the treatment group did significantly better in incorporating UDL principles into their lesson plans. The results on this maintenance post-test are again positive, 
demonstrating a high degree of maintenance (and often further improvement) between the first post-test and the maintenance post-test.

Frey et al. (2012) took a programmatic approach to implementing UDL across multiple core methods courses. This longitudinal study involved deep collaboration among faculty to incorporate UDL principles and practices across all of the pre-service teacher's methods course. The pre-service teachers were evaluated using their student-teaching portfolios, self-assessments, and pre-service teacher observations. Quantitatively, this study showed that the pre-service teachers appropriately used strategies for adapting their instruction to students with exceptionalities and became increasingly more proficient as they went through the program. While this was a much more intensive approach to preparing pre-service teachers as compared to Spooner et al. (2007) and Courey et al. (2013), it also had significant gains in pre-service teacher performance. There are grounds to suggest that there are ways to thoroughly and systematically develop pre-service teacher knowledge of UDL through short-term interventions and longer-term, intensive interventions. However, none of the studies identified connected UDL to TPACK to see how learning about UDL effected foundational teacher knowledge. Preservice teachers have funds of foundational knowledge. These funds may have an impact on how well pre-service teachers are able to implement 
UDL. Nor did these studies look at how learning about UDL affected selfefficacy. Knowledge alone, without related positive attitudes and efficacy, is unlikely to result in pragmatic change in teacher behavior (e.g., MacFarlane \& Woolfson, 2013). While teacher knowledge, self-efficacy, and inclusive pedagogies are all important individual pieces of the preparedness of pre-service teachers, how those domains interact collectively may provide a more complete picture of the decisions that pre-service teachers make when determining appropriate practices for all students.

Furthermore, of the studies reviewed, the only way application of UDL knowledge has been examined is via the lesson plan in particular, what principles are reflected. No one has specifically examined the 4 pillars of UDL and the extent to which UDL promotes the use of more inclusive pedagogical practices. Examination of how UDL is applied is as important as the knowledge of UDL. Particularly understanding how the concepts of UDL can be applied to classroom situations may give insight as to how deeply these complex constructs are being used and give researchers more insight as to how pre-service teachers are moving to more inclusive thinking. UDL can be an overlay in which UDL is applied to TPACK and the self-efficacy to teach all students to create more inclusive classroom practices (see Figure 4) 

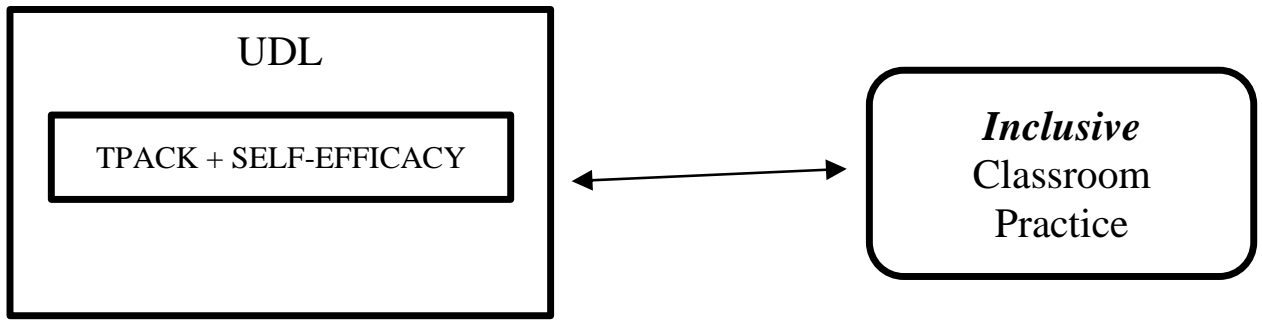

Figure 4. UDL as the overlay on TPACK and self-efficacy to teach all students, to result in inclusive classroom practice

\section{Summary and Rationale for Study}

General education pre-service teachers are expected to teach diverse learners, including those with disabilities, in the general education setting. Yet, when surveyed, pre-service teachers often report feeling unprepared to meet the needs of all students (Ayantoye \& Luckner, 2016; Leuszler, 2015; Tirado, 2016). This may be due to the fact that preservice teachers are not adequately prepared to teach in the diverse classrooms they are given once they enter the workforce (Forlin \& Chambers 2011, Scruggs \& Mastropieri, 1996). This raises the need to ensure that pre-service teachers are adequately prepared. However, it is unclear what-how to best prepare them.

There are many different ways to teach pre-service teachers. One way is through the use of active pedagogies, which have been shown to help pre-service teachers integrate content and pedagogy by applying what they learned to practical problems (Steinemann, 2003) while providing 
them with opportunities to work in a relatively safe classroom without the pressure of actual teaching conditions (Sileo, 1998). Although these practices have been researched in a variety of learning environments (e.g. Barrows \& Tamblyn, 1980; Feletti, 1997; Mitchell, 1993,), there has been little research to determine if active pedagogies, including practice-based experiences, have any impact on pre-service teacher preparedness.

The TPACK model provides guidance as to what pre-service teachers need to know in the form of foundational knowledge to be effective in the classroom (Mishra \& Koehler, 2007). Self-efficacy further focuses the practices pre-service teachers implement by filtering practices that they do not feel they can implement. Therefore, it is essential to look at both TPACK and self-efficacy as constructs in what practices teachers apply. Pre-service teachers with knowledge in technological, pedagogical, and content practices will likely create quality classroom practices; however, these practices may not be inclusive practices. UDL could be useful framework in aiding pre-service teachers in systematically and meaningfully adjusting to meet the needs of all the students in their classrooms. Further the TPACK model does not account for a pre-service teacher's self-efficacy to work with all students. Self-efficacy is shown to be a factor in a pre-service teacher's ability to implement the frameworks that they have learned (Schunk, 1995). In addition, research suggests that 
learning about disabilities and strategies to support students with disabilities, increases a pre-service teacher's self-efficacy about meeting the needs of those students (Meijer \& Foster, 1988; Podell \& Soodak, 1993). It can be hypothesized that learning about learners and implementing the UDL framework may increase a pre-service teacher's efficacy, thus helping them to implement practices that are the most inclusive.

To date, no study has examined how learning about UDL can be used as a way to improve pre-service teachers' fundamental knowledge (TPACK) and self-efficacy for working with diverse learners. In addition, there is a need to further understand best practices for teaching pre-service teachers and how practices effect pre-service teachers in a broader context beyond knowledge acquisition. Therefore, the purpose of this study is to examine the impact of using a practice-based approach as compared to a lecture-based approach to learn about the effect UDL has on pre-service teachers' fundamental knowledge for teaching, self-efficacy and UDL knowledge. Additionally this work examines the ability to application of UDL to prepare general education pre-service teachers to teach students with disabilities in an inclusive setting.

This is valuable to the education field as it can help teacher preparation programs determine the most effective practices for teaching 
preservice teachers and whether knowing about UDL can have a positive impact on knowledge for teaching and self-efficacy. Understanding what pre-service teachers should know, how to increase pre-service teacher's self-efficacy so that they can make positive classroom decisions, and how to reduce barriers to make classrooms more inclusive are fundamental in ensuring future teachers are equipped to meaningfully include all students.

\section{Research Questions}

Therefore, this study is intended to answer the following questions:

1. How does a Practice-Based approach compare with a LectureBased approach about UDL for improving pre-service teachers'

(a) fundamental knowledge for teaching, (b) knowledge of UDL

(c) reported self-efficacy, and (d) application of UDL for inclusive pedagogical practices?

2. What relationships exist between pre-service teachers' knowledge of UDL and application of UDL for inclusive pedagogical practices overall and by instructional condition? 


\section{CHAPTER 3}

\section{Methods}

The purpose of this study is to examine the impact of using a practice-based approach to teach UDL as compared to a lecture-based approach to learn about UDL on pre-service teachers' fundamental knowledge including UDL, self-efficacy and UDL application to prepare general education pre-service teachers to teach students with disabilities in an inclusive setting. This chapter includes information regarding, research design, sampling and participants, setting, measures, design of instruction, procedures, instrumentation, data collection, and the quantitative and qualitative methods used to analyze the data collected.

\section{Research Design}

This study employed a mixed methods triangulation design (Creswell, \& Plano Clark, 2003). This model included concurrent collection of both quantitative and qualitative data. After the data werecollected the qualitative data were transformed into numerical values that could be analyzed quantitatively, as shown in Figure 5. 


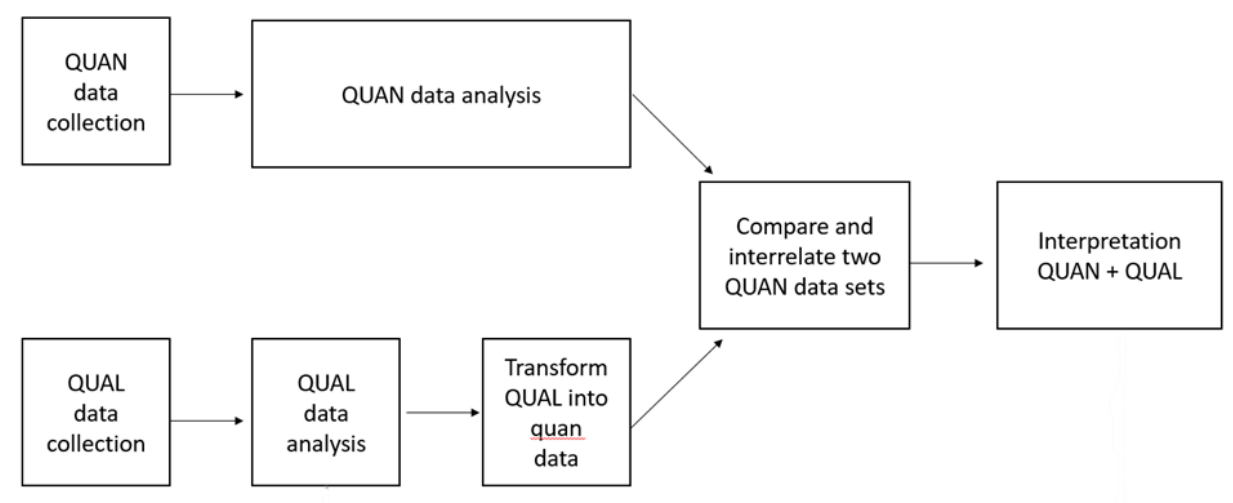

Figure 5. How QUAL data was transformed to QUAN using a triangulation design.

The design of the quantitative portion of the study was a random assignment pre-test, post-test group design (Gall, Gall, \& Borg, 1996; Spooner et al. 2007). Students from all four sections of the course were randomly assigned to one (practice-based or lecture-based) of two conditions. Because the students in each section of the course where this study was carried out are grouped by certification content areas (e.g., section one contains all early elementary pre-service teachers), it was important to randomize across classes to ensure the conditions of the study were as equivalent as possible. Participants were divided equally among the two conditions. 


\section{Sampling and Participants}

Sampling. A convenience sample was chosen for this study.

General education pre-service teachers in an introduction to special education course were chosen as the population of interest for two reasons. First, because of their progression in the education program, the participants were likely to have some knowledge about pedagogy and content, while likely having misconceptions or limited knowledge about teaching students with disabilities. Second, Universal Design for Learning is within the scope and sequence of content taught in this course, therefore it is aligned with this study.

To determine sufficient, statistical power, a power analysis was performed for a sample size estimation (GPower 3.1). Because there is no data on the effects of the type of intervention it was difficult to determine what the effect might be. However, because of the brevity of the study conditions, a moderate effect was chosen for this study (Cohen, 1988). With an alpha $=.05$ and an effect of .5 the projected sample size needed (GPower 3.1) was $N=74$.

After receiving IRB approval, all the students in the introduction to special education course were recruited to participate in this study. All 94 students consented to participate. However, only the 88 who completed all of the measures for this study were included in the analyses. Two 
students chose to withdraw after the intervention before the post-test measure. Three students did not complete the pre-test measure due to an absence from class and one student only completed $20 \%$ of the post-test.

Participant Demographics. The participants who completed all the measures were comprised of general education pre-service teachers preparing for certificates in early childhood education $(n=11)$, elementary education $(n=38)$, or secondary education $(n=39)$ with an emphasis in one or more content areas. Participants ranged in age from 18 to 44 years but the majority of the participants reported that they were in the 18 to 24 years age band $(n=86)$ with only two participants indicating that they were older than 24 . Of the participants, $78 \%$ were female, $18 \%$ were male, and $2 \%$ indicated that they identified with a gender not listed or preferred not to answer. Six percent of the population reported having a disability. All the students in this course were admitted as a phase II student in the College of Education, meaning they have met the initial requirements to continue in the education program and were in field placements in school districts.

\section{Setting of Study}

The study took place at a midwestern University within the introduction to special education course. This is a mandatory course for all general education major and is necessary for initial certification. That is 
taught by instructors who are trained in core special education topics but is overseen by an assistant professor in the Department of Special Education. The overseeing instructor regularly collaborated throughout this study with the instructors of the course to maintain consistency of rigor and content. For this semester, there were four instructors of the course during this study who were graduate level teaching assistants with some background related to special education. Materials for the course were designed by experts in the field and the materials were standardized across the four sections. Generally, this course covered topics including but not limited topics such as educational law, disabilities and their impacts, Response to Intervention, Positive Behavior Interventions and Supports, Universal Design for Learning, and other issues related to special education

\section{Measures and Scoring}

Four constructs were of focus and measured to determine the effect of the intervention in this study. They included (a) foundational knowledge for teaching (technological, content and pedagogical) (b) UDL knowledge, (c) self-efficacy, and (d) Universal Design for Learning application. Several measures were used to examine these constructs.

TPACK Infused UDL Survey (Benton-Borghi, 2013). The purpose of this measure is to understand amount of foundational 
knowledge that pre-service teachers report in relation to technology, pedagogy, content, and UDL, and observe how that reported knowledge changes post intervention. This measure is a 42 -item survey where participants rate their agreement for each item on a 5-point Likert scale (5 $=$ strongly agree, $4=$ agree, $3=$ neutral, $2=$ disagree, $1=$ strongly disagree). (See Appendix B for the items.) A higher total score on this measure indicates a stronger self-assessment of TPACK as well as UDL within the TPACK domains, with the highest overall score being 210. For the purpose of this study subscores of the TPACK and TPACK UDL questions were created. The TPACK questions consisted of 32 items related to the TPACK framework. This was interpreted as foundational knowledge. The construct of UDL knowledge was created from the TPACK UDL questions. There were 10 questions related to UDL within this measure. In previous studies, the TPACK and TPACK UDL components of this were used with both pre-service and practicing teachers with reliability and validity (Benton-Borghi, 2011, Schmidt et al., 2009). The reliability for the measure was strong, receiving a Cronbach's alpha score of 0.96 on pre-test and 0.94 on post-test.

\section{Twenty-First Century Teacher's Sense of Efficacy Scale}

(Benton-Borghi \& Chang, 2012). The purpose of the Twenty-First Century Teacher's Sense of Efficacy Scale (T-TSE) survey is to 
understand how general education pre-service teachers rate their efficacy in working with students who may struggle, including those with disabilities. The T-TSE is a -point Likert scale survey $(1=$ nothing, $3=$ very little, $5=$ some influence, $7=$ quite a bit, and $9=$ a great deal). It contains 19 questions (see Appendix C) from which a total score 171 can be generated. Higher scores mean higher self-efficacy. In previous research this measure has been used and has been determined to be a reliable valid measure of self-efficacy (Benton-Borghi, 2013). The reliability for the measure was strong, receiving a Cronbach's alpha score of 0.92 on pre-test and 0.94 on post-test.

Scenario-based Assessment (SBA). Scenario-based assessments are open-ended authentic tasks used to better comprehend understandings and misunderstandings of participants while also measuring the effectiveness of the intervention (Sadler, 2007). For this particular study, the researcher created SBA measured the participants' ability to apply UDL concepts. The SBA used in this study involved giving participants the demographic data of a classroom along with the corresponding planned lesson goal, a list of materials to be utilized, the teaching method to be used, and the assessment to be used (Appendix D). The task required the participants to revise each section of the lesson plan and then 
provide a justification for the revision based on what they understand from the UDL framework.

Participants' responses were scored on a researcher-developed rubric using a 2-point scale with a maximum of 16 points possible. Points were distributed based on three criteria: 0 points if a revision was not made; 1 point if a revision was made but was not connected to UDL; and 2 points if a revision was made employing UDL principles and vocabulary (see Appendix E for the rubric used). To ensure the validity of the rubric, an expert in UDL who has training from CAST reviewed it. Minor revisions were made based on the review prior to its use in the study.

\section{Intervention Design and Development}

This study consisted of two conditions: a practice-based condition and a lecture-based condition. Both conditions involved similar UDL instruction. This ensured that inferences could be made about the way that the content was presented and not differences due to unequal content. After consulting with a panel of three experts (one additional graduate student, a general educator with a Ph.D. in education who also trains educators for CAST, and an individual who writes and consults about UDL) about the most important components of UDL, a few topics were chosen as focus topics: (a) learner variability and UDL guidelines, (b) 
UDL goals, (c) UDL methods and materials, and (d) UDL assessment.

See Table 1 for the content covered in each condition.

Table 1

Content Covered in Each Condition

\begin{tabular}{ll}
\hline \multicolumn{1}{c}{ Practice-based } & \multicolumn{1}{c}{ Lecture-based } \\
\hline Introduction video (4 minutes) & Video Lecture with slides \\
UDL defined & including: \\
Station expectations & Explicit articulation of student \\
Explicit articulation of student & outcomes \\
Uutcomes & UDL defined \\
& Learner variability \\
Station 1 & UDL guidelines \\
Learner variability & Four curricular pillars \\
UDL guidelines & Goals \\
& Flexibility \\
Station 2 & Separating means from ends \\
Learning goal defined & Methods \\
Flexibility & Role of technology \\
Separating means from ends & Materials \\
& Role of technology \\
Station 3 & Assessment \\
Learning environment & Construct relevance \\
(including methods & Student choice \\
and materials defined) & Clear expectations \\
Role of technology & UDL vocabulary \\
Examples of technology to & Barrier \\
meet UDL & Access \\
\hline &
\end{tabular}


Station 4

Assessment

Construct relevance

Student choice

Clear expectations

Note. ${ }^{\text {a }}$ topic not covered in other condition

Framework

Learning environment

Summarization

Content analysis for content overlap. Content for the two conditions was analyzed and developed to ensure that both of the conditions covered the same content. The content for the stations was determined by the researcher. The researcher and a panel of experts then examined the lecture slides that were typically used for the class. It was found that there was only a $54 \%$ overlap in the developed materials and the lecture slides. This was insufficient to meet the criteria of material similarity. A new lecture script was developed and the script was examined for content overlap. The script was revised until all of the essential content was included in the script. The station had opportunities of exploring iPad applications in the materials section, while those technologies were only generally referenced in the video. The resulting new lecture material and developed station materials had a $94 \%$ overlap, which was determined sufficient (Choudary \& Liu, 2007); See Appendix F for copies of the lecture slides). Once there was agreement on the content and content overlap, both station materials and the lecture video were produced. 
Practice-based Intervention (treatment condition). Four

learning stations were developed by the researcher. Each station was structured in a similar way and included four elements: (a) an introduction to the concept, (b) resources to guide the participants to gain a better understanding of the UDL topic specific to the station, (c) a choice from a list of hands-on activities, and (d) a reflection to help participants determine if they had learned the concept and were ready to move to the next station, or were lacking understanding and needed to revisit a concept. (See Appendix G for copy of the content of each station). The expert panel was consulted throughout the creation of these stations.

The stations were developed with the UDL principles embedded in them. Each station had multimodal choices for participants to learn from. Students also had choices of activities to participate in at each station. After stations were developed, an expert on UDL scored the stations based on the UDL guidelines (see Figure 6). It was consensus of the researcher as well as the expert that the stations covered UDL content appropriately as well as serving as a model of UDL

I. PROVIDE MULTIPLE MEANS OF REPRESENTATION:

1. Provide options for perception 1.1 Customize the display of information 
1.2 Provide alternatives for auditory information

1.3Provide alternatives for visual information

2. Provide options for language and symbols

2.1Define vocabulary and symbols

3. Provide options for comprehension

3.2 Highlight critical features, big ideas, and relationships

3.3Guide information processing

3.4 Support memory and transfer

II. Provide Multiple Means for Action and Expression:

4. Provide options for physical actions

4.1 Provide varied ways to respond

4.2 Provide varied ways to interact with materials

4.3 Integrate assistive technologies

5. Provide options for expressive skills and fluency

5.1Allow choices of media for communication

5.2 Provide appropriate tools for composition and problem solving

5.3Provide ways to scaffold practice and performance

6. Provide options for executive functions

6.3Facilitate managing information and resources

6.4 Enhance capacity for monitoring progress

III. Provide Multiple Means for Engagement:

7. Provide options for recruiting interest

7.1Increase individual choice and autonomy

7.2Enhance relevance, value, and authenticity

8. Provide options for sustaining effort and persistence

8.1 Heighten salience of goals and objectives

8.2Vary levels of challenge and support

8.3Foster collaboration and communication

9. Provide options for self-regulation 


\subsection{Develop self-assessment and reflection}

Figure 6. UDL principles addressed in learning stations.

Lecture-based Intervention (control condition). After the appropriate content was determined and a script was approved by the expert panel, lecture slides were created. To ensure the quality of the slides and that the content was presented in the clearest manner, the slides were developed using Mayer's (2008) standards for multimedia production. While some of the principles could not be accounted for, requirements for the principles of coherence, signaling, redundancy, spatial contiguity, temporal contiguity, multimedia, and personalization were met. On the other hand, the requirements for principles of segmenting, pre-training, and modality were not met. The lecture slides and script were recorded and uploaded to YouTube so that they could be easily accessed with a password by the instructor. A final check by the panel was performed and the video was approved before it was used in classes.

Piloting of interventions (treatment and control). Both of the conditions, problem- based and lecture-based, were piloted with a small focus group of undergraduate education pre-service teachers. The purpose was to ensure that the content was accessible for learners with little UDL 
knowledge and to check the time required to complete the conditions. This focus group consisted of 3 females and 1 male. The group was asked to participate in the stations just as they would if they were participants in the study. From the piloting, it was determined that an introduction to the stations was needed for participants to understand their role and expectations for the learning activities. A short video was made as a result. One learning activity was not perceived to be strongly connected to the goals of the station and was eliminated from a station. Two additional assistive technology applications were added to the materials learning station to clarify the range of technologies available. After piloting, stations were again checked for overlap with the lecture video and sufficient overlap remained.

The same focus group piloted the lecture-based video. After receiving feedback from pilot participants, the speaking rate of the lecturer was adjusted and examples were provided to illustrate learner variability and learner choice. A new version of the video was recorded based on suggestions.

\section{Procedures}

Recruitment and consent. Procedures to conduct research within the College of Education were followed, including receiving approval from the associate dean for academic student success and student affairs. 
IRB approval (see Appendix A) was completed prior recruitment. The supervising teacher of the course was contacted. Once she approved the project within the course, the researcher met with and obtained consent from all instructors.

A week before the scheduled study, the researcher attended the last 30 minutes of each of the course section's lectures. Because two sections were held at the same time and day at different locations, these two sections were condensed into one section. All students were told about the purpose of the study and read the participant consent documents. No identifying data was collected from the students. Each student was asked to choose a four-digit identification number to match pre- and post-test data. The researcher did not have access to any student names or other identifying information.

Pre-testing. Immediately after consenting to the study, students took the pre-test. All of the measures of the pre-test were delivered using a Qualtrics survey during the same class period in which students consented to the study.

Intervention procedures. All interventions took place one week after the initial consent and pre-testing. Students came to class at their normal scheduled time with the exception of the class that has a concurrent meeting time. These sections were combined to meet at the 
same time in one location to maintain consistent timing of the intervention. These sections had been combined prior to this study and it was not unusual for them to meet together. This also allowed the researcher to administer the pre-testing, intervention and post-test at the exact same time in the semester for all for the sections. On the day of the intervention, the classroom instructor gave announcements for the day, if applicable. Identification numbers were read as well as posted to separate them into the correct groups.

Students in the lecture-based group exited the regular meeting space and were escorted to a similar classroom in the same building. Once all students were seated in the classroom, a research assistant started the video lecture. Following the lecture, the students were directed to complete the post-test using the given link to a Qualtrics survey. The average time for the control group to complete the video lecture and posttest was 70.36 minutes.

Participants in the treatment group watched a video giving them instructions on how to complete the stations in the classroom. The stations were located in the corners of the classroom and individuals participated in the stations. Each station had a flier to instruct students on the resources and activities for that station. Quick response $(\mathrm{QR})$ codes directed the students to the appropriate resources. Students could choose 
to use their own device or a provided iPad to navigate each station. The researcher was available to answer questions about the station procedures but did not answer questions relating to the content of the intervention. Once students had completed the intervention, they were directed to take the post-test through the exact same Qualtrics link as the control group counterpart. The students were allowed to leave when they were finished. The average time the students in the treatment group spent was 68.2 minutes, which was similar to the control group. See Figure 7 for an overview of the intervention schedule.

\begin{tabular}{|c|c|c|}
\hline $\begin{array}{l}\text { Pre-Test } \\
\text { Monday or Tuesday } \\
\text { (depending on class }\end{array}$ & \multicolumn{2}{|c|}{$\begin{array}{l}\text { Following Monday or Tuesday } \\
\text { Study took place during their regular class meeting time }\end{array}$} \\
\hline $\begin{array}{l}\text { Researcher explained } \\
\text { study and answered }\end{array}$ & & \\
\hline questions last 30 & Both Groups & Practice-based \\
\hline $\begin{array}{l}\text { Participants } \\
\text { consented }\end{array}$ & $\begin{array}{l}\text { Participants } \\
\text { thanked for } \\
\text { participation }\end{array}$ & $\begin{array}{l}\text { Four minute introduction video played } \\
\text { Participants explored four stations } \\
\text { Post-test given after completion of } \\
\text { stations }\end{array}$ \\
\hline Directed to pre-test & All participants & \\
\hline $\begin{array}{l}\text { through a link in } \\
\text { Canvas site } \\
\text { Similar learning } \\
\text { activity available for } \\
\text { non-consenting } \\
\text { students }\end{array}$ & $\begin{array}{l}\text { given randomized } \\
\text { assignments }\end{array}$ & $\begin{array}{l}\text { Lecture-based } \\
\text { Participants taken to different } \\
\text { classroom within the building } \\
\text { Video started by trained assistant } \\
\text { Post-test given after completion of } \\
\text { video }\end{array}$ \\
\hline
\end{tabular}

Figure 7. Intervention schedule. 
Treatment fidelity. Treatment fidelity for the intervention group was measured during the stations experience to ensure that all participants were engaged with each station. This was measured by requiring students to complete a checklist when they finished each station to ensure they were receiving the information from the station. This was given through a digital form (Figure 8). Intervention participants completed 94\% of selfchecks.

Student Self-Reflection ${ }^{\text {a }}$ Station 1

Student number

Please check which resources you used: __ Video $1 \ldots$ Text $1 \ldots$ Audio 1

Please check which activity you engaged in: __ UDL Wheel __ Card Sort

Self-Reflection: Can you answer the following questions? (3 knowledge-

Note. ${ }^{\text {a }} \mathrm{QR}$ code was used to direct participant to a Google Form. Figure 8. Sample of participant reflection form completed at each station.

In addition to ensuring treatment fidelity, a walkthrough was performed each day with a checklist to make sure all materials were working properly (Figure 9). Treatment fidelity checks measured at $100 \%$. 
Data preparation and entry. A Qualtrics survey was utilized to collect the participants' pre- and post-test data. All data was downloaded into an Excel spreadsheet by the researcher and $25 \%$ of all items were checked to ensure the data accurately transferred between programs. All the data generated from the rubric was calculated across categories and entered into a single excel worksheet by both the researcher and another trained data-entry person. Once the data was double counted and entered, the two spreadsheets were compared and any discrepancies were discussed and remediated on an individual basis. This process accounted for any counting or data entry errors. Then, all data was merged into one data file using the R program. The researcher checked $25 \%$ of the data on both the original Qualtrics data and the spreadsheet data to insure the data were merged correctly by student ID and category. 
Date

Time:

Initials of

Reviewer

Introduction video functioning? Y N

QR code directs to resources properly? Check if yes, note any

problems in coordinating box

\begin{tabular}{|l|l|l|l|l|}
\hline & Station 1 & Station 2 & Station 3 & Station 4 \\
\hline $\begin{array}{l}\text { Resources } \\
\text { linked can } \\
\text { be accessed }\end{array}$ & & & & \\
& & & & \\
\hline $\begin{array}{l}\text { Activities } \\
\text { linked OR } \\
\text { materials are } \\
\text { available }\end{array}$ & & & & \\
\hline $\begin{array}{l}\text { Self-check } \\
\text { form works }\end{array}$ & & & & \\
\hline
\end{tabular}

Figure 9. Procedural fidelity checklist.

Data preparation and entry. A Qualtrics survey was utilized to collect the participants' pre- and post-test data. All data was downloaded into an Excel spreadsheet by the researcher and $25 \%$ of all items were checked to ensure the data accurately transferred between programs. All the data generated from the rubric was calculated across categories and entered into a single excel worksheet by both the researcher and another trained data-entry person. Once the data was double counted and entered, 
the two spreadsheets were compared and any discrepancies were discussed and remediated on an individual basis. This process accounted for any counting or data entry errors. Then, all data was merged into one data file using the $\mathrm{R}$ program. The researcher checked $25 \%$ of the data on both the original Qualtrics data and the spreadsheet data to insure the data were merged correctly by student ID and category.

\section{Threats to Validity and Reliability}

The time between measures was kept constant for all groups. The pre-test was identical to the post-test, so it may have sensitized the participants to the information in the intervention in which participants engaged. However, both groups received the same pre-test, therefore, the effects would be equivalent across groups. Steps were taken to control for Hawthorne effect (Gaskell, 2012) by clearly communicating to all participants that their responses would not have an effect on their class grade as well as the importance of honest answers as the researcher was trying to understand a phenomenon rather than expecting a certain response. Because this was a randomized trial, it is likely that the trial effect was equal across groups, thus minimizing the impact on the findings.

\section{Data Analysis}


Four constructs were examined for this study (a) foundational knowledge for teaching including, (b) knowledge of UDL, (c) reported self-efficacy and (d) UDL application. The following will explain the analysis that were used to examine each construct. Descriptive statistics are reported including mean, standard deviation, skewness, and kurtosis for each measure for both groups (practice-based and lecture-based). All assumptions (linearity, normality, and homoscedasticity) were checked prior to the analysis to make sure that the analyses could be done appropriately.

To answer the first research question, the following analysis were conducted.

Foundational knowledge for teaching. Data from the TPACK infused UDL survey was used to determine difference in foundational knowledge for teaching from pre-test to post-test and between groups (problems-based and lecture-based). This assessment includes both items on TPACK knowledge as well as items examining UDL knowledge within TPACK. The items regarding UDL were removed from these analyses to focus solely on change in TPACK. Data from each group were visually analyzed with box plots as well as violin plots to determine the potential for pre-test differences as well as possible outliers that may skew the data set. An analysis of variance (ANOVA) on mean growth scores from pre- 
test to post-test was conducted. Cohen's d was used to determine the effect size of the UDL instruction had on TPACK knowledge for both groups. Where effect sizes were reported the following scale is generally used to interpret the magnitude of an effect based on $d$ : small effect, $0<d<.2$, moderate effect $.2<d<.8$, large effect $d>.8$ (Rosenthal, Cooper \& Hedges, 1994).

An ANOVA was also conducted to determine if significant pre-test differences between the problem-based group and the lecture based group. Because there was a difference between groups and analysis of covariance (ANCOVA) was performed to examine the effects of the intervention controlling for pre-test differences.

UDL knowledge. The items of the TPACK infused UDL survey related to UDL were removed from the data set and a subscore was created. This score was used to calculate participant's reported UDL knowledge. An ANOVA of gain scores was performed to examine growth from pre-test to post-test. In addition, an ANOVA was run to determine if there were between group differences at pre-test. Because there were differences, an ANCOVA was used to determine the effect of the instruction on groups.

Reported self-efficacy. Data from the Twenty-first Century Teacher's Sense of Efficacy (T-TSE) scale was used to determine 
difference in reported self-efficacy from pre-test to post-test and between groups (problems-based and lecture-based Data from each group were visually analyzed with box plots as well as violin plots to determine the potential for pre-test differences as well as possible outliers that may skew the data set. An ANOVA on mean growth scores from pre-test to post-test was conducted. Cohen's d was used to determine the effect size of the UDL instruction on participants' self-efficacy. An ANOVA was also conducted to determine if significant pre-test differences between the problem-based group and the lecture-based group. Because there was a difference between groups and ANCOVA was performed to examine the effects of the intervention controlling for pre-test differences.

UDL application. The scenario-based assessment was used to examine participants' ability to apply UDL knowledge. Scores on this assessment were transformed into quantitative data using a rubric to get an overall score. First, the SBAs were scored, using the rubric, to generate a total score to be analyzed using quantitative procedures. To check for interrater reliability, $33 \%$ of the responses were dually scored using the rubric provided (Gall, Gall \& Borg, 2007). Reliability scores were computed for the scoring using the rubric and was calculated for each response by taking the number of agreements divided by the number of agreements and disagreements multiplied by 100 . Across all responses the 
interrater agreement for each reference to UDL term in the responses was $89.7 \%$ (ranging from $81.3 \%-95.6 \%$ ). These disagreements were resolved by discussing disagreements and adding vocabulary to further defined the criteria in the rubric. The first 20 responses were dual coded with another researcher to check for reliability and found to have appropriate interrater reliability. The primary researcher then coded 40 responses independently. Fifteen additional responses were dual coded, and interrater reliability was found to be acceptable. This pattern of independent scoring and dual scoring included 4 cycles to ensure that rate drift was minimal (Harik, 2009).

Second, the content of the SBAs was analyzed based on UDL concepts (engagement, action and expression, representation, accessibility, barrier, technology, all learners, choice) that were determined by a panel of experts as central to instruction on both lectures for quantity and quality. Initially, these data were then quantitatively analyzed. The data for this measure violated normality assumptions a non-parametric test were used. The Kruskal-Wallis test was used to examine the impact of group on the UDL-SBA scores. The Wilcoxon matched pairs was used to examine pre-test to post-test growth. In addition, the effect size of each group instruction was calculated using Cohen's $d$ ANCOVAs were 
conducted to examine the differences between groups controlling for pretest differences.

\section{Relationship between UDL knowledge and application. To} answer the second research question, the relationship between UDL knowledge and UDL application, the following analysis were performed.

Quantitative analyses. An analysis of Pearson's coefficient correlation was conducted to determine if a relationship between the two measures. After an unexpected finding a linear regression analysis was performed to determine the relationship of group, UDL knowledge score and UDL application score for both groups. An outlier was determined to significantly change the results of the data, so the Bonferroni test was used to locate and remove the participant from the analysis. With the participant removed this data was fit to the same linear regression model.

Qualitative analyses. In addition to quantitatively transforming the SBA data to use in analyses, qualitative content analyses were performed to examine qualitative relationships between groups. The flow of analysis used to examine the qualitative data occurred in four steps (Miles \& Huberman, 1994): (a) compiling qualitative responses from SBA; (b) generating categories, subthemes, and themes to identify important issues; and (c) establishing trustworthiness (Lincoln \& Guba, 1985). Responses from the SBA were compiled by group and pre-test and 
post-test. First, key terms were determined from the content that was covered in both the practice-based and lecture-based interventions related to UDL. Experts in the field reviewed the content covered in both conditions, as well as the objectives for the intervention and identified 7 terms that were most important to understanding the content: engagement, representation, expression, choice, accessibility, technology, and all students. The term all students was chosen as it best incorporated the idea of inclusivity (i.e. all students can learn, designing for all students). Data was then searched for terms these terms. All data identified as containing was compiled into respective codes (Dicle \& Dicle, 2018). These codes were then categorized by themes: frameworks, codes that were based on the structure or vocabulary related UDL principles; implementation, codes that were related to how a teacher would carry out UDL ideas in the classroom; and who, responses related to who would benefit. These items were grouped to more fully explain the findings.

Once the data was coded and placed into themes, to determine quantity (number of times the word was used) a count was taken for each group. The count process involved: each individual overall response was coded with either a 0 (term not present) or a 1 (term present) for each term or form of the term was used. For example, if the response had engagement or engage it was coded with a 1 . If the response had engage in 
the response 3 times it was still coded as a 1 . This reduced the inflation of counts if a participant used a term multiple times in the response (Bakerville, et al., 2001). Each response could have used multiple different terms and would receive a 1 for each of the unique terms used. Table 2 provides example of responses that were coded as a 1 for each term. These terms were grouped into themes: terms that relate to the UDL framework (engagement, representation, expression); terms that relate to implementation of UDL (choice, accessibility, technology) and who (all students). These themes were analyzed to better understand the patterns that emerged from the data. Table 2 provides example of responses that were coded as a 1 for each term.

Table 2

Examples of Coded Responses Containing UDL Terms

\begin{tabular}{lll}
\hline Theme & Counted Term & Example response \\
\hline Eramework & $\begin{array}{l}\text { "To implement UDL strategies, she should } \\
\text { provide options for recruiting interest and } \\
\text { engagement."* }\end{array}$ \\
"this would help with engagement because they \\
have more autonomy"* \\
"multiple means of engagement" \\
Representation \\
$\begin{array}{l}\text { "UDL prioritizes different means of engagement } \\
\text { and these stations would allow that to happen } \\
\text { because the students would be participating in } \\
\text { different activites and have different modes of } \\
\text { information presented to them."* }\end{array}$ \\
\end{tabular}


Action and Expression

Choice

Accessibility
"In order to align with UDL principles, Mrs. Kim needs to provide a variety of representations"

"multiple ways to represent information"

"Mrs. Kim wants students to copy definitions, but this represents an action and expression barrier. Some students may physically struggle with this task, while others may find themselves bored with it."**

"Mrs. Kim needs to provide her students with options for assessment (expression \& action). Her students should utilize a variety of media for demonstrating their understanding, not just written text."*

"Providing multiple means of expression"

"Students who aren't as strong writers will struggle with this but if you give them the choice they will be able to do the assignment more comfortably and with more confidence."*

"UDL uses a variety of choices in order for students to use their strengths to learn best."

"Giving students choice"

"Based on UDL concepts, I know that traditional learning materials create various barriers for diverse learners. Instead, educators must be flexible with texts and use materials in ways that make learning more accessible for all students"*

"UDL makes knowledge more accessible, and by providing other ways to access the information, you are allowing more kids to learn"*

UDL requires access for most

"it seems to be a strategy of using technology in the classroom to allow students of all learning preferences to participate in a way that will best assess them." * 
"I learned how technology can be useful with UDL and how there are different apps to help people with learning."

"Learning more about technology."

Who

All Students "UDL, from my understanding, is all about modifying and creating environments which will work best for all students or giving options because all students learn differently and thus, one assessment does not prove all students do or do not understand the material"**

"UDL is a way for all students to be given a pathway to learn."*

"All students have different learning styles"

Note. $*$ Responses identified as high quality (containing term and scored 2 on rubric) are indicated.

Second, in an attempt to capture the nuances of the quality of responses that existed between the groups, the data was analyzed for the terms based on the data from the rubric and the transformed counted data. All of responses that contained terms were separated from the larger data sets for each group (practice-based and lecture-based). Of these data, all of the responses that were scored a 2 on using the rubric in the previous analysis were identified. These responses were identified as high quality, as they contained both appropriate UDL concepts as well as appropriate UDL vocabulary. Each group (practice-based and lecture-based) were analyzed individually. To illustrate this in Table 2 responses that were 
given both coded as having a term (1) and identified as high quality ( 2 on the rubric) are noted with an asterisk.

The researcher and a graduate student both coded $35 \%$ of the responses to ensure reliability of both the coding and the quantity counts. Reliability scores were computed for the coding of inclusion of terms. Reliability was calculated for each response by taking the number of agreements divided by the number of agreements and disagreements multiplied by 100 . Across all responses the interrater agreement for each reference to UDL term in the responses was 97\%. Disagreements for this part of the coding primarily revolved around oversights and were resolved by re-counting together for a revised total count. This data was compiled into matrixes to examine patterns that existed (Creswell \& Plano Clark, 2007). 


\section{CHAPTER FOUR}

\section{Results}

\section{Descriptive Statistics}

Three measures were used to determine the results of two different instructional approaches about UDL on pre-service teachers. The descriptive statistics of these measures are reported in the following section. The results as they apply to the research questions are described in the remainder of this chapter.

TPACK infused UDL Survey (TPACK-UDL). This test is reported using a single overall score TPACK infused UDL (TPACKUDL) as well as 2 subscores-TPACK (no UDL) and a UDL knowledge subscore. Pre-test and post-test scores for these measures were examined for meeting normality assumptions. Descriptive statistics for these scores are also reported in Table 3. With values of 0.17 (pre-test) and -0.19 (posttest) TPACK-UDL data were considered to be symmetrical (Field, 2012). Normal distribution is indicated by a kurtosis value close to 3 (Field, 2012). Kurtosis for this measure were also at an appropriate level (pre-test $=3.47$, post-test $=3.82$ ) to be considered normally distributed (Field, 2012). The null hypothesis for the Shapiro-Wilk test was accepted for both TPACK-UDL pre-test and post-test, which indicated that the data were normally distributed. (Field, 2012). 
The TPACK (no UDL) scores were symmetrical (skewness for pre-test $=-0.09$ and post-test $=-0.05)$ and normally distributed (kurtosis pre-test $=3.41$ and post-test 3.48 ). The null hypothesis of normally distributed was accepted for both pre-test and post-test scores (Table 3).

The UDL knowledge subscores were symmetrical with skewness values of 0.35 for pre-test and -0.63 for post-test. Kurtosis values were also within the normal range with values of 3.01 for pre-test and 3.89 for post-test. The null hypothesis of normality from the Shapiro-Wilks test was accepted for UDL knowledge pre-test. However, the null hypothesis was rejected for the post-test $(p=0.010)$.

\section{Twenty-First Century Teacher's Sense of Efficacy Scale (T-} TSE). This test is reported using an overall score of pre-service teacher self-efficacy. The overall T-TSE (pre-test and post-test) were examined for assumptions of normality via skew and kurtosis. As can be seen in Table 3, with the acceptable skewness ranging from -0.5 to 0.5 , all data (pre-test $=0.23$, post-test $=-0.4$ ) were considered to be symmetrical (Field, 2012). The skewness values of 2.88 (pre-test) and 2.96 (post-test) are also considered to be acceptable for the test as a whole. The null hypotheses for the Shapiro-Wilk test was accepted, which indicated a normal distribution for the T-TSE. A summary of descriptive statistics 
(mean, standard deviation, median, minimum, maximum) are reported in Table 3.

Scenario Based Assessment (SBA). The transformed qualitative data were analyzed to test normality assumptions. The assumption of normal distribution skewness was met in the pre-test (-.09). The post-test shows a slight skewness to the left (-1.4), while not considered symmetrical it is in the acceptable range of -2 to 2 to meet the assumption. Assumptions of kurtosis were met for the pre-test (kurtosis $=2.20)$; however, a kurtosis of 4.8 in post-test indicated that there was the possibility of unwanted outliers (Field, 2012). The data were examined for possible outliers and while there are extreme cases, it was found not to be due to measurement error. It was determined to keep the data as is (see Table 3). The null hypothesis of normality for the Shapiro-Wilk test was accepted for the pre-test. In post-test, the null hypothesis was rejected ( $p$ $<0.001)$ indicating that the data were not normally distributed. 
Table 3

Descriptive statistics and tests of normality

\begin{tabular}{|c|c|c|c|c|c|c|c|c|}
\hline Measure & Mean & $S D$ & Median & Minimum & Maximum & Skewness & Kurtosis & $\begin{array}{l}\text { Shaprio- } \\
\text { Wilkp- } \\
\text { value }\end{array}$ \\
\hline $\begin{array}{l}\text { TPACK- } \\
\text { UDL Pre- } \\
\text { test }\end{array}$ & 146.04 & 22.40 & 146.0 & 94 & 204 & 0.17 & 3.47 & 0.17 \\
\hline $\begin{array}{l}\text { TPACK- } \\
\text { UDL Post- } \\
\text { test }\end{array}$ & 164.15 & 19.48 & 164.0 & 99 & 210 & -0.19 & 3.82 & 0.33 \\
\hline $\begin{array}{l}\text { TPACK Pre- } \\
\text { test }\end{array}$ & 118.33 & 16.07 & 119.5 & 74 & 157 & -0.09 & 3.41 & 0.41 \\
\hline $\begin{array}{l}\text { TPACK } \\
\text { Post-test } \\
\text { UDL }\end{array}$ & 126.43 & 14.18 & 126.0 & 83 & 160 & -0.05 & 3.48 & 0.54 \\
\hline $\begin{array}{l}\text { Knowledge } \\
\text { Pre-test } \\
\text { UDL }\end{array}$ & 27.78 & 7.65 & 27.0 & 11 & 47 & 0.35 & 3.01 & 0.15 \\
\hline $\begin{array}{l}\text { Knowledge } \\
\text { Post-test }\end{array}$ & 37.62 & 6.31 & 39.0 & 16 & 50 & -0.63 & 3.89 & $0.01 *$ \\
\hline $\begin{array}{l}\text { T-TSE Pre- } \\
\text { test }\end{array}$ & 100.90 & 21.54 & 103.0 & 54 & 161 & 0.23 & 2.88 & 0.76 \\
\hline $\begin{array}{l}\text { T-TSE Post- } \\
\text { test }\end{array}$ & 117.26 & 21.40 & 119.0 & 63 & 159 & -0.40 & 2.96 & 0.13 \\
\hline
\end{tabular}




\begin{tabular}{|c|c|c|c|c|c|c|c|c|}
\hline $\begin{array}{l}\text { UDL-SBA } \\
\text { Pre-test }\end{array}$ & 7.44 & 3.64 & 7.0 & 0 & 15 & -0.09 & 2.20 & 0.09 \\
\hline $\begin{array}{l}\text { UDL-SBA } \\
\text { Post-test }\end{array}$ & 11.72 & 3.04 & 12.0 & 0 & 16 & -1.04 & 4.80 & $<0.001 *$ \\
\hline
\end{tabular}

Note: Shapiro-Wilk Test of Normality is rejected for UDL Knowledge Post-test and UDL-SBA Post-test.

$* p<.05$ 
Research Question 1: How does a Practice-Based approach compare with a LectureBased approach in improving pre-service general education teachers (a) fundamental knowledge for teaching (b) knowledge about and UDL (c) reported self-efficacy and (d) application of UDL?

Fundamental Knowledge (Teaching and UDL combined) Analyses were conducted to examine differences in TPACK-UDL scores between students receiving a practice-based station intervention about UDL in relation to participants receiving UDL instruction through a lecture. Box plots and violin plots were used to initially examine the difference between groups (see Figures 10 and 11). The box plots indicate both groups had growth following a UDL intervention. Initial examination of the mean scores and box plots indicate the stations group had lower scores at pre-test than the lecture group. Descriptive statistics show that participants in the station group scored lower at pre-test $(M=142.34, S D=23.5)$ than the lecture group $(M=149.4, S D=21.05)$, however these differences were not statistically significant. These data also indicate that all participants in both groups scored similarly at post-test (stations $[M=163.73, S D=22.23]$ lecture $[M=165.26, S D=18.72])$. 


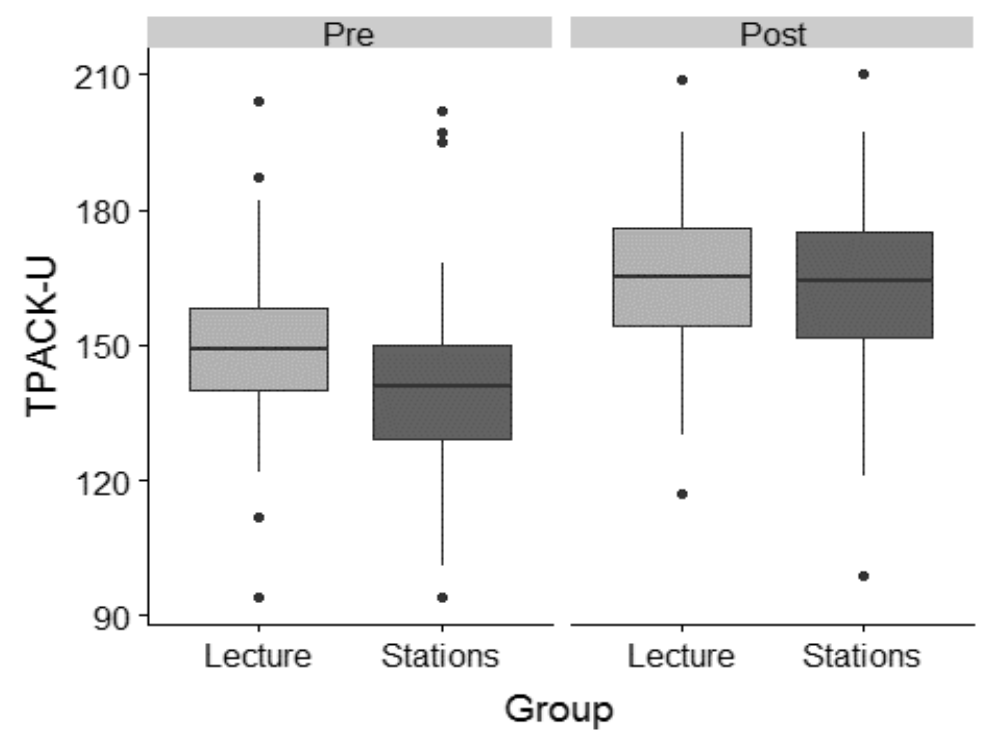

Figure 10. Box plot of pre-test and post-test score of TPACK infused UDL for each condition.

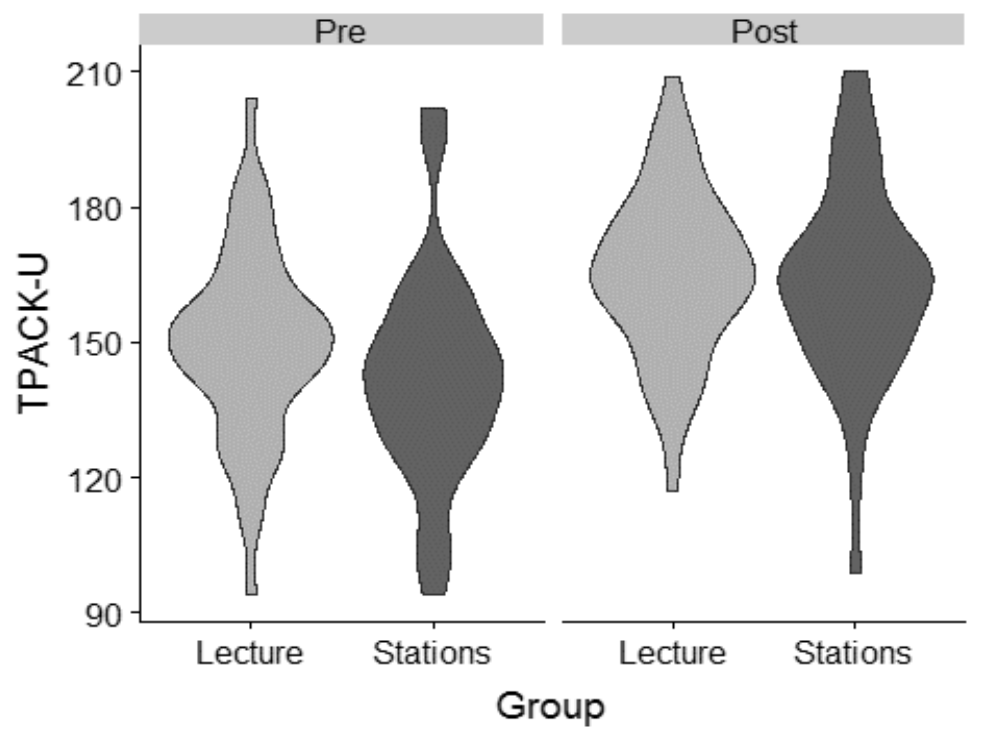

Figure 11 Violin plot of pre-test and post-test scores of TPACK infused UDL for each condition.

An ANOVA of gain scores was conducted to examine the difference in for TPACK-UDL gain scores between instructional approaches. Levene's test for equality of 
variances indicated equal variances $(F(1,76)=0.42, p=0.52)$, thus the assumption of homoscedasticity was meet. The independent variable of group included two levels: practice-based instruction and lecture-based instruction. The dependent variable gain in TPACK-UDL score from pre-test to post-test. The ANOVA was not significant $(F(1,76)$ $=2.21, p=.14$ ). But, practice-based participants had 6.08 points more gain compared to participants who received lecture-based instruction. This is reflected by an effect size between groups for the TPACK infused UDL measure that was moderate $(d=.34)$. The analysis of TPACK-UDL gain scores showed significant growth from pre-test to post-test $(\beta=14.53, t(76)=5.09, p<.001)$. Growth effects of the lecture participants $(d=.80)$ were large. The practice-based stations condition had a slightly larger effect $(d=.93)$ for growth.

Descriptive statistics show that pre-service teachers in the practice-based group had higher gain scores for TPACK-UDL $(M=18.5, S D=15.7)$ than the participants in the lecture-based group $(M=13.7, S D=21.3)$.

An ANCOVA was used to test for differences in post-test scores between instructional approaches, while accounting for pre-test differences. The independent variable was instruction approach with two levels: practice-based and lecture-based. The TPACK-UDL pre-test score was used as a covariate. The TPACK-UDL post-test score was the dependent variable. The ANCOVA was not significant, $F(1,75)=0.29, p=0.59$. While there was no statistically significant difference between the practice-based stations group and the lecture group, the statistical model estimated that the practice-based group scored 1.94 points higher on the post-test. The effect of instructional approach on TPACK-UDL post-test score was small, partial $\eta^{2}=0.004$. The pre-test score accounted 
for variation in the post-test scores, with a 1-point increase in the pre-test score indicating a 0.57 point increase in the post-test score.

Comparing the estimated marginal means for TPACK infused with UDL showed that the higher post-test scores were estimated in the practice-based group $(M=165)$ compared to the lecture-based group $(M=163)$.

Results of the analyses of growth on the TPACK infused UDL survey for the two groups can be summarized as follows: (a) both groups made significant gains from pretest to post-test; (b) while not statistically significant, the practice-based (treatment group) did score approximately 1.94 points higher than students in the lecture (control group); and (c) overall there was a large effect of growth for the practice-based treatment.

\section{Fundamental Knowledge Teaching: TPACK (without UDL component)}

An ANOVA of TPACK gain scores was used to assess the impact of instructional approach on foundational knowledge. The independent variable is instructional approach group with two levels: practice-based and lecture-based. TPACK gain score (UDL questions removed) from pre-test to post-test was the dependent variable. The ANOVA was not significant, $F(1,76)=0.87, p=0.35$. The analysis of TPACK gain scores showed significant growth from pretest to posttest $(\beta=6.32, t(76)=3.1, p=0.003)$. The effect of instructional approach on TPACK gain was small, as assessed by Cohen's $d=$ 0.21 .

Descriptive statistics show that pre-service teachers in the practice-based group had higher gain scores for the original TPACK $(M=9.05, S D=12.7)$ than the participants in the lecture-based group $(M=6.32, S D=13.1)$. 
To test for differences in TPACK post-test scores between instructional groups, an ANCOVA was used. Groups with two levels of practice-based and lecture-based were used as the independent variable. The dependent variable was TPACK post-test score, with TPACK pre-test score used as a covariate. The ANCOVA was not significant, $F(1$, 75) $=0.0005, \mathrm{p}=0.98$. The there was no effect of group on TPACK post-test score partial $\eta^{2}=0.000006$

Comparing the estimated marginal means for original TPACK showed that, unlike other measures, slightly higher post-test scores were estimated in the lecture-based group $(M=127)$ compared to the practice-based group $(M=126)$.

Analyses of growth on the TPACK infused UDL survey with out the UDL questions for the two groups can be summarized as follows: (a) both groups made significant gains from pre-test to post-test; (b) lecture-based groups did score slightly higher than the practice-based groups, however this was not significantly different.

\section{UDL Knowledge (UDL from TPACK)}

As the UDL subscore post-test from the TPACK was not normally distributed, a Kruskill-Wallis test was performed. Groups were the independent variable. The gain from pre-test to post-test of UDL knowledge was the dependent variable. The effect of condition on gain scores was suggestive, Kruskal-Wallis $\chi^{2}=3.60, \mathrm{df}=1, p=0.058$. The nonparametric Wilcoxon matched pairs test of UDL subscore from the TPACK show significant gains from pre-test to post-test, $V=47, p=<.001$.

Descriptive statistics show that pre-service teachers in the practice-based group had higher gain scores for self-reported UDL knowledge $(M=11.6, S D=7.4)$ than the participants in the lecture-based group $(M=8.4, S D=6.8)$. 
An ANCOVA was also performed to further look at difference in post-test score between groups accounting for the pre-test differences. Instructional group was the independent variable. The dependent variable was UDL knowledge post-test score with the UDL knowledge pre-test score as a covariate. The ANCOVA was not significant, $F(1,79)=1.18, p=0.28$. A non-parametric version was not needed for this model, as the residuals were normally distributed (Lomax \& Hahs-Vaughn, 2013) Shapiro-Wilk Normality test $W=0.98, p=0.36$. The practice-based participants performed numerically better than the lecture-based participants scoring approximately 1.37 points higher on this subscore. This effect is considered small, partial $\eta^{2}=0.015$.

Comparing the estimated marginal means for UDL TPACK subscore showed that higher post-test scores were estimated in the practice-based group (mean=12.0) compared to the lecture-based group (mean=11.5).

In summary, both groups had statistically significant differences from pre-test to post-test. Comparing practice-based to the lecture condition, there were no statistically significant differences, however, the practice-based group did perform better than the lecture-based group.

\section{Self-Efficacy: (T-TSE)}

To assess the impact of the delivery (practice-based compared to lecture-based) on reported self-efficacy, the differences between groups were inspected visually as well as statistically analyzed. Box plots and violin plots were created to visually inspect the data for changes, as well as assess the distribution in each group. Figure 12 is a box plot and Figure 13 is violin plot of total T-TSE test score. These illustrate that both groups 
had gains in self-efficacy. These plots also illustrate the variance that exists in both pretest and post-test.

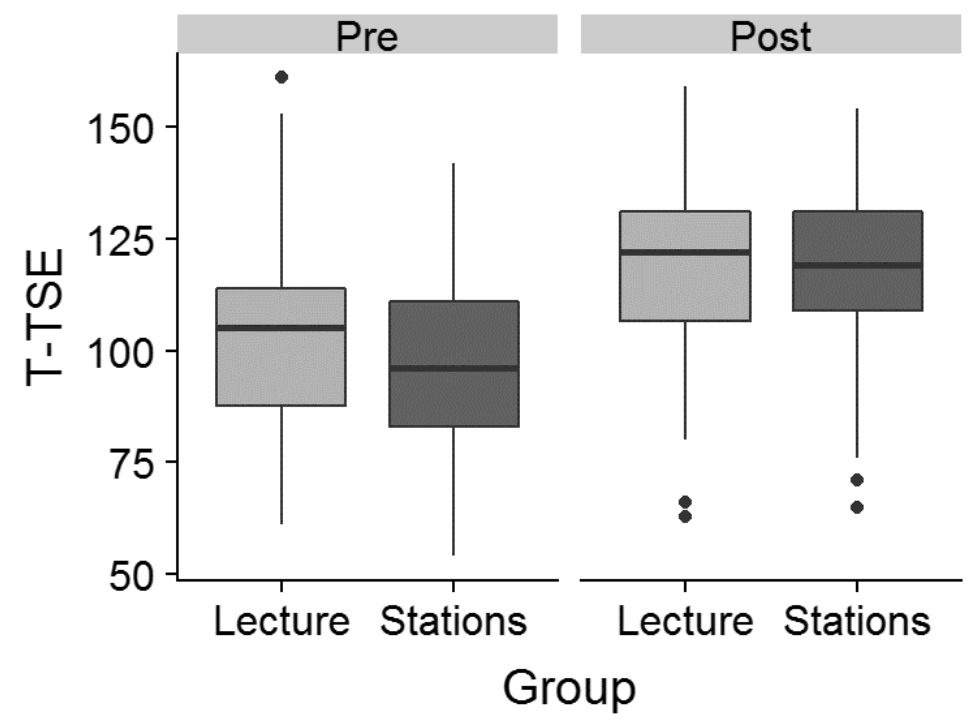

Figure 12 Box plot of T-TSE

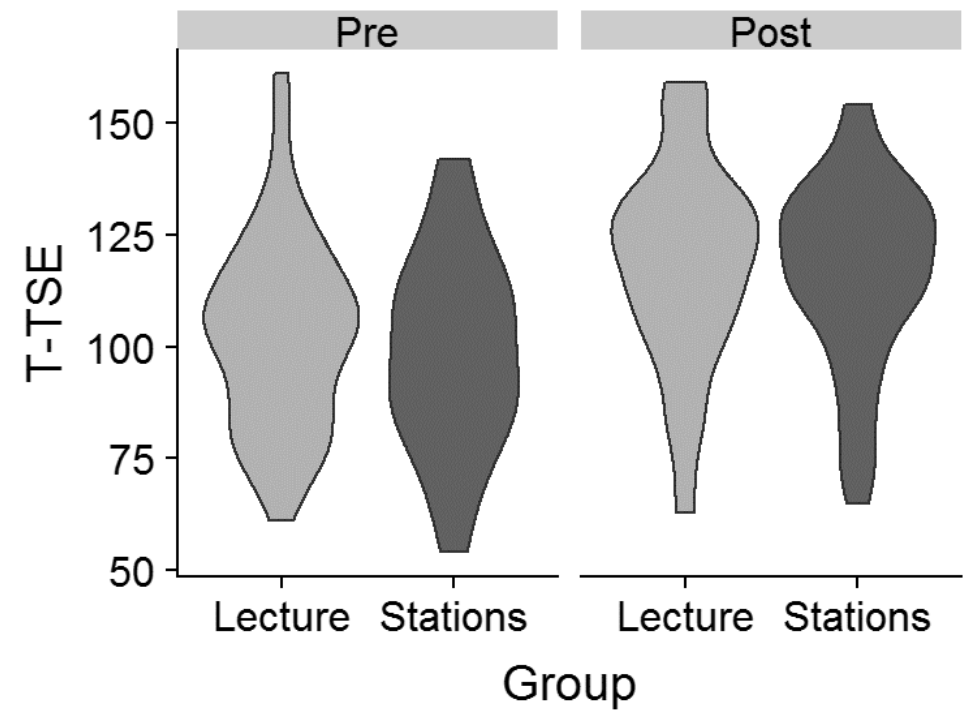

Figure 13 Violin plot of T-TSE

To determine if there were significant differences in growth between lecturebased and practice-based, an ANOVA of gain scores was conducted. The independent variable was instructional approach with two levels: practice-based and lecture-based. 
The dependent variable was gain score calculated from the T-TSE pre-test and post-test scores. Assumptions regarding equal variances between groups was met, as Levene's test for equality of variances indicated equal variances $(F(1,80)=1.65, p=.0 .203)$. The ANOVA was not significant, $F(1,80)=1.31, p=0.26)$. The difference between the practice-based approach and lecture-based approach had an effect size of $d=.25$, which is considered moderate.

However, across groups the analysis of T-TSE gain scores showed significant growth from pre-test to post-test $(\beta=13.72, t(80)=4.78, p<.001)$. The growth from pretest to post-test in the lecture condition had an effect size of $d=.70$, while the growth in stations condition had an effect size of $d=.84$. Growth in the lecture condition had a moderate effect while growth in the practice-based station condition had a large effect on participant's reported self-efficacy.

Descriptive statistics show that pre-service teachers in the practice-based group had higher gain scores for self-efficacy $(M=20.6, S D=17.8)$ than the participants in the lecture-based group $(M=14.5, S D=18.3)$.

ANCOVA was conducted to compare the effectiveness of the intervention in increasing post-test scores, whilst controlling for pre-test scores. Instructional approach was the independent variable. Post-test T-TSE score was the dependent variable, with the T-TSE pre-test score as a covariate. Pre-test score significantly influenced post-test score $(\beta=0.62, t(79)=6.86, p<.001)$. In other words, a 1-point increase in pre-test score indicated a 0.62 point increase in post-test score. The ANCOVA was not significant, $F(1$, 79) $=0.24, p=0.62$. Although not statistically significant, after controlling for pre-test 
difference, students in the station group had a numerical difference scoring 1.89 points higher on the post-test. This effect is considered small, partial $\eta^{2}=0.003$.

Comparing the estimated marginal means for T-TSE showed that the higher posttest scores were estimated in the practice-based group (mean=118) compared to the lecture-based group (mean=116).

In summary, both groups had statistically significant differences from pre-test to post-test. Both groups had moderate to large effect sizes in growth from pre-test to posttest. Comparing practice-based to the lecture condition, there were no statistically significant differences, however, examination of the means the practice-based group reported higher self-efficacy than the lecture-based group.

\section{Application of UDL: SBA.}

Analyses were run to examine the difference between groups in participant's ability to apply UDL concepts to a scenario. The SBA data was central to examining this construct. Box plots and violin plots were used to visually examine the group difference in the SBA assessment (see

Figure 14 and Figure 15). Like previous analyses, the box plot and violin plot illustrate the variance and growth the occurred from pre-test to post-test while also illustrating the differences in the condition groups at pre-test. The practice-based group $(M=6.7$, $S D=3.87)$ scored lower on the pre-test than the lecture-based condition $(M=8.09$, $S D=3.34)$. While at post-test they scored similarly, practice-based $(M=11.81, S D=2.86)$ and lecture-based $(M=11.47, S D=3.22)$. 


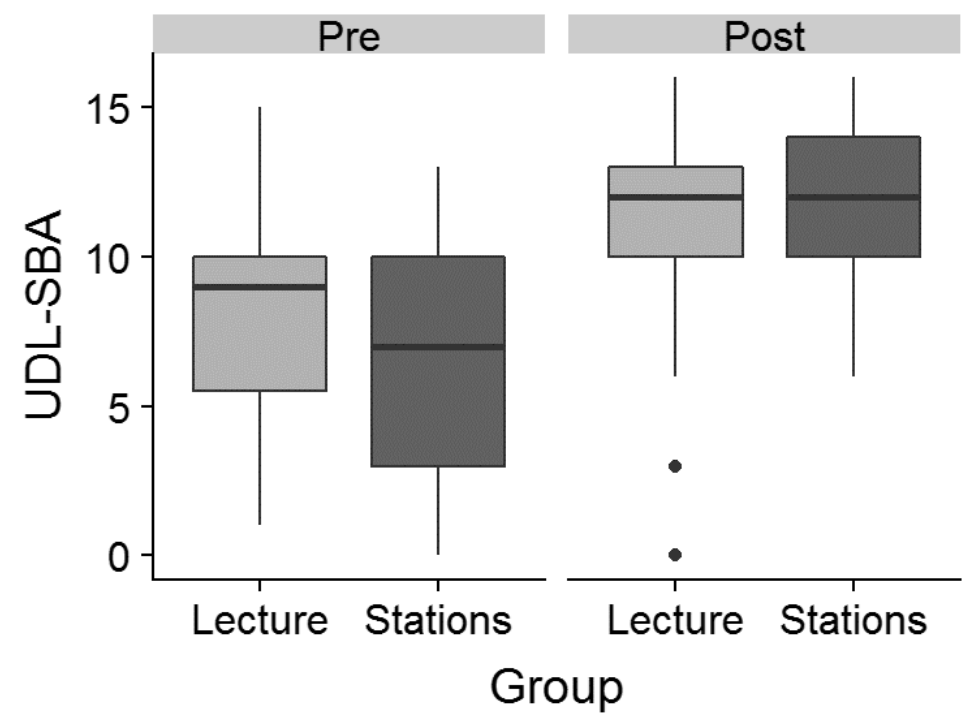

Figure 14. Boxplot of SBA scores.

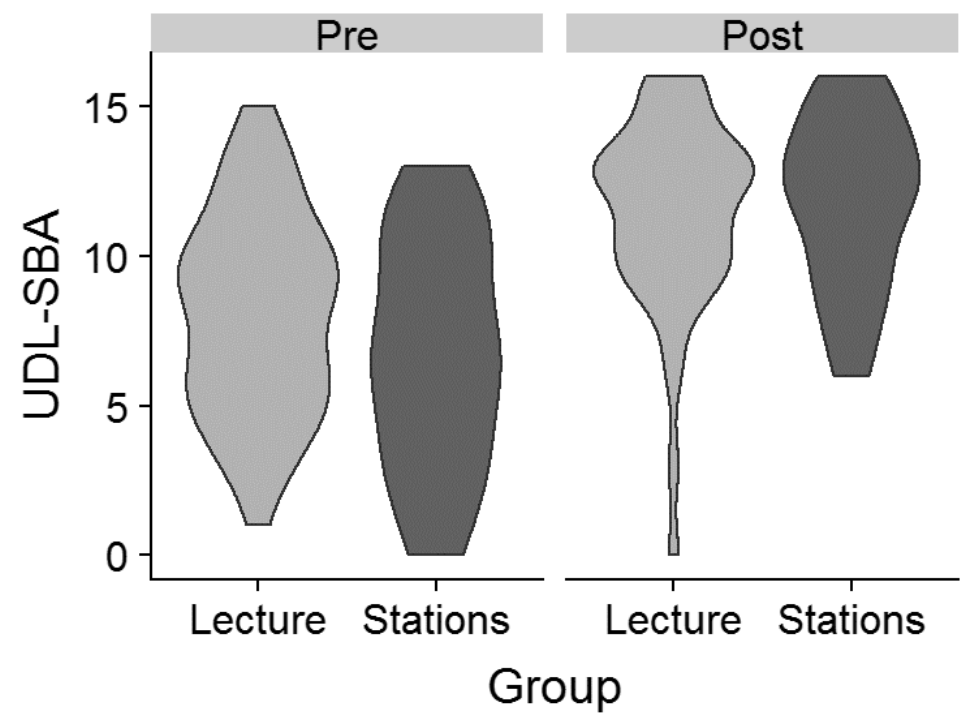

Figure 15. Violin plot of SBA scores.

Prior to conducting formal testing, a Levene's test was conducted to test for homoscedasticity. The Levene's test for equality of variances indicated equal variances $(F(1,80)=0.11, p=0.745)$. Due to the extreme kurtosis and violated normality assumptions of the UDL-SBA scores, a nonparametric Kruskal-Wallis test was used to assess the impact of group on UDL-SBA gain scores. The independent variable was 
instructional approach with two levels: practice-based and lecture-based. The dependent variable was gain score from UDL-SBA pre-test to post-test. This test indicated that condition did not significantly impact UDL-SBA gain, Kruskal-Wallis $\chi^{2}=2.04, \underline{d f}=1, p$ $=0.15$. The method of instruction had a moderate effect $(d=0.39)$.

Because normality assumptions were not meet for UDL-SBA scores, a nonparametric Wilcoxon matched pairs test was used to look for significant gains from pre-test to post-test. Results showed that there was a significant gain from pre-test to post-test for both groups, $V=96, p<.001$. Effect sizes show that the lecture group had a large Cohen's $d$ effect $(d=1.03)$ for growth. The practice-based group reflected an even larger effect $(d=1.5)$ for difference between pre-test and post-test scores.

Descriptive statistics denote that larger gains in UDL-SBA scores were seen in the practice-based group $(M=5.03, S D=3.40)$ compared to the lecture-based group $(M=$ 3.67, $S D=3.48)$.

An ANCOVA test was performed to look for an effect of instructional approach on UDL-SBA post-test score. Instructional group (practice-based and lecture-based) were independent variables. The UDL-SBA post-test score was the dependent variable with UDL-SBA pre-test score used as a covariate. A single outlier was removed as it led to non-normally distributed errors. The ANCOVA was not significant, $F(1,78)=0.22, p=$ 0.64. However, once again the numerical advantage was to the stations group, as the statistical model estimated that they scored 0.25 points higher on the post-test. The effect of instructional approach was small, partial $\eta^{2}=0.003$.

In summary, both groups had statistically significant differences from pre-test to post-test in their ability to apply UDL knowledge to a scenario. Both groups had large 
effect sizes in growth from pre-test to post-test. Comparing practice-based to the lecture condition, there were no statistically significant differences, however, examination of the means the practice-based group scored higher on the SBA than the lecture-based group.

\section{Research Question 2: What relationship exist between knowledge and application of UDL overall and by instructional group?}

To answer this question, the relationships were examined both quantitatively and qualitatively. Quantitative data was used to examine the relationship by comparing the UDL knowledge scores with the SBA application scores to look for correlation and predictability between measures. Qualitative data was used to examine the relationship by exploring the terminology used in two ways, the quantity of usage of key terms and the quality of usage of the terms for each group.

\section{Quantitative Results}

Pearson correlation of the UDL-SBA and UDL subscores from the TPACK survey gain scores were calculated. For all participants, the correlation between UDL subscore from the TPACK infused UDL and the UDL-SBA measure was very small and not statistically different from zero, $r(80)=0.006, p=0.95$. When examining instructional conditions separately, a negative correlation trended between the UDL subscore of the TPACK-UDL and the SBA for the lecture-based participants $(r(41)=-$ $.26, p=.09$ ), while a positive correlation for the practice-based participants was estimated $(r(37)=0.20, p=.23)$. In other words, while the corrections between UDLSBA and UDL subscores for each group were not significant the differences in the correlations was unexpected. 
Because the negative correlation in lecture-based and positive correlation in practice-based groups was an unexpected finding, further linear regression models were constructed to formally investigate an interaction between group and UDL knowledge on UDL-SBA. In this regression model, UDL-SBA post-test score was the dependent variable. The UDL-SBA pre-test score was fit as a covariate for internal validity and to account for variation in post-test scores. Group with two levels (practice-based and lecture-based), UDL knowledge post-test score, and an interaction between group and UDL knowledge post-test score were fit as explanatory, independent variables in the regression. The linear model was significant, $F(4,77)=7.745, p<0.001$. All explanatory variables had significant effects: group $(\beta=-8.096, t(77)=-2.283, p=0.025)$, UDL knowledge $(\beta=-0.145, t(77)=-2.187, p=0.032)$, and group $\times$ UDL knowledge interaction $(\beta=0.231, t(77)=2.475, p=0.016)$. Group had a small effect size, partial $\eta^{2}=$ 0.004. UDL Knowledge post-test score had a small effect size, partial $\eta^{2}=0.011$. Group $\times$ UDL knowledge interaction had a moderate effect, partial $\eta^{2}=0.074$. Figure 16 illustrates this interaction.

Scores from a single participant were identified as outliers looking for mean-shifts using studentized residuals (studentized residual $=-4.23$, Bonferroni-corrected $p=0.005$ ). Regression analysis was repeated removing this outlier. Again, the linear model was significant, $F(4,76)=7.826, p<0.001$. UDL knowledge post-test score did not have a significant effect on UDL-SBA post-test score $(\beta=-0.093, t(77)=-1.515, p=0.13)$. However, the main effect of group $(\beta=-6.477, t(77)=-2.003, p=0.049)$ and the interaction between UDL knowledge and group $(\beta=0.180, t(77)=2.111, p=0.038)$ had significant effects. UDL Knowledge had no main effect, partial $\eta^{2}=0$. Group had a small 
effect, partial $\eta^{2}=0.003$. The interaction between group and UDL knowledge has a moderate effect, partial $\eta^{2}=0.055$.

Results from both Figure 16, Figure 17, and the regression analysis show that for participants in the lecture-based group there is no relationship between UDL subscore from the TPACK and UDL-SBA. However, for participants in the practice-based approach, their self-reported UDL subscore was significantly associated with their UDLSBA score. In summary, results from the regression analysis indicate that while the participants in the lecture group reported higher UDL knowledge, their actual ability to apply the content to the SBA was unaffected. In contrast, self-reported UDL knowledge (TPACK) of participants in the practice-based group more accurately predict and are associate with their scenario-based assessment scores. This is also complimented by results in which participants in the practice-based stations condition showed larger selfreported UDL subscore and UDL-SBA gains. 


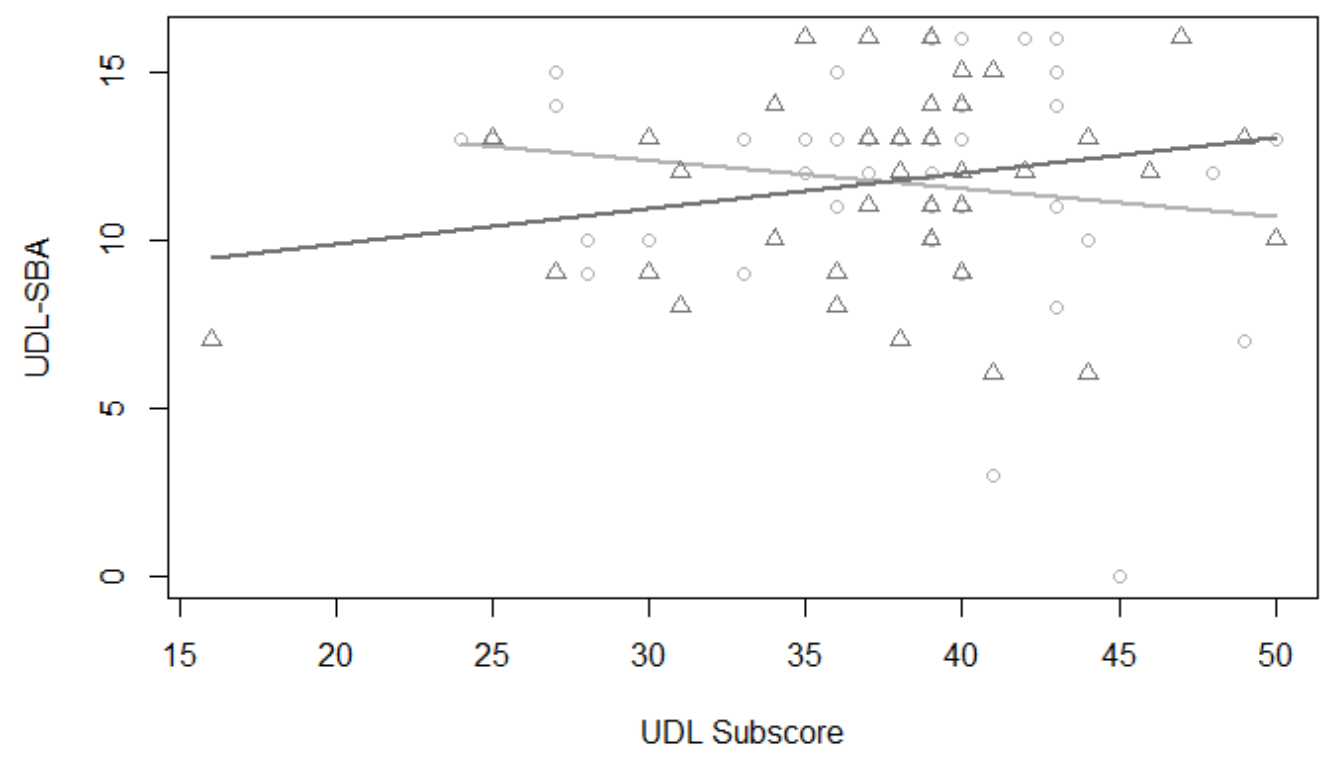

Figure 16. Scatterplot of SBA data compared to TPACK UDL subscore data. Subjects assigned to Lecture are plotted in light grey circles. Subjects assigned to practice-based are plotted in dark grey triangles. 


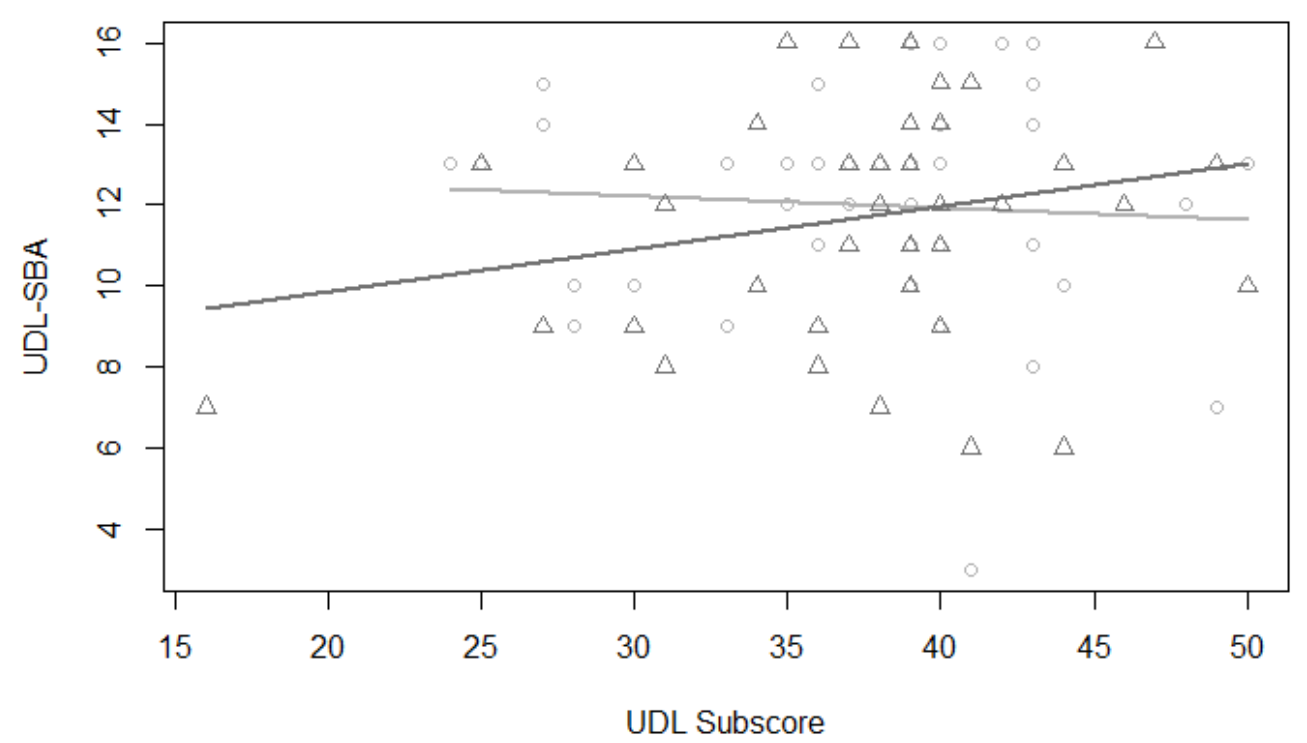

Figure 17. Scatterplot of UDL-SBA data compared to TPACK UDL subscore data with an outlier participant removed. Subjects assigned to Lecture are plotted in light grey circles. Subjects assigned to Stations are plotted in dark grey triangles.

\section{Qualitative Data Results}

To further investigate the difference between groups the responses to the SBA were examined qualitatively using a content analysis approach. Data from the content analysis was examined in two ways: quantity (number of times words occurred) and quality (depth of justification resulting in a score of 2 on the rubric and containing identified terminology).

Quantity of terms. Frequencies of terms were counted (see matrix Table 4). The most frequently terms overall (both instructional conditions) in the pre-test were technology (57) and access (28). When looking at overall themes, students initially, in pre-test, used terms related to implementation more frequently, and used vocabulary terms related to the framework less frequently. Overall from pre-test to post-test both 
groups grew considerably in knowledge of the UDL framework as demonstrated by the increase in the quantity of terms related to the framework theme (engagement, representation, and expression). These terms showed the most growth overall.

When looking at the patterns that existed between each group there are differences that can be noted for each group. In the pre-test both groups scored similarly in the number of times they used vocabulary terms across all 7 terms. The lecture-based group used the vocabulary in the post-test more frequently, especially in regards to terms related to the UDL framework. For example the lecture-based group used went from not using the term representation in pre-test to 28 counts of the term in post-test. This pattern is similar in engagement and action and expression. Participants in the practice-based group did not share that same growth their usage of framework terms. In contrast, the practice-based group had more growth in regards to implementation. These individuals used terms such as choice and accessibility more frequently than the individuals in the lecture-based group at post-test.

In summary both groups had gains in their usage of terminology related to UDL from pre-test to post-test however the gains were related to different themes. Participants in the practice-based group had larger gains in regards to terms related to implementation. Participants in the lecture-based group had gain in the terms related to framework terminology. 
Table 4

Counts of UDL terminology in SBA responses for Quantity

\begin{tabular}{|c|c|c|c|c|c|c|c|}
\hline \multirow[t]{3}{*}{ Theme } & \multirow[t]{3}{*}{ Responses } & \multicolumn{4}{|c|}{ Groups } & & \\
\hline & & \multicolumn{2}{|c|}{ Practice-based } & \multicolumn{2}{|c|}{ Lecture-based } & \multicolumn{2}{|c|}{ Overall } \\
\hline & & Pre & Post & Pre & Post & Pre & Post \\
\hline \multirow[t]{3}{*}{ Framework } & $\begin{array}{l}\text { Engagement } \\
\text { (engage) }\end{array}$ & 6 & 8 & 13 & 30 & 19 & 38 \\
\hline & $\begin{array}{l}\text { Representation } \\
\text { (represent) }\end{array}$ & 0 & 8 & 0 & 28 & 0 & 36 \\
\hline & $\begin{array}{l}\text { Action and } \\
\text { Expression } \\
\text { (act and/or } \\
\text { express) }\end{array}$ & 0 & 8 & 0 & 12 & 0 & 20 \\
\hline \multirow[t]{3}{*}{ Implementation } & Choice(s) & 6 & 22 & 10 & 16 & 16 & 38 \\
\hline & $\begin{array}{l}\text { Access } \\
\text { accessibility }\end{array}$ & 16 & 28 & 12 & 1 & 28 & 29 \\
\hline & Technology & 25 & 28 & 32 & 28 & 57 & 56 \\
\hline Who & All students & 14 & 19 & 10 & 10 & 24 & 29 \\
\hline
\end{tabular}

Quality of Response. In addition to examining changes in quantity (number of times a word was used), the quality of the results were examined to see what changes occurred by examining the responses that were coded as a 2 using the rubric. A " 2 " response was conceptualized as a quality response as it contained both vocabulary and conceptual knowledge (see Table 5). Similar to the quantity of responses, both groups showed growth in the quality of responses. The theme that showed the most growth was terms related to implementation. The specific term that had the most growth was technology (19 more instances in which the term was identified in a quality response 
from pre-test to post-test). However, this growth was more evenly spread across themes as all terms.

Differences between groups were also noted in this analysis. Participants in the practice-based group had more counts of quality responses on all identified terms. For example, students in the practice-based group mentioned representation in a quality response 8 times in post-test while the lecture-based group did not mention representation in a quality way in post-test.

Table 5.

Counts of Quality responses (rubric score of 2 and vocabulary) on SBA

\begin{tabular}{|c|c|c|c|c|c|c|c|}
\hline \multirow[t]{3}{*}{ Theme } & \multirow[t]{3}{*}{ Responses } & \multicolumn{4}{|c|}{ Groups } & & \\
\hline & & \multicolumn{2}{|c|}{ Practice-based } & \multicolumn{2}{|c|}{ Lecture-based } & \multicolumn{2}{|c|}{ Overall } \\
\hline & & Pre & Post & Pre & Post & Pre & Post \\
\hline \multirow[t]{3}{*}{ Framework } & $\begin{array}{l}\text { Engagement } \\
\text { (engage) }\end{array}$ & 0 & 8 & 2 & 5 & 2 & 10 \\
\hline & $\begin{array}{l}\text { Representation } \\
\text { (represent) }\end{array}$ & 0 & 8 & 0 & 3 & 0 & 11 \\
\hline & $\begin{array}{l}\text { Action and } \\
\text { Expression } \\
\text { (act and/or } \\
\text { express) }\end{array}$ & 0 & 8 & 0 & 0 & 0 & 8 \\
\hline \multirow[t]{3}{*}{ Implementation } & Choice(s) & 2 & 14 & 4 & 13 & 6 & 27 \\
\hline & $\begin{array}{l}\text { Access } \\
\text { accessibility }\end{array}$ & 2 & 17 & 2 & 1 & 4 & 18 \\
\hline & Technology & 3 & 14 & 4 & 12 & 7 & 26 \\
\hline Who & All students & 2 & 11 & 4 & 6 & 6 & 16 \\
\hline
\end{tabular}

In summary, the qualitative differences noted can be summarized as follows: (a) both groups had gain in both the quantity and the quality of the terminology they used in 
the SBA, (b) participants in the lecture-based group used the terminology related to the framework more frequently at post-test whereas participants in the practice-based group used terminology related to implementation more frequently at post-test, and (c) when examining quality of response, practice-based group had more growth and more quality responses connected to all of the terms examined. 


\section{CHAPTER 5}

\section{Discussion}

The purpose of this study was to compare the impact of two different instructional conditions - problems-based and lecture-based — about Universal Design for Learning (UDL) on pre-service general education teacher's ability to apply inclusive classroom practices. Specifically, the study examined shifts in pre-service teacher (a) foundational knowledge bases for teaching (technological, pedagogical, and content), (b) knowledge related to UDL, (c) changes in self-efficacy related to teaching diverse students with learning differences, and (d) their ability to apply UDL content into classroom scenario.

\section{Summary of Findings}

Based on the results of this study, two main findings have emerged. First, the results of this study suggest that a practice-based instructional conditions has advantages in preparing pre-service general education teachers for inclusion. It is important to acknowledge that for both conditions, improvements were noted in all four constructs that were examined. Furthermore, there were no statistical differences between the instructional conditions on the four constructs. However, there was evidence that favored the practice-based instructional conditions. Examination of the means and in some cases the effect sizes (e.g., TPACK score, UDL knowledge score, self-efficacy score and UDL application score) favored the practice-based instructional conditions.

Closer examinations of the data revealed some patterns of improvement between the practice-base group and the lecture-based group suggesting that there are advantages to using a practice-based approach to teaching UDL. In the first qualitative analysis in which counts of terms were taken, the lecture-based learning group had higher total 
counts in post-test than the practice-based group. That is to say that when the participants in the lecture-based group were directly taught the UDL framework, they were more likely to use these terms when responding to a scenario. However, the patterns of UDL terminology used in terms of quality, the practice-based group had more responses that were identified higher quality responses. This suggest that the practice-based methodology used to teach UDL resulted in participants who are able to more meaningfully incorporate vocabulary as well as concepts into their application UDL. The finding of practice-based participants more meaningfully applying content from the intervention is further supported by pieces of the quantitative analysis. When looking at the relationship between UDL knowledge score (UDL subscore of the TPACK) and application of UDL (SBA), a negative correlation was found for the lecture-based group as opposed to the practice-based group. The regression analyses demonstrated UDL knowledge in the lecture-based group did not predict their scores on the SBA. However, in the practice-based group there was a strong relationship on ULD knowledge and application.

Benedict (2018) states that teaching is a complex job that requires both knowledge and application of practices. Others have suggested that the affordances this type of methodology is that it goes beyond the knowing and requires pre-service teachers to apply (Benedict et al. 2018; Brownell, 2005; Linguarist/Kraft et al. 2014). That is, they take knowledge and apply it to classroom situations. The type of knowledge and skills are not learned from a book, listening to a lecture or studying alone (Phelps, 2009; Ball \& Forzani, 2009). Development of these skills and knowledge take repeated opportunities to practice using the knowledge and skills in classroom contexts (Phelps, 2009). This study 
provides some support to the claim that practice-based approaches help pre-service teachers go beyond knowing information to being able to apply the knowledge.

A second main finding from this study is, regardless of instructional condition, it appears that UDL as a focus of content can serve as a mechanism or "lens" to move preservice teachers to using more inclusive classroom practices. This is evidenced by the fact that participants came into the study with understanding and ideas regarding their knowledge and self-efficacy to teach at pre-test.. On both measures, TPACK knowledge and self-efficacy the mean of participants scored themselves near the middle of the scale. Similarly on average the students were getting half of the points possible on the pre-test. This illustrates that the participants had ideas and were revising the lesson plan on the SBA, but the ideas were not aligned with UDL and/or the ideas were not inclusive revisions. After the intervention about UDL there was not only an increase in the TPACK-UDL score and the SBA score, positive shifts were also noted in the qualitative analyses suggesting that the students were identifying more inclusive instructional ideas and strategies. Further their efficacy to work with diverse populations rose; that is after the UDL intervention they felt more confident in working with diverse learners.

Pre-service teachers gain possible practices to use in their classrooms from their experience or coursework. These methods and practices may be effective or they may create barriers for students. Self-efficacy serves as a filter for these practices. If a preservice teachers thinks that they can successfully implement the practice, the practice is more likely to be applied to instructional situations Pajadres, 2004). When UDL is taught as a tool for pre-service teachers to use, these filtered practices, are further focused to inclusive practices to be implemented. If the UDL lens is removed, pre-service teachers 
would implement practices but without the focus to think inclusively that the UDL lens provides.

Interesting an additional finding was discovered. Students entered the study with average scores on TPACK infused UDL and self-efficacy scores. This suggests that in general, participants felt they knew how to work with diverse learners and felt somewhat confident about it. With instruction, participants improved in both measures. This could be interpreted as the participants had a more refined approach and way of thinking. It was unexpected to seen growth on self-efficacy measures. In the literature, typically when individuals learn concepts there is an initial dip in their efficacy. They tend to realize they overestimated abilities or knowledge and, initially, the self-efficacy score drops (Tschannen-Morin \& Hoy, 2007). This did not happen immediately after this intervention. This may be a reflection of where the students are in their program and may be more of a reflection of their immaturity for teaching or a lack of experience with teaching students with disabilities.

\section{Limitations}

Several limitations apply to this study. These limitations can be classified into two primary categories: (a) sample size and composition and (b) limitations of the measures. First, while the sample size use for this study $(N=88)$ was powered, it still was small for randomizing efforts. The groups for each condition had unequal variance that likely would have been mitigated by a larger pool of students. In addition, the sample was fairly homogenous, therefore, it does not represent the full diversity of all pre-service teachers nationally. While statistically the study is generalizable, a larger sample size with a more diverse population may show differences not shown in this study. 
Second, another limitation to this study was the use of measures that relied on self-reporting of knowledge both for the TPACK and UDL as well as self-efficacy. While self-reporting can be accurate (e.g., Bandura, 2006), it is possible that response bias, in which the respondent responds to items in a way that may make them "look good" (Howard, 1980), may have occurred. Additional forms of measurement for knowledge (e.g., quiz) and observations to further examine self-efficacy may be necessary. Also, the UDL-SBA was used to measure the ability of pre-service teachers to apply their knowledge, this application was not into actual classroom practice. While others have indicated that this is a good proximal measure of application (Sadler, 2014) it is not a true measure of UDL into practice.

\section{Implications for Further Research}

This work begins to answer the call that Brownell (2005) made for the need to increase research surrounding pre-service teacher preparation however, additional research is still needed. First, replication of this study to verify the current findings is necessary. To extend this study, an exploration of the relationships among the constructs may give a broader look at how pre-service teachers are prepared and factors that may impact their ability to apply practices. There is research the show the influence TPACK has on teacher behavior (e.g.: Angeli, 2005; Archambault \& Barnett, 2010; Neiss, 2012; ). There is also research that connects self-efficacy to teacher behavior (e.g.: Coladari, 1992; Cornikdu et. al., 2018; Tchannen-Moran \& Hoy, 2001). Additionally, there is research that connects UDL with teaching practices. Before this study was completed, no study that looked at these three factors in a single model had been attempted. While each of these factors are impactful on teacher behavior independently, a broader look at these 
constructs in unison may give more insight into pre-service teacher decision making and best practices. This could be done by implementing structural equation modeling or path analysis to better understand the mediating and moderating factors and relating to practice-based and lecture-based opportunities. For example, self-efficacy could be a moderating factor in a pre-service teacher's ability to apply UDL knowledge to a given scenario.

Second, the Universal Design for Learning framework is based on the premise that teachers will "proactively plan" for student variability (Rose, Meyers \& Gordon, 2014). The Universal Design for Learning application measure (SBA) required preservice teachers to retroactively change a lesson plan. It is possible that requiring the participants to proactively plan for a scenario may lead to differences in their ability to apply the knowledge that they gained from the UDL condition. Extending this study to determine if pre-service teachers can apply UDL into classroom practice would be valuable as this would further extend our understanding of the impact of UDL.

Finally, the changes observed in this study were positive given the short duration of the intervention. However, it the qualitative research suggests that there were still many students who did not integrate the UDL concepts or vocabulary in a meaningful way. This data suggests that these students may have needed more support and time in learning about and applying UDL. UDL is a complex framework that involves multiple layers (e.g. Rose and Meyer, 2005). Additional research to examine increasing the amount of time and opportunities to engage in content, particularly in the practice-based group, may result in greater positive shifts across measures. 


\section{Implications for Practice}

Both the qualitative data and the quantitative data, point to the fact that practicebased opportunities lead to students applying UDL concepts in a more meaningful way. However, carefully designing practice-based opportunities can be labor intensive as well as more time consuming for students to gain understanding and have to opportunity to apply that knowledge. Instructors should look for situations in which practice-based approaches can be incorporated into courses so that pre-service teachers are given the time and space for a productive experience.

Additionally, UDL not only promotes a change in thinking to more broadly considering the needs of the learners, it increases self-efficacy for working with the diversity that is typical of today's classrooms. Researchers have demonstrated that there is a strong connection between high self-efficacy and positive classroom actions (Elhoweris \& Alsheikh, 2006; Forlin, Loreman \& Earle, 2006; Rojewski \& Pollard, 1993). Therefore, using UDL as a way to think about learners as well as increase preservice teachers' self-efficacy to positively impact all students, may have lasting positive effects in the classrooms and should taught to all general education pre-service teachers

\section{Conclusion}

With the movement towards inclusion, general education teachers are expected to teach in classrooms that are increasing in diversity, especially in regards to meaningfully including students with disabilities into the classroom (NAEP, 2018; Martin, 2018). Yet, many pre-service general education teachers report feeling unprepared and lacking the self-efficacy to meet the needs of all the learners in their classrooms (Ayantoye \& Luckner, 2016; Condoni, 2016). Beyond feeling unprepared, findings from research 
suggest that these preservice teachers also lack the knowledge and skills to effectively teach all students (Washburn, Joshi, \& Cantrell, 2011; Schumm \& Vaughn, 2009).

As a result, teacher preparation programs have applied various "enhancements" to their programs to better prepare teachers to work with diverse learners when they enter the workforce (van Laarhoven et al., 2007). Although enhancements are recommended, there is little research about how and what to include to enhance existing programs. Despite the lack of research, one enhancement related to the "how" of enhancing programs is through the use of active pedagogies such as practice-based approaches (e.g., Brownell, 2005; Benedict, 2018). While the research based is not deep at this time regarding practice-based opportunities for preservice teachers, there is evidence that points to the benefits of this type of approach including: (a) more automaticity in decision making (Phelps, 2009), (b) confidence building opportunities, and (c) time and space to problem solve solutions (Antonious \& Kyriakides, 2013).

From the content perspective, the "what" to teach at the college level particularly in relation to preparing teachers to work with diverse learners, a strong recommendation is Universal Design for Learning. Universal Design for Learning is a framework that promotes inclusion of learners in instruction and, when applied in courses, yields consistent positive results in preparing pre-service teachers to be more inclusive as well as increasing the efficacy to teach diverse learners (Courey et al, 2014; Spooner et al 2004). However, to date no study has examined the use of a practiced-based approach about UDL and whether that results in pre-service teachers increasing in both knowledge about and self-efficacy to use inclusive practices in the classroom. 
In conclusion, this study adds to and extends the current research of experimental studies on two fronts, the affordances of practice-based approaches on pre-service teachers, and the lens that UDL provides to prepare pre-service teachers with sound inclusive pedagogy When Universal Design for Learning is taught to pre-service teachers, meaningful shifts are seen in their ability to incorporate more inclusive practices. Pre-service teachers' foundation knowledge, self-efficacy and UDL knowledge are all positively impacted when UDL is taught, regardless of the instructional model. It is difficult to study effective pre-service teacher practices and yet essential for pre-service teacher preparation for later success. This study is a new way of looking at both how we prepare pre-service teachers (through practice-based approaches) and what we equip preservice teachers with (UDL) to be effective in the classroom. While questions about how constructs interact still remain, this study does provide findings that being to fill the research gap in pre-service teacher education. Universal Design for Learning is a promising practice when preparing general education pre-service teachers for inclusive environments when a practice-based approach is used. 


\section{References}

Abbitt, J. T., \& Klett, M. D. (2007). Identifying influences on attitudes and self-efficacy beliefs towards technology integration among pre-service educators. Electronic Journal for the Integration ofTtechnology in Education, 6(1), 28-42.

Able, H., Sreckovic, M. A., Schultz, T. R., Garwood, J. D., \& Sherman, J. (2015). Views from the trenches: Teacher and student supports needed for full inclusion of students with ASD. Teacher Education and Special Education, 38(1), 44-57. https://doi.org/10.1177/0888406414558096

Albion, P. R. (1999). Self-efficacy beliefs as an indicator of teachers' preparedness for teaching with technology. Society for Information Technology \& Teacher Education International Conference (pp. 1602-1608). Association for the Advancement of Computing in Education (AACE).

Allday, R., Neilsen-Gatti, S., \& Hudson, T. (2013). Preparation for inclusive education in teacher education pre-service curricula. Teacher Education and Special Education, 36, 298-311. https://doi.org/10.1177/0888406413497485

Allinder, R. M. (1994). The relationship between efficacy and the instructional practices of special education teachers and consultants. Teacher Education and Special Education, 17(2), 86-95. https://doi.org/10.1177/088840649401700203

Alsheikh, N., \& Elhoweris, H. (2006). Teachers" attitudes towards inclusion. International Journal of Special Education, 21(1), 115-118.

Anderson, D. H., \& Lignugaris/Kraft, B. (2006). Video-case instruction for teachers of students with problem behaviors in general and special education classrooms. 
Journal of Special Education Technology, 21(2), 31-45.

https://doi.org/10.1177/016264340602100203

Angeli, C. (2005). Transforming a teacher education method course through technology: Effects on pre-service teachers' technology competency. Computers \& Education, 45 (4), 383-398. https://doi.org/10.1016/j.compedu.2004.06.002

Albanese, M. A. (1993). Problem-Based Learning: A Review of Literature on Its Outcomes and Implementation Issues. Academic Medicine, 68(1), 52-81. https://doi.org/10.1097/00001888-199301000-00012

Archambault, L. M., \& Barnett, J. H. (2010). Revisiting technological pedagogical content knowledge: Exploring the TPACK framework. Computers \& Education, 55(4), 1656-1662.

https://doi.org/10.1016/j.compedu.2010.07.009

Ayantoye, C. A., \& Luckner, J. L. (2016). Successful students who are deaf or hard of hearing and culturally and/or linguistically diverse in inclusive settings. American Annals of the Deaf, 160(5), 453-466. https://doi.org/10.1353/aad.2016.0008

Bandura, A. (2006). Guide for constructing self-efficacy scales. In F. Pajares \& T. C. Urdan (Eds.), Self-efficacy beliefs of adolescents (pp. 307-337). Greenwich, CT: Information Age

Bandura, A. (1997). Self-efficacy: The exercise of control. Macmillan.

Bandura, A. (1978). Reflections on self-efficacy. Advances in Behaviour Research and Therapy, 1(4), 237-269. https://doi.org/10.1016/0146-6402(78)90012-7

Bannister-Tyrrell, M., Mavropoulou, S., Jones, M., Bailey, J., O'Donnell-Ostini, A., \& Dorji, R. (2018). Initial teacher preparation for teaching students with 
exceptionalities: Pre-service teachers' knowledge and perceived competence. Australian Journal of Teacher Education, 43(6), 19-34.

https://doi.org/10.14221/ajte.2018v43n6.2

Barrows, H. S., \& Tamblyn, R. M. (1980). Problem-based learning: An approach to medical education. Springer Publishing Company.

Baskerville, N. B., Hogg, W., \& Lemelin, J. (2001). Process evaluation of a tailored multifaceted approach to changing family physician practice patterns improving preventive care. The Journal of Family Practice, 50(3), 242-249.

Benedict, A., Holdheide, L., Brownell, M., \& Foley, A. M. (2016). Learning to teach: Practice-based preparation in teacher education. Special Issues Brief. Washington. DC: American Institutes for Research.

Benton-Borghi, B. H. (2013). A Universally Designed for Learning (UDL) infused Technological Pedagogical Content Knowledge (TPACK) practitioners' model essential for teacher preparation in the 21st Century. Journal of Educational Computing Research, 48(2), 245-265.

Benton-Borghi, B. H., \& Chang, Y. M. (2011). Critical Examination of Candidates' Diversity Competence: Rigorous and Systematic Assessment of Candidates' Efficacy to Teach Diverse Student Populations. Teacher Educator, 47(1), 29-44.

Boud, D., \& Feletti, G. (1997). Changing problem-based learning: Introduction to the second edition. The challenge of problem-based learning, 1-14.

Bransford, J. D., Darling-Hammond, L., \& LePage, P. (2005). Preparing Teachers for a Changing World: Introduction. Preparing Teachers for a Changing World: What teachers should Learn and be able to do, 1-39. 
Braslavsky, C., \& American Association of Colleges for Teacher Education. (2002).

Teacher education and the demands of curricular change. AACTE.

Brownell, M. T., Ross, D. D., Colón, E. P., \& McCallum, C. L. (2005). Critical features of special education teacher preparation: A comparison with general teacher education. The Journal of Special Education, 38(4), 242-252. https://doi.org/10.1177/00224669050380040601

Brownell, M. T., Chard, D., Benedict, A., \& Lignugaris, B. (2018). Preparing general and special education preservice teachers for Response to Intervention: A practicebased approach. In Handbook of Response to Intervention and Multi-Tiered Systems of Support (pp. 137-161). Routledge.

Beutel, D., \& Tangen, D. (2018). The impact of intercultural experiences on preservice teachers' preparedness to engage with diverse learners. Australian Journal of Teacher Education, 43(3), 168. https://doi.org/10.14221/ajte.2018v43n3.11

Brunsting, N. C., Sreckovic, M. A., \& Lane, K. L. (2014). Special education teacher burnout: A synthesis of research from 1979 to 2013. Education and Treatment of Children, 37(4), 681-711. https://doi.org/10.1353/etc.2014.0032

Bull, P. (2009). Self-efficacy and technology integration: Perceptions of first year teaching fellows to technology integration in education. In I. Gibson, R. Weber, K. McFerrin, R. Calsen, \& D. A. Willis (Eds.), Proceedings of the Society for Information Technology \& Teacher Education International Conference 2009, (pp. 1768-1776). AACE.

CAST (2018). Universal Design for Learning Guidelines version 2.2. Retrieved from http://udlguidelines.cast.org 
Center for Applied Special Technology. (2019, April): Home. Retrieved from: http://www.cast.org/

Can, Ş., Doğru, S., \& Bayir, G. (2017). Determination of Pre-service Classroom Teachers' Technological Pedagogical Content Knowledge. Journal of Education and Training Studies, 5(2), 160-166. https://doi.org/10.11114/jets.v5i2.2083

Cohen, J. (1988). Statistical power analysis for the behavioral sciences (2nd ed.). Hillsdale, NJ: Lawrence Earlbaum Associates.

Coladarci, T. (1992). Teachers' sense of efficacy and commitment to teaching. The Journal of Experimental Education, 60(4), 323-337. https://doi.org/10.1080/00220973.1992.9943869

Cook, B. G. (2002). Inclusive attitudes, strengths, and weaknesses of pre-service general educators enrolled in a curriculum infusion teacher preparation program. Teacher Education and Special Education, 25, 262-277. https://doi.org/10.1177/088840640202500306

Cornoldi, C., Capodieci, A., Colomer Diago, C., Miranda, A., \& Shepherd, K. G. (2018). Attitudes of primary school teachers in three western countries toward learning disabilities. Journal of Learning Disabilities, 51(1), 43-54. https://doi.org/10.1177/0022219416678408 Courey, S. J., Tappe, P., Siker, J., \& LePage, P. (2013). Improved lesson planning with universal design for learning (UDL). Teacher Education and Special Education, 36(1), 7-27. https://doi.org/10.1177/0888406412446178 
Coyne, P., Pisha, B., Dalton, B., Zeph, L., \& Cook Smith, N. (2010). Literacy by design: A universally designed digital reading approach for young students with significant intellectual disabilities. Remedial and Special Education.

Creswell, J. W., Plano Clark, V. J., \& Hanson, W. E. (2003). Handbook of mixed methods in social and behavioral research. Advanced Mixed Methods Research Designs, 212.

Dalton, B., Pisha, B., Eagleton, M., Coyne, P., \& Deysher, S. (2002). Engaging the text: Strategy instruction in a computer-supported reading environment for struggling readers. Executive Summary. Center for Applied Special Technology.

Darling-Hammond, L. (2008). Teacher learning that supports student learning. Teaching for intelligence, 2(1), 91-100.

De Jong, R., Mainhard, T., Van Tartwijk, J., Veldman, I., Verloop, N., \& Wubbels, T. (2014). How pre-service teachers' personality traits, self-efficacy, and discipline strategies contribute to the teacher-student relationship. British Journal of Educational Psychology, 84(2), 294-310. https://doi.org/10.1111/bjep.12025

Dymond, S. K., Renzaglia, A., Rosenstein, A., Chun, E. J., Banks, R. A., Niswander, V., \& Gilson, C. L. (2006). Using a participatory action research approach to create a universally designed inclusive high school science course: A case study. Research and Practice for Persons with Severe Disabilities, 31(4), 293-308. https://doi.org/10.1177/154079690603100403

Edyburn, D. L. (2000). Assistive technology and mild disabilities. Mental retardation, 612, 10-6. 
Edyburn, D. L. (2010). Would you recognize universal design for learning if you saw it? Ten propositions for new directions for the second decade of UDL. Learning Disability Quarterly, 33(1), 33-41. https://doi.org/10.1177/073194871003300103

Enochs, L. G., Scharmann, L. C., \& Riggs, I. M. (1995). The relationship of pupil control to preservice elementary science teacher self-efficacy and outcome expectancy. Science Education, 79(1), 63-75. https://doi.org/10.1002/sce.3730790105

Emmer, E. T., \& Stough, L. M. (2001). Classroom management: A critical part of educational psychology, with implications for teacher education. Educational Psychologist, 36(2), 103-112. https://doi.org/10.1207/S15326985EP3602_5

Field, A., Miles, J., \& Field, Z. (2012). Discovering statistics using R. Sage publications. Fisher, D., Frey, N., \& Thousand, J. (2003). What do special educators need to know and be prepared to do for inclusive schooling to work?. Teacher education and Special Education, 26(1), 42-50. https://doi.org/10.1177/088840640302600105

Forlin, C., \& Chambers, D. (2011). Teacher preparation for inclusive education: Increasing knowledge but raising concerns. Asia-Pacific Journal of Teacher Education, 39(1), 17-32. https://doi.org/10.1080/1359866X.2010.540850

Frey, T. J., Andres, D. K., McKeeman, L. A., \& Lane, J. J. (2012). Collaboration by design: Integrating core pedagogical content and special education methods courses in a preservice secondary education program. The Teacher Educator, 47(1), 45-66. https://doi.org/10.1080/08878730.2011.632473

Gall, M. D., Borg, W. R., \& Gall, J. P. (1996). Educational research: An introduction. Longman Publishing. 
Garland, K. V., Vasquez III, E., \& Pearl, C. (2012). Efficacy of individualized clinical coaching in a virtual reality classroom for increasing teachers' fidelity of implementation of discrete trial teaching. Education and Training in Autism and Developmental Disabilities, 502-515.

Gess-Newsome, J. (1999). Pedagogical content knowledge: An introduction and orientation. In examining pedagogical content knowledge (pp. 3-17). Springer, Dordrecht.

Gibson, S., \& Dembo, M. H. (1984). Teacher efficacy: A construct validation. Journal of Educational Psychology, 76(4), 569. https://doi.org/10.1037/0022-0663.76.4.569

Graham, C. R. (2011). Theoretical considerations for understanding technological pedagogical content knowledge (TPACK). Computers \& Education, 57(3), 19531960. https://doi.org/10.1016/j.compedu.2011.04.010

Gregg, N. (2012). Increasing access to learning for the adult basic education learner with learning disabilities: Evidence-based accommodation research. Journal of Learning Disabilities, 45(1), 47-63. https://doi.org/10.1177/0022219411426855

Hall, T. E., Cohen, N., Vue, G., \& Ganley, P. (2015). Addressing learning disabilities with UDL and technology: Strategic reader. Learning Disability Quarterly, 38(2), 72-83. https://doi.org/10.1177/0731948714544375

Hahs-Vaughn, D. L., \& Lomax, R. G. (2013). An introduction to statistical concepts. Routledge.

Harvey, M. W., Yssel, N., Bauserman, A. D., \& Merbler, J. B. (2010). Preservice teacher preparation for inclusion: An exploration of higher education teacher-training 
institutions. Remedial and Special Education, 31(1), 24-33.

https://doi.org/10.1177/0741932508324397

Hehir, T. (2009). Policy foundations of universal design for learning. A policy reader in universal design for learning, 35-45.

Heller, J. I., Daehler, K. R., Wong, N., Shinohara, M., \& Miratrix, L. W. (2012). Differential effects of three professional development models on teacher knowledge and student achievement in elementary science. Journal of Research in Science Teaching, 49(3), 333-362. https://doi.org/10.1002/tea.21004

Harris, J. B. \& Hofer, M. J. (2011). Technological Pedagogical Content Knowledge (TPACK) in action: A descriptive study of secondary teachers' curriculum-based, technology-related instructional planning. Journal of Research on Technology in Education, 43(3), 211-229. https://doi.org/10.1080/15391523.2011.10782570

Hathaway, D., \& Norton, P. (2018). Evaluating Learning Outcomes. In Understanding Problems of Practice (pp. 51-61). Springer, Cham. https://doi.org/10.1007/978-3319-77559-3_5

Harik, P., Clauser, B. E., Grabovsky, I., Nungester, R. J., Swanson, D., \& Nandakumar, R. (2009). An examination of rater drift within a generalizability theory framework. Journal of Educational Measurement, 46(1), 43-58.

Hoy, A. W., Hoy, W. K., \& Davis, H. A. (2009). Teachers' self-efficacy beliefs. In K. R. Wenzel \& A. Wigfield (Eds.), Educational psychology handbook series. Handbook of motivation at school (pp. 627-653). New York, NY, US: Routledge/Taylor \& Francis Group. 
Israel, M., Ribuffo, C., \& Smith, S. (2014). Universal Design for Learning innovation configuration: Recommendations for teacher preparation and professional development (Document No. IC-7). Retrieved from University of Florida, Collaboration for Effective Educator, Development, Accountability, and Reform Center website: http://ceedar. education. ufl.edu/tools/innovation-configurations.

Jamil, F. M., Downer, J. T., \& Pianta, R. C. (2012). Association of pre-service teachers' performance, personality, and beliefs with teacher self-efficacy at program completion. Teacher Education Quarterly, 39(4), 119-138.

Jiménez, T. C., Graf, V. L., \& Rose, E. (2007). Gaining access to general education: The promise of universal design for learning. Issues in Teacher Education, 16(2), 4154.

Jorgensen, C. M. (2018). It's more than" just being in": Creating authentic inclusion for students with complex support needs. Brookes Publishing Company, Baltimore, MD.

Klassen, R. M., \& Tze, V. M. (2014). Teachers' self-efficacy, personality, and teaching effectiveness: A meta-analysis. Educational Research Review, 12, 59-76. https://doi.org/10.1016/j.edurev.2014.06.001

Klassen, R. M., \& Chiu, M. M. (2010). Effects on teachers' self-efficacy and job satisfaction: Teacher gender, years of experience, and job stress. Journal of Educational Psychology, 102(3), 741. https://doi.org/10.1037/a0019237

Koehler, M. J., \& Mishra, P. (2008). Introducing TPCK. AACTE Committee on Innovation and Technology (Ed.), The handbook of technological pedagogical 
content knowledge (TPCK) for educators (pp. 3-29). Mahwah, N]: Lawrence Erlbaum Associates.

Koh, J. H. L., \& Chai, C. S. (2014). Teacher clusters and their perceptions of technological pedagogical content knowledge (TPACK) development through ICT lesson design. Computers \& Education, 70, 222-232. https://doi.org/10.1016/j.compedu.2013.08.017

Kortering, L. J., McClannon, T. W., \& Braziel, P. M. (2008). Universal design for learning: A look at what algebra and biology students with and without high incidence conditions are saying. Remedial and Special Education, 29(6), 352-363. https://doi.org/10.1177/0741932507314020

Lancaster, J., \& Bain, A. (2010). The design of pre-service inclusive education courses and their effects on self-efficacy: A comparative study. Asia-Pacific Journal of Teacher Education, 38(2), 117-128. https://doi.org/10.1080/13598661003678950

Landrum, T. J., \& McDuffie, K. A. (2010). Learning styles in the age of differentiated instruction. Exceptionality, 18(1), 6-17. https://doi.org/10.1080/09362830903462441

Lee, S. H., Wehmeyer, M. L., Soukup, J. H., \& Palmer, S. B. (2010). Impact of curriculum modifications on access to the general education curriculum for students with disabilities. Exceptional Children, 76(2), 213-233. https://doi.org/10.1177/001440291007600205

Leuszler, L. (2015). Teacher knowledge and self-efficacy for the inclusion of students with autism spectrum disorders in the regular classroom (Doctoral dissertation, Nipissing University) 
Lignugaris/Kraft, B., \& Harris, S. (2014). Teacher preparation: Principles of effective pedagogy. In P. T. Sindelar, E. D. McCray, M. T. Brownell, \& B. Lignugaris/Kraft (Eds.), Handbook of research on special education teacher preparation (pp. 233-254). New York, NY: Routledge.

Lin, T. C., Tsai, C. C., Chai, C. S., \& Lee, M. H. (2013). Identifying science teachers' perceptions of technological pedagogical and content knowledge (TPACK). Journal of Science Education and Technology, 22(3), 325-336. https://doi.org/10.1007/s10956-012-9396-6

Lombardi, T. P., \& Hunka, N. J. (2001). Preparing general education teachers for inclusive classrooms: Assessing the process. Teacher Education and Special Education, 24, 183-197. https://doi.org/10.1177/088840640102400303

Loewenberg Ball, D., \& Forzani, F. M. (2009). The work of teaching and the challenge for teacher education. Journal of Teacher Education, 60(5), 497-511. https://doi.org/10.1177/0022487109348479

Meijer, C. J. W., \& Foster, S. F. (1988). The effect of teacher self-efficacy on referral chance. The Journal of Special Education, 22(3), 378-385. https://doi.org/10.1177/002246698802200309

Mergler, A., Carrington, S., Kimber, M., \& Bland, D. (2016). Inclusive values: Exploring the perspectives of pre-service teachers. Australian Journal of Teacher Education, 41(4), 2.

https://doi.org/10.14221/ajte.2016v41n4.2

Meyer, A., Rose, D.H., \& Gordon, D. (2014). Universal design for learning: Theory and Practice. Wakefield, MA: CAST Professional Publishing. 
Mishra, P., \& Koehler, M. J. (2006). Technological pedagogical content knowledge: A framework for teacher knowledge. Teachers College Record, 108(6), 1017-1054. https://doi.org/10.1111/j.1467-9620.2006.00684.x

Moore, W. P., \& Esselman, M. E. (1994). Exploring the Context of Teacher Efficacy: The Role of Achievement and Climate.

Mouza, C. (2016). Developing and assessing TPACK among pre-service teachers. Handbook of technological pedagogical content knowledge (TPACK) for educators, 169.

National Center on Universal Design for Learning at CAST (2019, April.) Welcome to the UDL center! Retrieved from: https://medium.com/udl-center/new-udlcenter$16 c e 1923 f d 19$

Niess, M. L. (2012). Re-Thinking Pre-Service Mathematics Teachers Preparation: Developing Technological, Pedagogical, and Content Knowledge (TPACK). In Developing Technology-Rich Teacher Education Programs: Key Issues (pp. 316336). IGI Global.

Niemi, H., \& Nevgi, A. (2014). Research studies and active learning promoting professional competences in Finnish teacher education. Teaching and Teacher Education, 43, 131-142. https://doi.org/10.1016/j.tate.2014.07.006

Niemi, H., Nevgi, A., \& Aksit, F. (2016). Active learning promoting student teachers' professional competences in Finland and Turkey. European Journal of Teacher Education, 39(4), 471-490. https://doi.org/10.1080/02619768.2016.1212835 
Norman, K., Caseau, D., \& Stefanich, G.P. (1998). Teaching students with disabilities in inclusive science classrooms: Survey results. Journal of Science Education, 82, $127-146$.

Oliver, R. M., \& Reschly, D. J. (2010). Special education teacher preparation in classroom management: Implications for students with emotional and behavioral disorders. Behavioral Disorders, 35(3), 188-199. https://doi.org/10.1177/019874291003500301

Özgün-Koca, S. A., Meagher, M., \& Edwards, M.T. (2010). Pre-service Teachers' Emerging TPACK in a Technology-Rich Methods Class. The Mathematics Educator, 19(2), 10-20.

Phelps, G. (2009). Just knowing how to read isn't enough! Assessing knowledge for teaching reading. Educational Assessment, Evaluation and Accountability, 21(2), 137-154. https://doi.org/10.1007/s11092-009-9070-6

Podell, D. M., \& Soodak, L. C. (1993). Teacher efficacy and bias in special education referrals. The Journal of Educational Research, 86(4), 247-253. https://doi.org/10.1080/00220671.1993.9941836

Reinke, W. M., Herman, K. C., \& Stormont, M. (2013). Classroom-level positive behavior supports in schools implementing SW-PBIS: Identifying areas for enhancement. Journal of Positive Behavior Interventions, 15(1), 39-50. https://doi.org/10.1177/1098300712459079

Ripley, S. (1998). Collaboration between General and Special Education Teachers. Teaching Strategies. Journal of Early Education and Family Review, 5(4), 16-20. 
Rojewski, J. W., \& Pollard, R. R. (1993). A Multivariate Analysis of Perceptions Held By Secondary Academic Teachers Toward Students with Special Needs. Teacher Education and Special Education, 16(4), 330-341. https://doi.org/10.1177/088840649301600406

Rose, D. H., \& Gravel, J. W. (2009). Getting from here to there: UDL, global positioning systems, and lessons for improving education. A policy reader in universal design for learning, 5-18.

Sadler, T. D., \& Zeidler, D. L. (2009). Scientific literacy, PISA, and socioscientific discourse: Assessment for progressive aims of science education. Journal of Research in Science Teaching: The Official Journal of the National Association for Research in Science Teaching, 46(8), 909-921.

Savery, J. R. (2015). Overview of problem-based learning: Definitions and distinctions. Essential readings in problem-based learning: Exploring and extending the legacy of Howard S. Barrows, 9, 5-15.

Schmidt, D. A., Baran, E., Thompson, A. D., Mishra, P., Koehler, M. J., \& Shin, T. S. (2009). Technological pedagogical content knowledge (TPACK) the development and validation of an assessment instrument for preservice teachers. Journal of Research on Technology in Education, 42(2), 123-149. https://doi.org/10.1080/15391523.2009.10782544

Schunk, D. H. (1991). Self-efficacy and academic motivation. Educational Psychologist, 26, 207-231. https://doi.org/10.1207/s15326985ep2603\&4_2

Scott, L. A., Thoma, C. A., Puglia, L., Temple, P., \& D'Aguilar, A. (2017). Implementing a UDL framework: A study of current personnel preparation 
practices. Intellectual and Developmental Disabilities, 55(1), 25-36.

https://doi.org/10.1352/1934-9556-55.1.25

Scruggs, T. E., \& Mastropieri, M. A. (1996). Teacher perceptions of mainstreaming/inclusion, 1958-1995: A research synthesis. Exceptional Children, 63(1), 59-74. https://doi.org/10.1177/001440299606300106

Sharma, U., Forlin, C., \& Loreman, T. (2008). Impact of training on pre-service teachers' attitudes and concerns about inclusive education and sentiments about persons with disabilities. Disability \& Society, 23(7), 773-785. https://doi.org/10.1080/09687590802469271

Sharma, U., Forlin, C., Loreman, T., \& Earle, C. (2006). Pre-Service Teachers' Attitudes, Concerns and Sentiments about Inclusive Education: An International Comparison of Novice Pre-Service Teachers. International Journal of Special Education, 21(2), 80-93.

Shulman, L. (1987). Knowledge and teaching: Foundations of the new reform. Harvard Educational Review, 57(1), 1-23. https://doi.org/10.17763/haer.57.1.j463w79r56455411

Shulman, L. S. (1986). Those who understand: Knowledge growth in teaching. Educational Researcher, 15(2), 4-14. https://doi.org/10.3102/0013189X015002004

Sileo, T. W., \& Prater, M. A. (1998). Preparing professionals for partnerships with parents of students with disabilities: Textbook considerations regarding cultural diversity. Exceptional Children, 64(4), 513-528. https://doi.org/10.1177/001440299806400407 
Sousa, D. A., \& Tomlinson, C. A. (2011). Differentiation and the brain: How neuroscience supports the learner-friendly classroom. Solution Tree Press.

Specht, J., McGhie-Richmond, D., Loreman, T., Mirenda, P., Bennett, S., Gallagher, T., ... \& Lyons, W. (2016). Teaching in inclusive classrooms: Efficacy and beliefs of Canadian preservice teachers. International Journal of Inclusive Education, 20(1), 1-15. https://doi.org/10.1080/13603116.2015.1059501

Spooner, F., Baker, J. N., Harris, A. A., Ahlgrim-Delzell, L., \& Browder, D. M. (2007). Effects of training in universal design for learning on lesson plan development. Remedial and Special Education, 28(2), 108-116. https://doi.org/10.1177/07419325070280020101

Stand, J. (2000). The" Hawthorne effect"-what did the original Hawthorne studies actually show. Social Work Environmental Health, 26(4), 363-367.

Steinemann, A. (2003). Implementing sustainable development through problem-based learning: Pedagogy and practice. Journal of Professional Issues in Engineering Education and Practice, 129(4), 216-224. https://doi.org/10.1061/(ASCE)10523928(2003)129:4(216)

Strawderman, C., \& Lindsey, P. (1995). Keeping up with the times: Reform in teacher education. Journal of Teacher Education, 46(2), 95-101. https://doi.org/10.1177/0022487195046002003

Sze, S. (2009). A literature review: Pre-service teachers' attitudes toward students with disabilities. Education, 130(1), 53-57. 
Tschannen-Moran, M., Hoy, A. W., \& Hoy, W. K. (1998). Teacher efficacy: Its meaning and measure. Review of Educational Research, 68(2), 202-248. https://doi.org/10.3102/00346543068002202

Tirado, D. E. (2016). Supporting general education teachers in working with students diagnosed with an emotional behavior disorder.

Thompson, A. D., \& Mishra, P. (2007). Breaking news: TPCK becomes TPACK! Journal of Computing in Teacher Education, 24, 38, 64.

Tomlinson, C. A., \& McTighe, J. (2006). Integrating Differentiated Instruction and Understanding by Design: Connecting Content and Kids. Association for Supervision and Curriculum Development.

Van Laarhoven, T. R., Munk, D. D., Lynch, K., Bosma, J., \& Rouse, J. (2007). A model for preparing special and general education preservice teachers for inclusive education. Journal of Teacher Education, 58(5), 440-455. https://doi.org/10.1177/0022487107306803

Vaughn, S., Bos, C. S., \& Schumm, J. S. (2007). Teaching students who are exceptional, diverse, and at risk in the general education classroom. Allyn \& Bacon.

Verloop, N., Van Driel, J., \& Meijer, P. (2001). Teacher knowledge and the knowledge base of teaching. International Journal of Educational Research, 35(5), 441-461. https://doi.org/10.1016/S0883-0355(02)00003-4

Vitelli, E. M. (2015). Universal design for learning: Are we teaching it to preservice general education teachers?. Journal of Special Education Technology, 30(3), 166-178. https://doi.org/10.1177/0162643415618931 
Washburn, E. K., Joshi, R. M., \& Cantrell, E. B. (2011). Are preservice teachers prepared to teach struggling readers? Annals of Dyslexia, 61(1), 21-43. https://doi.org/10.1007/s11881-010-0040-y

Wehmeyer, M. L. (2006). Universal design for learning, access to the general education curriculum and students with mild mental retardation. Exceptionality, 14(4), 225235. https://doi.org/10.1207/s15327035ex1404_4

Wilson, S. M., Shulman, L. S., \& Richert. A. E. (1987). '150 different ways' of knowing: representations of knowledge in teaching. In Calderhead, J. (Ed.), Exploring teachers' thinking (pp. 104-124). London: Cassell educational.

Wolfolk, A., \& Hoy, W. (1990). Prospective teachers' sense of efficacy and belief about control. Journal of Educational Psychology, 82(1), 81-91. https://doi.org/10.1037/0022-0663.82.1.81

Woodcock, Stuart, Brian Hemmings, and Russell Kay (2012). "Does study of an inclusive education subject influence pre-service teachers' concerns and selfefficacy about inclusion?." (2012): 1.

Zeichner, K. (2012). The turn once again toward practice-based teacher education. Journal of Teacher Education, 63(5), 376-3 https://doi.org/10.1177/002248711244578982. 


\section{Appendix A}

\section{IRB Approval}

붕

Institutional Review Board

University of Missouri-Columbia

FWA Number: 0002876

IRB Registration Numbers: 00000731,00009014

482 McReynolds Hall

Columbia, MO 65211

573-882-3181

irb@missouri.edu

February 04,2019

Principal Investigator: Mary Elizabeth Decker

Department: VP Undergraduate Studies

Your IRB Application to project entitled Effects of Pre-Service Teacher Engagement in a Universal Design for Learning Problem-Based Learning Experience was reviewed and approved by the MU Institutional Review Board according to the terms and conditions described below:

$\begin{array}{ll}\text { IRB Project Number } & 2013756 \\ \text { IRB Review Number } & 244887 \\ \text { Funding Source } & \text { STAR Program } \\ \text { Initial Application Approval Date } & \text { February 04, 2019 } \\ \text { IRB Expiration Date } & \text { February 04, 2020 } \\ \text { Level of Review } & \text { Exempt } \\ \text { Project Status } & \text { Active - Exempt } \\ \text { Exempt Categories (Revised Common } & 45 \text { CFR 46.104d(1) } \\ \text { Rule) } & \text { Minimal Risk } \\ \text { Risk Level } & \text { Internal Grant (ex. Research council, } \\ \text { Internal Funding } & \text { etc) }\end{array}$

The principal investigator (PI) is responsible for all aspects and conduct of this study. The PI must comply with the following conditions of the approval:

1. No subjects may be involved in any study procedure prior to the IRB approval date or after the expiration date.

2. All changes must be IRB approved prior to implementation utilizing the Exempt Amendment Form.

3. The Annual Exempt Form must be submitted to the IRB for review and approval at least 30 days prior to the project expiration date to keep the study active or to close it.

4. Maintain all research records for a period of seven years from the project completion date.

If you have any questions, please contact the IRB at 573-882-3181 or irb@missouri.edu.

Thank you,

MU Institutional Review Board 


\section{Appendix B}

\section{TPACK infused UDL Survey}

Benton-Borghi 2013

For the purpose of this survey you are responding with your abilities as they are TODAY in ideal teaching situations with adequate support.

Strongly Disagree $(S D)=1$, Disagree $(D)=2$, Neither Agree/Disagree $(N)=3$, Agree $(A)=4$, Strongly Agree $(\mathrm{SA})=5$

\begin{tabular}{ll}
\hline TK & Technological Knowledge \\
TK1 & I know how to solve my own technical problems \\
TK2 & I can learn technology easily \\
TK3 & I keep up with important new technologies \\
TK4 & I frequently play around with technology \\
TK5 & I know about a lot of different technologies \\
TK6 & I have the technical skills I need to use technology \\
TKU & UDL Infused Technological Knowledge
\end{tabular}

TKU1 I know how to use/choose technology that is universally designed for student learning

TKU2 I know about different assistive technologies

TKU3 I know how to use technologies that support participants' learning to meet all participants' needs

TKU4 I can use assistive technology in teaching and learning

TKU5 I know information about assistive technology and access to curricular content

TKU6 I can select assistive technology that supports student access to the curriculum content

TKU7 I can select assistive technology that supports access to the curriculum content for the full spectrum of learners

PK Pedagogical Knowledge

PK1 I know how to assess student performance in a classroom

PK2 I can adapt my teaching based upon what students currently understand or do not understand

PK3 I can adapt my teaching style to different learners

PK4 I can assess student learning in multiple ways

PK5 I can use a wide range of teaching approaches in a classroom setting

PK6 I am familiar with common student understandings and misconceptions

PK7 I know how to organize and maintain classroom management

PKU UDL infused Pedagogical Knowledge

PKU1 I know how to apply universally designed for learning (UDL) principles to teach for student learning

PKU2 I know how to apply universally designed for learning (UDL) principles to assess for student learning

\section{CK Content Knowledge}

Secondary Pre-service teachers should only answer the questions for their specific content areas (literacy, social studies, mathematics, science, and art). Elementary 
pre-service teachers should only answer the questions for the specific content areas in which they will be teaching generally, while they may feel stronger in one content area than another how do you generally feel about the content you may be teaching.

CK1 I have sufficient knowledge about mathematics (or language arts, social studies, science, art or music)

CK2 I can use a mathematics (or language arts, social studies, science, art, music) way of thinking

CKU UDL infused Content Knowledge**

CKU3 I have various ways and strategies of developing my understanding of mathematics (or language arts, social studies, science, art or music)

TCK Technological Content Knowledge

TCK1 I can select effective teaching approaches to guide student thinking and learning in my content

TCK2 I know about technologies that I can use for understanding and doing mathematics (or language arts, social studies, science, art or music

TCKU UDL infused Technological Content Knowledge **

TCKU1 I know about technologies that I can use to increase student access to the content

TCKU4 I can use technology increasing student background knowledge of content

TPK Technological Pedagogical Knowledge

TPK1 I can choose technologies that enhance the teaching approaches for a lesson

TPK2 I can choose technologies that enhance participants' learning for a lesson

TPK3 My teacher education program has caused me to think more deeply about how technology could influence the teaching approaches I use in my classroom

TPK4 I am thinking critically about how to use technology in my classroom

TPK5 I can adapt the use of technologies to different teaching activities

TPK6 I can choose technologies that enhance the content for a lesson

TPKU UDL infused Technological Pedagogical Knowledge***

TPKU1 I can design ways incorporate technology into my instruction that enables all learners to be successful

TPKU2 I can use technology to encourage participants to represent their knowledge in a variety of ways

TPKU3 I can represent content in a variety of ways using technology to meet the needs of all learners in my classroom

TPACK Technological Pedagogical Content Knowledge

TPACK1I can select technology to use in my classroom that enhances what I teach, how I teach and what participants learn

TPACK2I can use strategies that combine content, technologies and teaching approaches that I learned about in my coursework in my classroom

TPACK3I can teach lessons that appropriately combine content, technologies and teaching approaches

TPACKU UDL Infused TPACK 
TPACKU1 I can teach lessons that appropriately combine content, technologies and teaching approaches combined with principles of universal design for learning to meet the needs of all learners 


\section{Appendix C}

\section{Twenty-First Century Teacher's Sense of Efficacy Scale}

Benton Benton-Borghi $(2006,2012,2014)$

For the purpose of this survey you are responding with your abilities as they are TODAY in ideal teaching situations with adequate support.

How much can you do? Nothing (1), Very little (3), Some influence (5), Quite a bit (7) A great deal (9)

1. How much can you do to control disruptive behavior of student in the classroom?

2. How much can you do to motivate student who show low interest in school work?

3. How much can you do to get participants to believe they can do well in school work?

4. How much can you do to help participants to value learning?

5. To what extent can you craft good questions for participants?

6. How much can you do to get participants to follow classroom rules?

7. How much can you do to calm participants who are disruptive or noisy?

8. How well can you establish a classroom management system with participants in your classroom?

9. How much can you use a variety of assessment strategies for participants?

10. To what extent can you provide alternative explanations or examples when participants are confused?

11. How much can you assist families in helping their participants do well in school?

12. How well can you implement alternative strategies in your classroom?

13. How well can you motivate participants who require assistive and accessible technology for students in your classroom?

14. To what extent can you implement accommodations for assistive and accessible technology for participants in your classroom?

15. How much can you do to provide participants who require text readers and accessible digital content access to the curriculum content?

16. How much can you do to provide universally designed assessments to evaluate learning of participants in your classroom?

17. How much can you do to provide the curriculum content in specialized formats (digital, audio, translated) for participants who require them?

18. How much can you do to integrate technology to provide participants with opportunities to develop $21^{\text {st }}$-century skills?

19. How much can you do to provide universally designed instruction for participants to learn? 
Appendix D

Scenario Based Assessment

Scenario: Read the following scenario and respond to the 4 prompts related to the information given.

Mrs. Kim is unsatisfied with the way she is teaching and is ready to make some changes from the way that she traditionally thinks about her lessons and students. She just learned about Universal Design for Learning and wants to incorporate those ideas into her classroom. Your task is to think about the ways that Mrs. Kim traditionally teaches and determine how she may adjust her lesson to align with UDL principles. You will also be asked to justify your revision.

School Information: The students in this school are diverse. $13 \%$ of the population receive services for one or more disability; most of those students spend the majority of their day in the general education classroom. $56 \%$ of the students receive free or reduced lunch. $12 \%$ of the population is reading at or above grade level. $5 \%$ of the students are English Language Learners.

The following are goals, instructional materials, instructional methods and assessment related to a unit over the Holocaust. Think about how you might revise them so that they are more universally designed. You will also be asked to justify your revision, use what you already know or what you have learned about UDL to answer each question to the best of your ability.

Mrs. Kim's Goal: Students will learn 15 teacher chosen vocabulary words related to the Holocaust by looking up the words in the dictionary and copying the definitions.

How could this goal could be revised to be more aligned with UDL?

What information about UDL made you choose to revise in this way?

Mrs. Kim's Materials: All of the students will read sections of the assigned grade level textbook to learn about the Holocaust.

What are some ways that the instructional materials could be revised to be more aligned with UDL?

What information about UDL made you choose to revise in this way?

Mrs. Kim's Instructional Methods: Students will watch a 45-minute long video about Ann Frank as a whole class. 
What are some ways that the instructional methods could be revised to be more aligned with UDL?

What information about UDL made you choose to revise in this way?

Mrs. Kim's Assessment: Students will write a 5 paragraph informative essay about what they learned over the unit.

What are some ways that the assessment could be revised to be more aligned with UDL?

What information about UDL made you choose to revise in this way? 
Appendix E

Rubric for SBA

\begin{tabular}{|c|c|c|c|}
\hline & 0 point & 1 point & 2 points \\
\hline $\begin{array}{l}\text { Learning } \\
\text { Goals }\end{array}$ & $\begin{array}{l}\text { No clear } \\
\text { revision }\end{array}$ & $\begin{array}{l}\text { Goal is changed in an attempt to } \\
\text { make more inclusive }\end{array}$ & $\begin{array}{l}\text { Goal is changed to be aligned with } \\
\text { UDL principles- (IE: means are not } \\
\text { tied to method, multiple paths to } \\
\text { mastery) }\end{array}$ \\
\hline $\begin{array}{l}\text { Learning Goal } \\
\text { Justification }\end{array}$ & $\begin{array}{l}\text { No } \\
\text { justification } \\
\text { provided }\end{array}$ & $\begin{array}{l}\text { Justification is provided and is } \\
\text { more inclusive but does not use } \\
\text { UDL vocabulary }\end{array}$ & $\begin{array}{l}\text { Justification is provided, is more } \\
\text { inclusive AND uses UDL vocabulary } \\
\text { (IE. Representation, engagement, } \\
\text { action and expression, Choice, reduce } \\
\text { barriers) }\end{array}$ \\
\hline Materials & $\begin{array}{l}\text { No clear } \\
\text { revision }\end{array}$ & $\begin{array}{l}\text { Materials are revised in an attempt } \\
\text { to make more inclusive (I.E: } \\
\text { technology is added) }\end{array}$ & $\begin{array}{l}\text { Materials are added to provide } \\
\text { accessibility and choice }\end{array}$ \\
\hline Justification & $\begin{array}{l}\text { No } \\
\text { justification } \\
\text { provided }\end{array}$ & $\begin{array}{l}\text { Attempt is made to be more } \\
\text { inclusive however justification is } \\
\text { not tied to UDL practices (IE } \\
\text { students will learn better, textbook } \\
\text { is not at reading level) }\end{array}$ & $\begin{array}{l}\text { Justification is provided, is more } \\
\text { inclusive AND uses UDL vocabulary } \\
\text { (IE. Principles, Choice, reduce } \\
\text { barriers) }\end{array}$ \\
\hline Methods & $\begin{array}{l}\text { No clear } \\
\text { revision }\end{array}$ & $\begin{array}{l}\text { Attempt is made to be more } \\
\text { inclusive however justification is } \\
\text { not tied to UDL practices (IE } \\
\text { students will learn better, video is } \\
\text { too long) }\end{array}$ & $\begin{array}{l}\text { Method are varied (Ie individual, } \\
\text { group work) OR to provide } \\
\text { accessibility and choice }\end{array}$ \\
\hline Justification & $\begin{array}{l}\text { No } \\
\text { justification } \\
\text { provided }\end{array}$ & $\begin{array}{l}\text { Attempt is made to be more } \\
\text { inclusive however justification is } \\
\text { not tied to UDL practices (IE } \\
\text { students will learn better, movie } \\
\text { will get boring) }\end{array}$ & $\begin{array}{l}\text { Justification is provided, is more } \\
\text { inclusive AND uses UDL vocabulary } \\
\text { (IE. Principles, Choice, reduce } \\
\text { barriers) }\end{array}$ \\
\hline Assessment & $\begin{array}{l}\text { No clear } \\
\text { revision }\end{array}$ & $\begin{array}{l}\text { Assessment is changed in an } \\
\text { attempt to be more inclusive using } \\
\text { (adding choices, using rubric) }\end{array}$ & $\begin{array}{l}\text { Assessment is changed to assess their } \\
\text { knowledge of the Holocaust and not } \\
\text { their ability to write an essay. }\end{array}$ \\
\hline Justification & $\begin{array}{l}\text { No } \\
\text { justification } \\
\text { provided }\end{array}$ & $\begin{array}{l}\text { Attempt is made to be more } \\
\text { inclusive however justification is } \\
\text { not tied to UDL practices (adding } \\
\text { choices without clearly stating } \\
\text { why) }\end{array}$ & $\begin{array}{l}\text { Justification is provided AND uses } \\
\text { UDL vocabulary (IE. Multiple means } \\
\text { of representation, only assessing one } \\
\text { goal) }\end{array}$ \\
\hline
\end{tabular}




\section{Appendix $F$}

\section{PowerPoint slides for the Lecture-based Instruction}
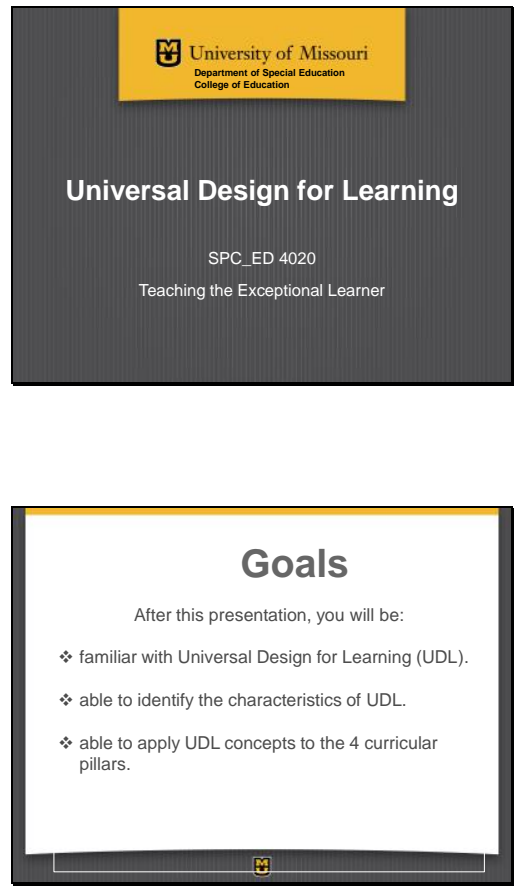

A Shift in How We Think About Students and Curriculum

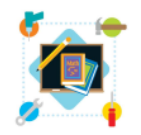

UDL is an attempt to fix the curriculum instead of trying to fix the student. 


\section{UDL Implementation}

Can you design to the edges?

Watch this video:

https://www.youtube.com/watch?v=4eBmyttcfU4
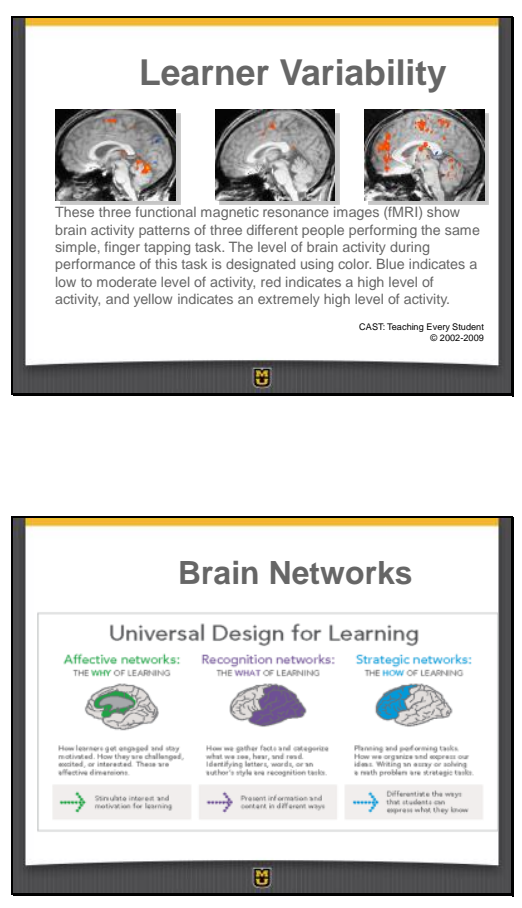

Equitable Opportunities

The basic UDL premise is that to provide equitable

opportunities to reach high standards across

variable students in our schools, we must:

- Provide multiple means of engagement

- Provide multiple means of representation

Provide multiple means of action and

expression 
Vocabulary

Framework: Universal Design for Learning is

a framework - not a checklist. It is the interio

frame around which you build the structure

that is to become your lesson. Just like a steel

or metal building frame, the UDL framework

has been carefully calibrated and tested to

ensure that it will stand the test of time.

Vocabulary

Learning Environment: When we talk about the learning

environment as it relates to UDL, we're talking about both

the space/location of your lesson, and the way the

students can use the space. In an ideal scenario a teacher

has the opportunity to tailor space to meet the needs of

students for each lesson, and to provide access to tools,

and resources are flexible in a

their use is not specifically prescribed by the teacher:

Vocabulary

Access: When we use the term "access" in a

conversation about UDL we can be referring to a

student's physical ability to access the

information, and/or to a student's ability to connec

with the information. If students have access it

means that they are given a reason to emotionally

attach to the lesson; they know they will have a

and they will have multiple chances to

demonstrate their understanding of the topic.

Everybody has some barriers to

$$
\text { learning }
$$

There are some barriers (like being hungry) that UDL

can't fix. But most academic barriers, like poor writing

skills, a small vocabulary base, or dinficulty with number

fluency, can be mediated by providing multiple means of

engagement, representation, action, and expressio

All students can succeed in a UDL classroom, meaning everybody can work towards mastery. 

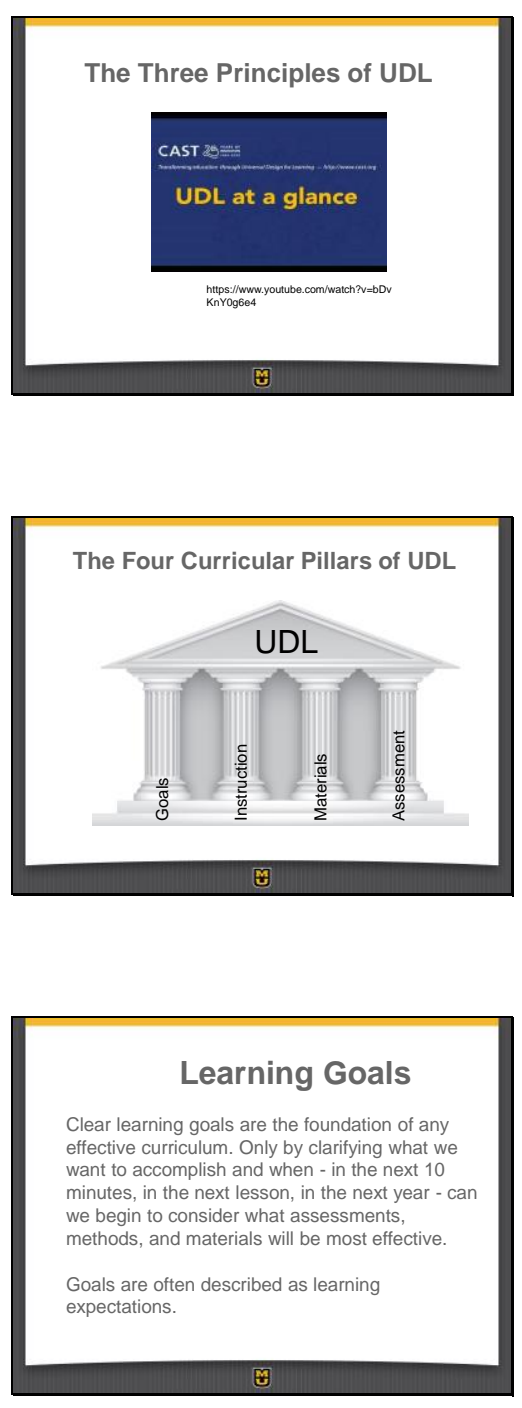

\section{Learning Goals}

From a UDL perspective, effective goals are

goals that:

Separate the means from the ends;

Consider all three learning networks;

Challenge all learners;

Actively involve learners. 

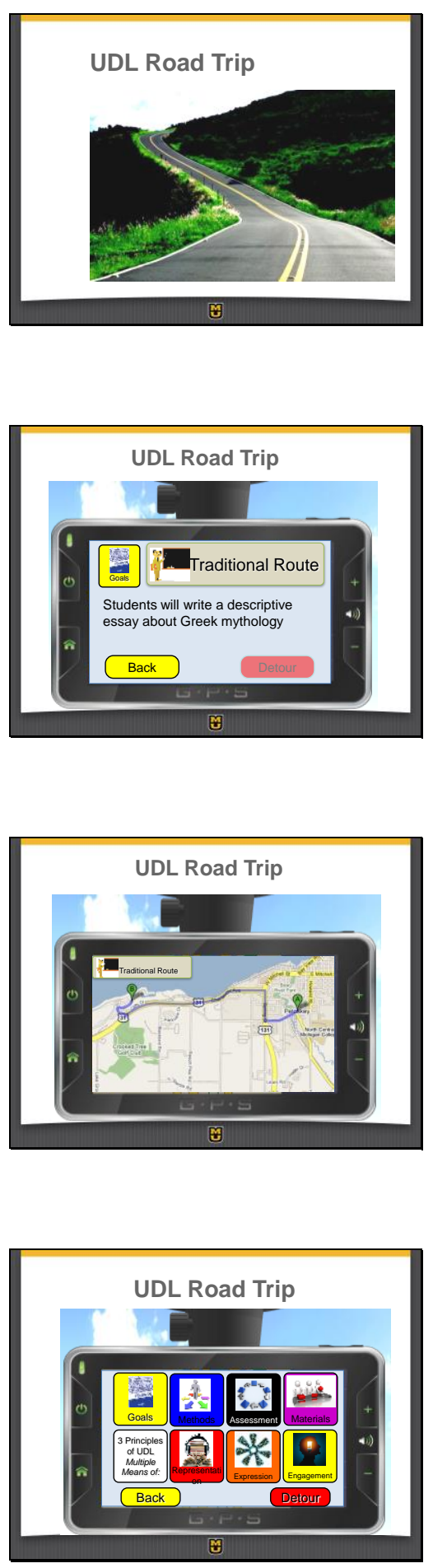

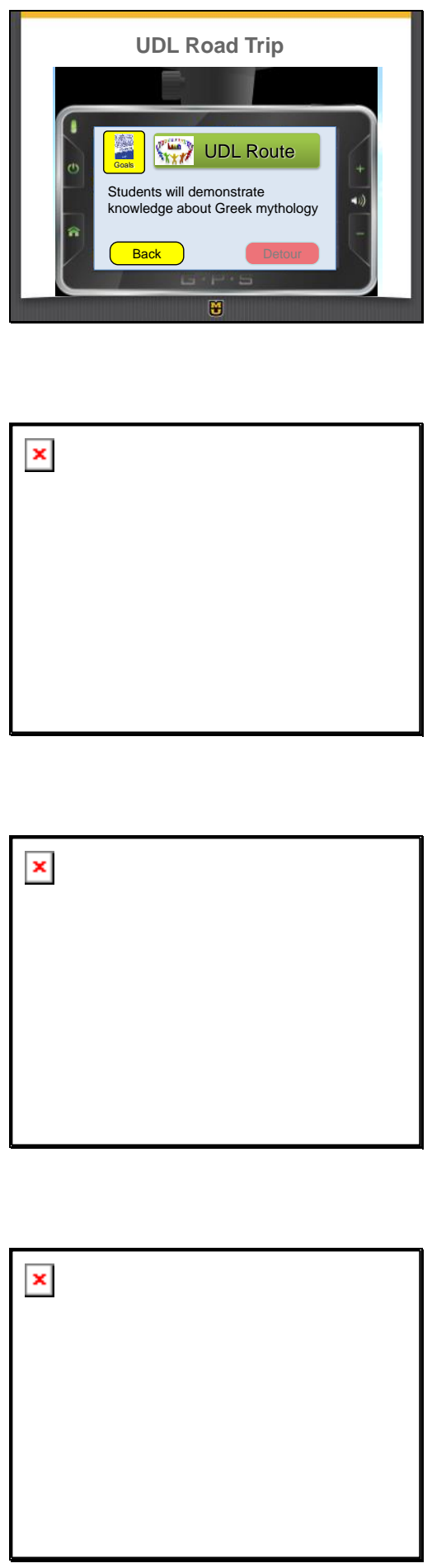

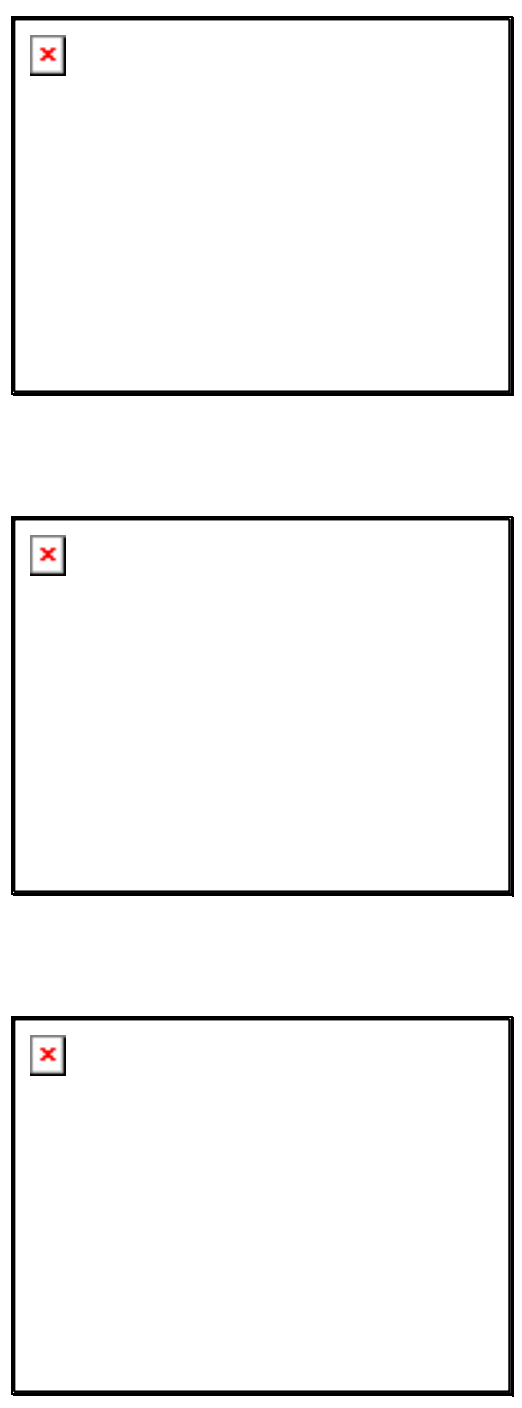

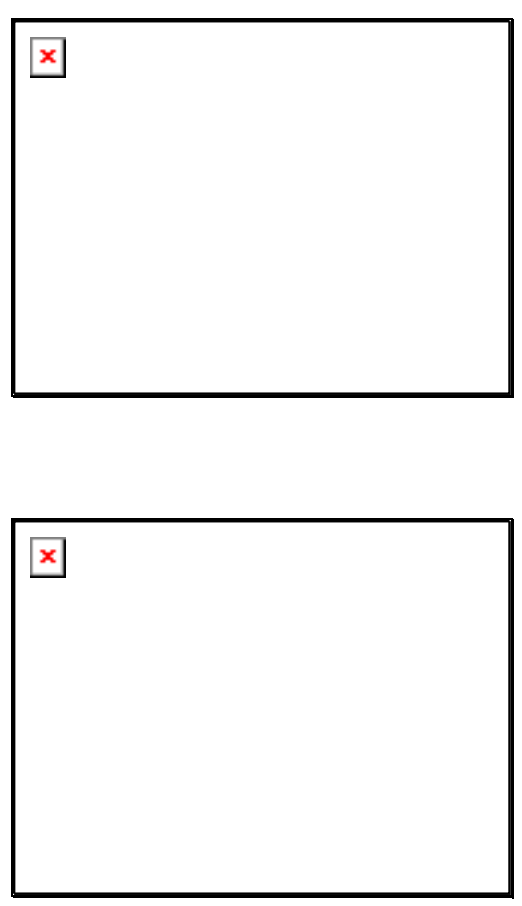


\section{Appendix $G$}

Instructional Stations for Practice-based Groups

Quick Response codes were removed for Copyright purposes

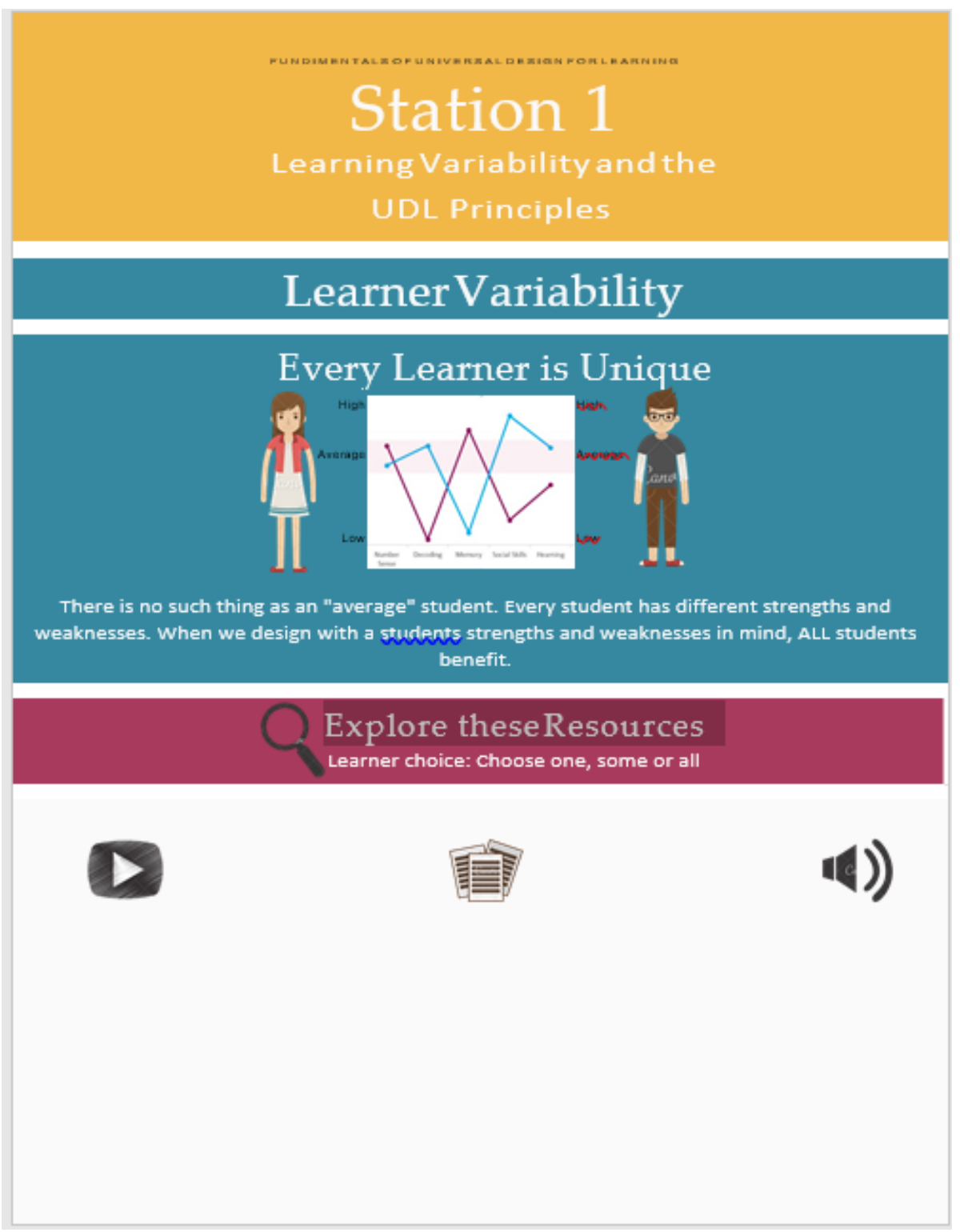




\section{The Principles} The foundation of UDL

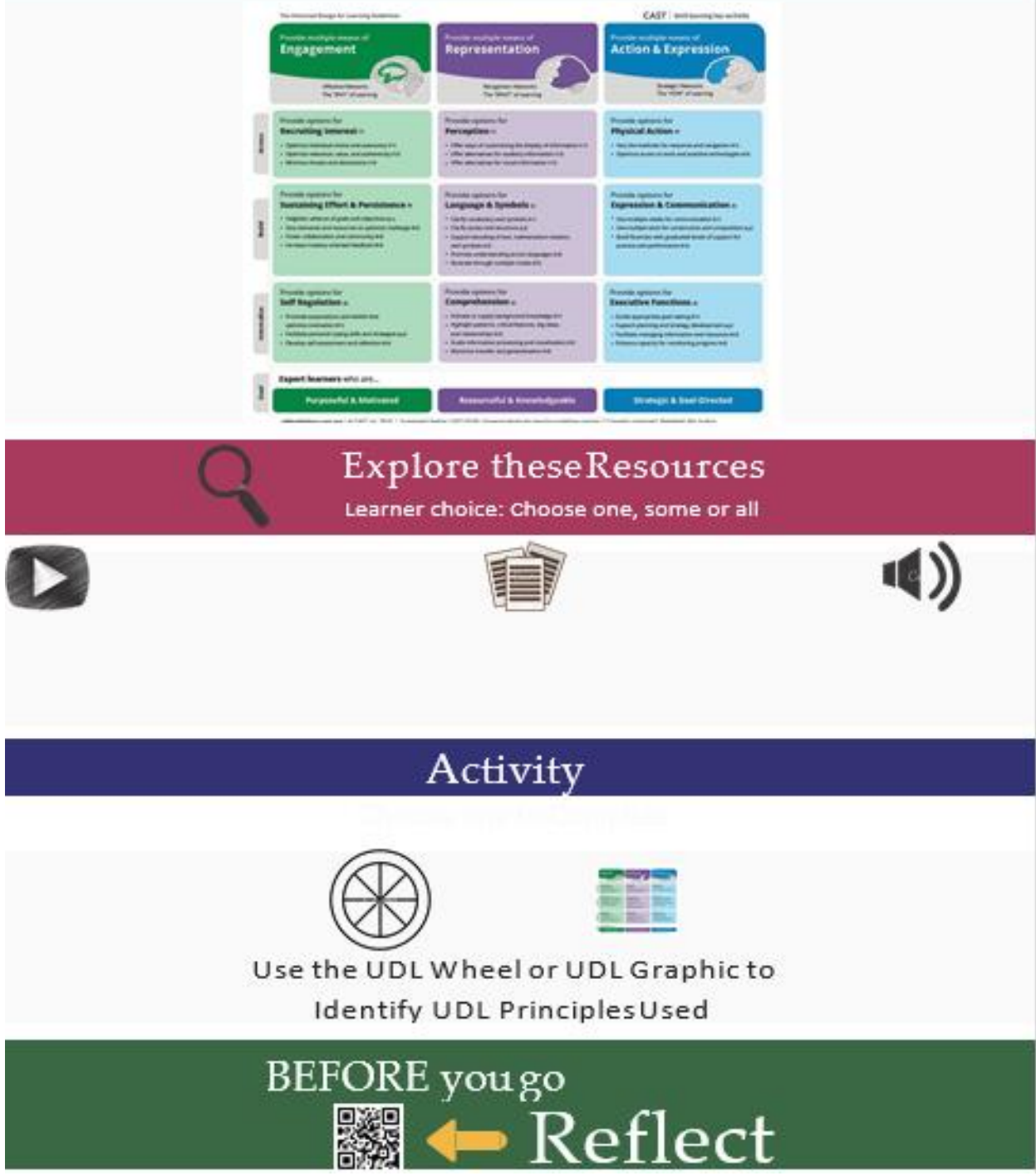


FUNDINENTALS OF UNIVER SAL OESICN FOR LEARNINC

\section{Station 2 UDL Goals}

\section{LEARNING GOALS}
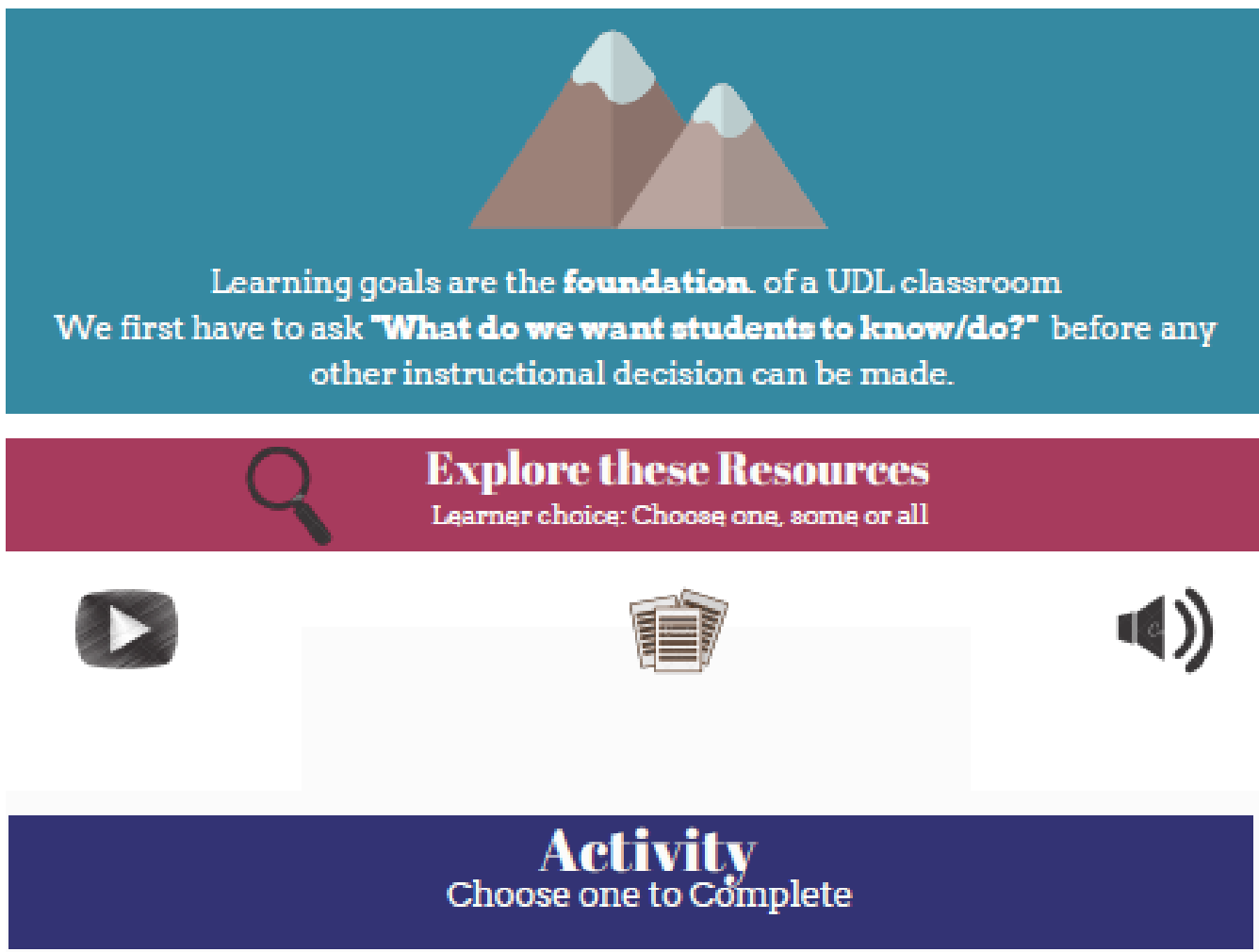

Are these UDL goals?
Card Sort

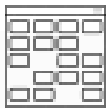
OR
Q.
Online Quiz

\section{BEFORE you go Reflect}




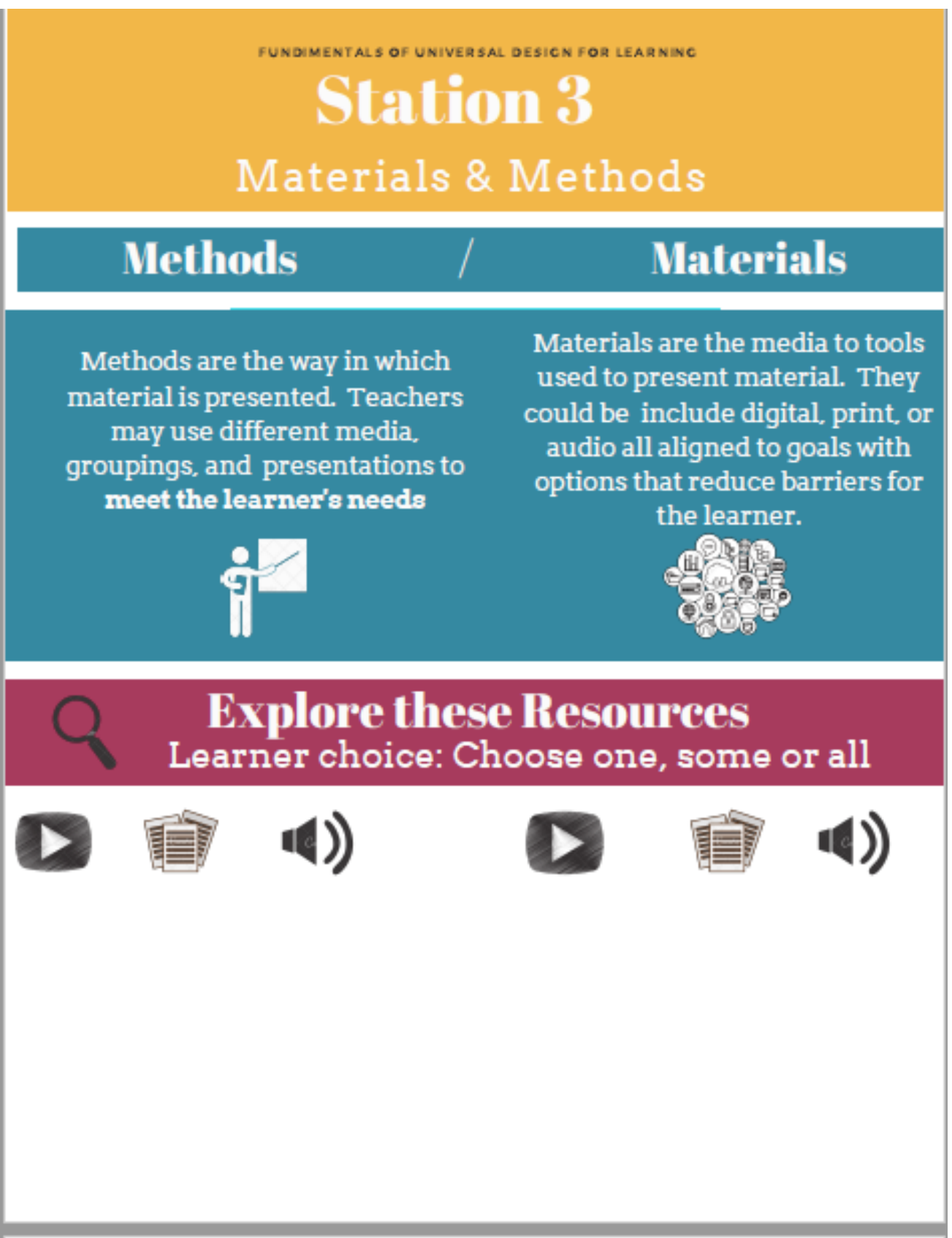




\section{Technology}

Technology is NOT synonymous with UDL.

However, technology can reduce barriers to how

students receive information (representation) and how student show what they know (action and expression). Technology can help with providing options in teaching

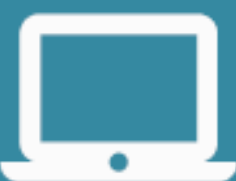
methods \& materials.

\section{Activity}

There are some common technologies that reduce barriers. Grab a student card and explore some apps that may be essential for the student to learn.

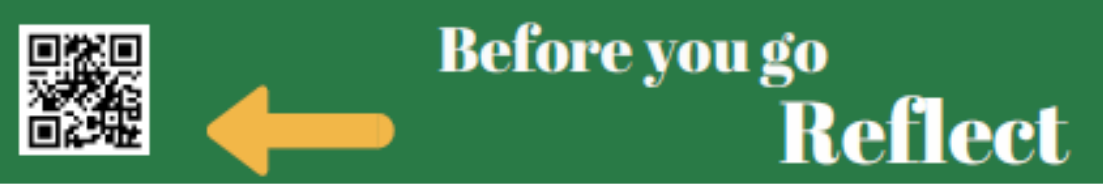


FUNOINENTALS OF UNIVEASAL OE SICN FOR LEARNINC

Station 4

Assessment

\section{Action and Expression}

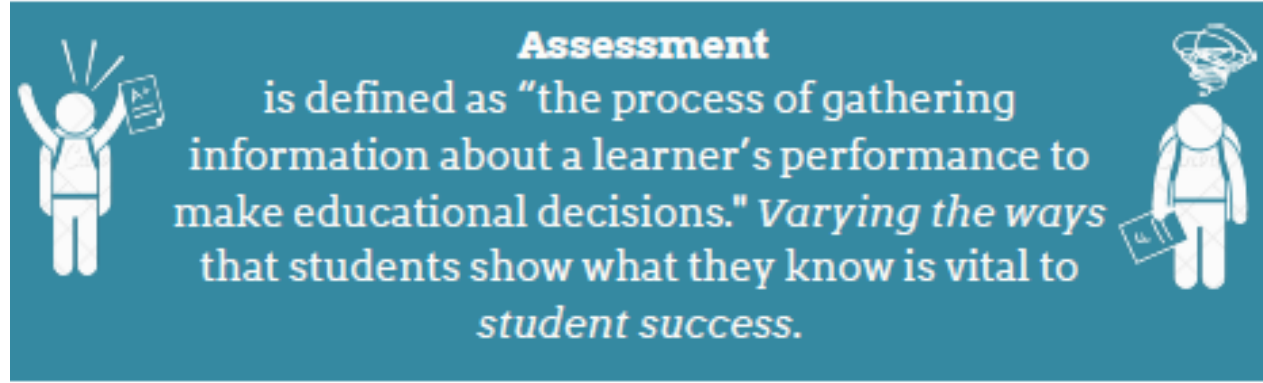

Resources

Learner choice: Choose one, some or all
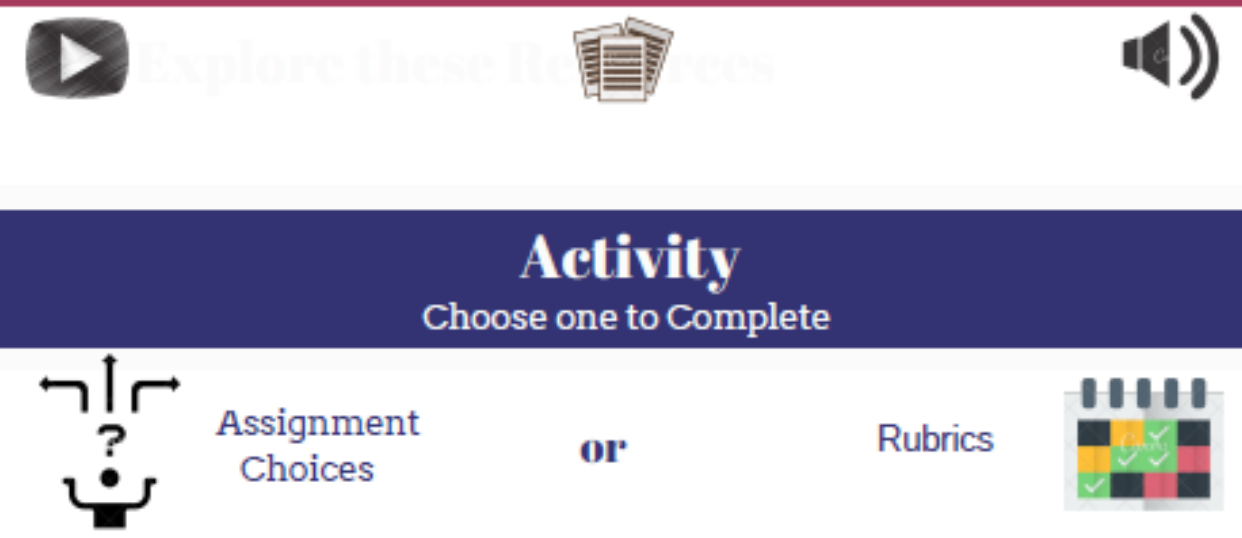

\section{BEFORE you go Reflect}




\section{VITA}

Mary Decker received her bachelor's degree in elementary education at Columbia College in Columbia, Missouri in 2005 and her master's in curriculum and instruction from the University of Missouri in Columbia, Missouri in 2007. She has held teaching positions in elementary classrooms at a variety of grade levels and schools. In 2012, Mary took time off to raise her children and was recruited to collect data for a National Institutes for Health research project. Through this projects she discovered a passion for research especially in regard to student behavior challenges and reading. Her research interests center primarily on accessibility and Universal Design for Learning, with a focus on teacher preparation.

Mary Decker is married and has four children and a menagerie of farm animals. In her spare time, she loves watching her children tackle their passions, reading and creating. She currently lives in a small town in central Missouri. 